\title{
FROM MY COLD, DEAD HANDS: DEMOCRATIC CONSEQUENCES OF SACRED RHETORIC
}

by

\section{Morgan Marietta}

B.Phil. in Economics \& Political Science, University of Pittsburgh, 1992

M.S. in History \& Policy, Carnegie Mellon University, 1997

Submitted to the Graduate Faculty of

Arts and Sciences in partial fulfillment

of the requirements for the degree of Doctor of Philosophy

University of Pittsburgh

2007 


\title{
UNIVERSITY OF PITTSBURGH ARTS AND SCIENCES
}

This dissertation was presented

by

\author{
Morgan Marietta
}

It was defended on

20 February 2007

and approved by

Michael Goodhart, Associate Professor, Department of Political Science, University of Pittsburgh

John Markoff, Professor, Departments of Sociology and Political Science, University of Pittsburgh

Bert Rockman, Professor, Department of Political Science, Purdue University

Philip Tetlock, Professor, Haas School of Business, University of California Berkeley

Dissertation Director: David Barker, Associate Professor, Department of Political Science, University of Pittsburgh 
Copyright by Morgan Marietta

2007 


\title{
FROM MY COLD, DEAD HANDS: DEMOCRATIC CONSEQUENCES OF SACRED RHETORIC
}

\author{
Morgan Marietta, $\mathrm{PhD}$ \\ University of Pittsburgh, 2007
}

\begin{abstract}
Civil society and democratic deliberation rely on compromise, but political leaders often express convictions that are sacred, grounded in non-negotiable appeals to transcendent authority rather than reasoned consequences. This study examines the political meaning of this form of persuasion, or the democratic consequences of sacred rhetoric. I find that the distinctive effects of sacred appeals are on political reasoning and motivation rather than on expressed opinions. Sacred rhetoric is not more effective in changing minds but in shifting the nature of public discourse, resulting in a more strident political culture. Absolutist appeals also encourage political intensity and engagement, creating a strong partisan incentive for their use. But they are not employed equally by both national parties. The direct political consequence of sacred rhetoric is an absolutist advantage for contemporary Republicans, while the more diffuse democratic consequences include increased citizen participation and decreased prospects for meaningful deliberation - a contradictory influence on the health of American democracy.
\end{abstract}




\section{TABLE OF CONTENTS}

$\begin{array}{ll}\text { INTRODUCTION } & 1\end{array}$

1.0 DEMOCRATIC CONSEQUENCES OF SACRED RHETORIC ． . . . . . 5

1.1 SACRED RHETORIC IN AMERICAN POLITICS . . . . . . . . . . . . 5

1.2 THE SACRED AND THE MUNDANE. . . . . . . . . . . . . . . . . . . . 9

1.2.1 The Essential Division _. . . . . . . . . . . . . . . . . 9

1.2.2 The Creation of the Sacred. . . . . . . . . . . . . . 11

1.2.3 The Persistence of the Sacred . . . . . . . . . . . . . . 14

1.3 SACRED VALUES AND SACRED RHETORIC . . . . . . . . . . . . 15

1.4 THE POLITICAL RAMIFICATIONS OF SACRED RHETORIC . . . . . . 23

2.0 VALUES AND VALUE CONFLICT

2.1 VALUES . . . . . . . . . . . . . . . . . . . . . . . . . . . 28

2.2 VALUE CONFLICT . . . . . . . . . . . . . . . . . . . . . . . . 30

2.3 SACRED VALUES . . . . . . . . . . . . . . . . . . . . . . . . 33

2.4 SACRED RHETORIC . . . . . . . . . . . . . . . . . . . . . . . 39

2.5 SACRED RHETORIC IN SOCIAL MOVEMENTS . . . . . . . . . . . . 43

2.6 SACRED RHETORIC IN POLITICAL PARTIES . . . . . . . . . . . . . 47

3.0 SACRED RHETORIC AND DEMOCRATIC HEALTH . . . . . . . . . . . . 50

3.1 THE NATURE AND ORIGINS OF DEMOCRATIC HEALTH . . . . . . . . 52

3.2 INTENSITY AND DEMOCRACY . . . . . . . . . . . . . . . . . . 56 
3.3 SACRED RHETORIC AND DEMOCRATIC HEALTH . . . . . . . . . 69

4. 0 THE PSYCHOLOGY OF THE SACRED APPEAL _. . . . . . . . . . . . 71

4.1 CONTAGION. . . . . . . . . . . . . . . . . . 72

4.2 OUTCOME AND PROCESS: THE SEVERAL FACETS OF PERSUSSION 73

4.3 THE REASONING EFFECT OF SACRED RHETORIC ．． . . . . . . . 77

4.4 THE ACTIVATION EFFECT OF SACRED RHETORIC . . . . . . . . . 79

5.0 FROM MY COLD, DEAD HANDS ． . . . . . . . . . . . . . . . . . 81

5.1 SUBJECTS: AN EXPERIMENTAL APPROACH . . . . . . . . . . . . . 82

5.2 THE EXPERIMENTAL DESIGN . . . . . . . . . . . . . . . . . . 88

5.3 RHETORIC AND REASONING . . . . . . . . . . . . . . . . . . . . . . 94

5.4 DISAGREEMENT AND ABSOLUTIST REASONING ．．． . . . . . . 98

5.5 THE IMPORTANCE OF POLITICAL REASONING $\quad . \quad . \quad . \quad . \quad . \quad . \quad . \quad .99$

6. 0 SACRED RHETORIC AND CIVIC ENGAGEMENT ． . . . . . . . . . . 102

6.1 SACRED MOTIVATION . . . . . . . . . . . . . . . . . . . 102

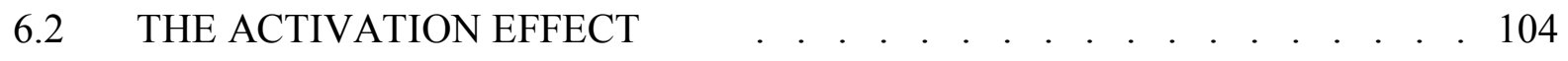

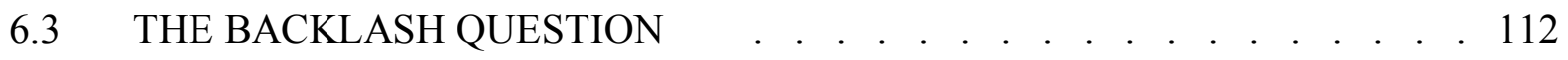

6.4 SACRED RHETORIC AND PARTICIPATORY DEMOCRACY . . . . . . 113

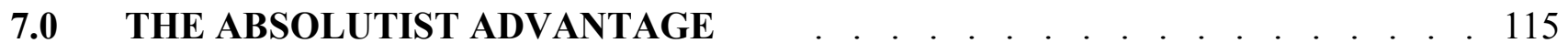

7.1 SACREDNESS IN PRESIDENTIAL RHETORIC . . . . . . . . . . . . 116

7.2 THE ROLE OF EXPLICIT RELIGION ． . . . . . . . . . . . . . . 117

7.3 “THAT WONDERFUL NOTE OF DISAGREEMENT" . . . . . . . . . 119

7.3.1 Sacred Domains ～. . . . . . . . . . . . . . . . . . . . . 127

7.4 PARTISAN REVERSALS . . . . . . . . . . . . . . . . . . . . . 130 
7.5 WINFRED SKINNER VERSUS MICHAEL FEINBERG . . . . . . . . . 133

7.6 NUMBERS, DETAILS, AND PLANS $\quad . \quad . \quad . \quad . \quad . \quad . \quad . \quad . \quad . \quad . \quad . \quad 135$

7.6.1 The Meaning of Fuzzy Math . . . . . . . . . . . . . . . . . . 136

7.7 “I'VE BEEN KNOWN TO MANGLE A SYLLABLE OR TWO” . . . . . . 137

7.8 THE ABSOLUTIST ADVANTAGE $\quad$. . . . . . . . . . . . . . . . . 139

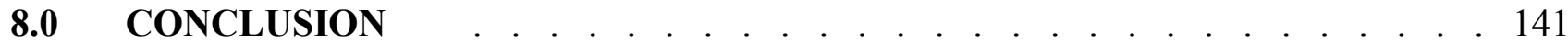

8.1 THE PSYCHOLOGICAL DYNAMICS OF SACRED RHETORIC . . . . . 142

8.2 DEMOCRATIC CONSEQUENCES . . . . . . . . . . . . . . . . . . 144

8.3 SACRED RHETORIC AND POLITICAL POWER . . . . . . . . . . . 149

BIBLIOGRAPHY . . . . . . . . . . . . . . . . . . . . . . . . . . . . . . 151 


\section{LIST OF TABLES}

Table 3.1

Table 3.2

Table 3.3

Table 3.4

Table 4.1

Table 5.1

Table 5.2

Table 5.3

Table 6.1

Table 6.2

Table 6.3

Table 7.1
Facets of the Democratic Health Debate 55

Democracy and Intensity from Different Perspectives . . . . . . . 64 The Role of Sacredness in Democratic Health ․ . . . . . . . 68

Democratic Consequences of Sacredness . . . . . . . . . . . 70

Forms of Political Persuasion . . . . . . . . . . . . . . . . . 74

Sacred Values in American Politics . . . . . . . . . . . . . . 90

Sacred Rhetoric Experiments, Hypothesis 1 . . . . . . . . . . . 94

Reasoning Effect Experimental Results _ . . . . . . . . . . 96

Sacred Rhetoric Experiments, Hypothesis 2 . . . . . . . . . . . 105

Activation Effect Experimental Results, Intensity . . . . . . . . 107

Activation Effect Experimental Results, Engagement $\quad$. . . . . 110

Sacred Rhetoric in the 2000 Presidential Debates _ . . . . . . . 122 


\section{LIST OF FIGURES}

Figure 2.1

Figure 3.1

Figure 3.2

Figure 3.3

Figure 3.4

Figure 5.1

Figure 6.1
The Inverse Relationship Between Personal and Social Value Conflict

33

Democratic Health as a Function of Aggregate Intensity Levels . . 58

Normative Descriptions of Democratic Health ․ . . . . . . . . 60

Intensity and Democratic Health . . . . . . . . . . . . . 65

Origins of Democratic Health ․ . . . . . . . . . . . . . 67

The Epistemology of Political Psychology . . . . . . . . . . . . 85

Activation Effects of Sacred Rhetoric ․ . . . . . . . . . . 111 


\title{
INTRODUCTION
}

\section{THE DISENCHANTMENT OF THE WORLD AND THE TENACITY OF THE SACRED}

\begin{abstract}
"The fate of our times is characterized by rationalization and intellectualization and, above all, by the 'disenchantment of the world.' Precisely the ultimate and most sublime values have retreated from public life."
\end{abstract}

Max Weber (1919) “Science as a Vocation"

When Weber wrote of the disenchantment of the world, he was observing the revolutionary changes of rising instrumentalism and bureaucratic order. But while he noted the advantages of rationalization, Weber had mixed feelings about what was gained and what was lost. He took clear note of what Western society was giving up: collective understanding, meaningful ritual, a sense of awe at the natural world, and perhaps most importantly, a commitment to unquestionable values. In this sense Weber is one of several influential scholars who argue that the Enlightenment led to various forms of alienation, including Marx (from the product of labor), Adorno (from personal responsibility), and Habermas (from community). However, as in many intellectual revolutions, it is easy to overemphasize the degree of change and exaggerate the passing of the old. To thinkers influenced by the Hegelian or Marxian dialectic it seems easy to forget that after the old order has been challenged and a new order has emerged (in Hegel's terms the thesis has met its anti-thesis and been resolved into a new synthesis), a healthy part of the original thinking may yet remain. In this sense our models of change can be misleading. The rumors of an idea's death, in other words, are often greatly exaggerated. This has become so much the case that it is important to point out the tenacity of the sacred. 
Part of the lure of the Enlightenment is the belief that reason and the ability to compromise have made major strides if not triumphed in contemporary society. In this view, the Enlightenment "would, by replacing the chaotic amalgam of guesswork, tradition, superstition, prejudice, dogma, fantasy, and 'interested error' that hitherto did service as human knowledge and human wisdom (and which by far the chief protector and instigator was the Church), create a new, sane, rational, happy, just and self-perpetuating human society." "But often the Enlightenment seems to be misunderstood as an achievement rather than as an ongoing project. Several facets of current scholarly thought reflect this misapprehension, including rational choice theory, pluralism, and anti-foundationalism. The prominence of rational choice theory is a reflection of the supposition that Enlightenment human nature has arrived - that individuals are self-aware and guided by reason. Similarly, the emphasis on pluralism reflects our desire to give respect to multiple views within a system of compromise. Moreover, pluralism rests on the philosophical foundation that because no single value can be justified above others, many must be permitted to flourish. ${ }^{2}$ In a similar vein, one of the major philosophical turns of recent scholarship is toward anti-foundationalism, or the rejection of transcendent values and human knowledge of the good. ${ }^{3}$ Hence contemporary scholarship (to the degree that it is characterized by these three trends, among others) builds a view of modern man as reasoning, compromising, and tolerant of opposing values. The combined weight of these pretenses leads scholars to downplay the fundamental attachments that remain, or the powerful role of the sacred.

\footnotetext{
${ }^{1}$ Isaiah Berlin, The Magus of the North, p. 28. See also Berlin, Crooked Timber of Humanity p. 5, 6-7: "The rational reorganization of society would put an end to spiritual and intellectual confusion, the reign of prejudice and superstition, blind obedience to unexamined dogmas, and the stupidities and cruelties of the oppressive regimes which such intellectual darkness bred and promoted... Men would no longer be victims of nature or of their own largely irrational societies: reason would triumph; universal harmonious cooperation, true history, would at last begin."

2 That is, we cannot show that individualism is inherently superior to communitarianism, or that secularism is superior to religiosity. This does not mean that as individuals we cannot choose our own preferences or starting points, but it does mean that just as we have that freedom we also must allow it to others; we have no persuasive basis for restricting others' choices that conflict with our own. See Berlin supra and William Galston, Liberal Pluralism.

${ }^{3}$ See Richard Rorty. One of the most influential works in twentieth century political theory, John Rawls' A Theory of Justice, is an attempt to establish standards of justice without recourse to a prior conception of the good. Habermas sums up the anti-foundationalist position of contemporary political theory by stating that "one no longer legitimates maxims, practices, and rules of action simply by calling attention to the contexts in which they were handed down" (Habermas 1996, 97).
} 
The indelibly sacred stance is akin to Martin Luther's dictum 'Here I stand, I can do no other." A truly sacred value is one for which we would rather die than yield. ${ }^{4}$ This test rarely comes to pass in democratic politics, but history does have its martyrs. More recently in American politics, we have had citizens who killed abortion doctors and gone unrepentant to their own execution. And people willing to sacrifice themselves for political or religious causes are still a powerful force in world politics. This kind of absolute conviction is akin to the distinction between holding ideas and "being held by them," described by Clifford Geertz in Islam Observed (Geertz 1983, 17). In this sense an idea is so ingrained in the thought process of an individual that it is essentially unquestionable. It will not escape the reader that several of these examples are religious. Clearly the more closely a value is tied to a religion, the more easily it is accorded sacred status. ${ }^{5}$ But it is important to note that while many sacred values are clearly religious, many are not. Sacred in the sense discussed here does not mean holy; it means absolute, which is often but not exclusively religious. ${ }^{6}$ Several values within American politics that are ostensibly secular may be held as sacred by many individuals or groups. ${ }^{7}$ This can be described as modern or secular sacredness.

\footnotetext{
${ }^{4}$ Sometimes the cannibalism taboo seems to have this character, though there are fascinating interpersonal differences in the strength of the sacred boundary. We may have more insight into its limits and exceptions because of specific historical examples when people faced the real choice of cannibalism or death. The Donner Party is probably the best known example, but a more instructive one may be the case of the Uruguayan rugby team stranded in the Andes, as recounted in the book and film Alive. Some of the men chose to eat their teammates who had perished in the plane crash, thereby surviving the ordeal; others chose not to and died.

${ }^{5}$ Secular norms do not seem to hold the same authority as those backed by a divine connection — "one must wonder whether, as an ultimate justification for the mandate to rule, the law of humankind can command the same intensity and reliability of assent as the law of God" (Markoff 1987, 168); "Don't do x because I say so has less impact than don't do x because God says so" (Tetlock 2003, 320 italics in original).

6 "Sacred values are often ultimately religious in character, but they need not have divine sanction. Sacred values can range from fundamentalists' faith in God to the liberal-social democratic dogma of racial equality to the radical libertarian commitment to the autonomy of the individual" (Tetlock et al 2000, 853). One can find definitions of the sacred that relate more specifically to the divine, but I opt for the broadest meaning (absolutism or nonnegotiability), which is also its most directly political meaning (the boundaries of decision-making and bargaining).

${ }^{7}$ However, many seemingly secular values may have older religious foundations, from which they have evolved to become ostensibly secular. The natural rights foundations of the Constitution are a prominent example (Locke held that the unalienable rights to life, liberty, and property were granted by God; in contemporary politics Americans often hold to the rights even if not to the original view of their source).
} 
The abrogation of sacred boundaries, either religious or secular, is not only offensive but is also a potential source of political motivation. Political participation, political activism, and political violence are in large measure reactions to what we consider intolerable. One of the unresolved facets of the current world is that significant groups of people choose violence in response to transgressions of their sacred boundaries. Hence one of the central problems of contemporary social science is to understand the boundaries of the sacred for different groups, how they interact, and how they change over time. This study does not address directly the larger conflicts that may be rooted in sacred boundaries and their transgressions, but it does begin to examine the root concept of sacredness and sacred rhetoric, the study of which will become increasingly important.

My contention is that if we are to understand the nature of citizen engagement, and thereby the health of democracy, we must consider the role of sacred thought. As the novelist Martin Amis wrote, people are more proud of what they believe than of what they know. ${ }^{8}$ In other words, Romantic rather than Enlightenment thinking maintains a strong hold on our minds and on our politics.

\footnotetext{
8 "On any longer view, man is only fitfully committed to the rational — to thinking, seeing, learning, knowing. Believing is what he's really proud of" (Amis 2002 "The voice of the lonely crowd" Harpers August, Vol. 305, No. 1827:15-18).
} 


\subsection{DEMOCRATIC CONSEQUENCES OF SACRED RHETORIC}

"The better to bring out the specific characteristics of life in a world capable of becoming sacred, I shall not hesitate to cite examples from many religions belonging to different periods and cultures."

Mircea Eliade (1957) The Sacred and the Profane, p. 15, italics added

Employing sacred rhetoric is an attempt to gain the political advantage of moving a position from the mundane world to the realm of the sacred. Mircea Eliade, the great sociologist of religion, wrote that human experience occurs in "a world capable of becoming sacred." Eliade meant that this was true of all humans, not merely the explicitly religious. The sacred was not only for the pious. Perhaps more important is his recognition that things - objects, people, ideas - can become sacred. We can be made to see their sacred aspect. This transition from mundane to sacred has important democratic consequences and imparts to its practitioners a significant electoral advantage.

\subsection{SACRED RHETORIC IN AMERICAN POLITICS}

Some of our best known political speeches have centered around what could be characterized as sacred rhetoric. JFK's vow that we would "pay any price, bear any burden" is an example that is frequently invoked. ${ }^{9}$ Another is Churchill's famous declaration that "we shall defend our island,

\footnotetext{
9 "Let every nation know, whether it wishes us well or ill, that we shall pay any price, bear any burden, meet any hardship, support any friend, oppose any foe, in order to assure the survival and the success of liberty" (Inaugural Address, 20 January 1961). These lines are paraphrased frequently. The second sentence of the Democratic response (by Richard Gephardt) to the President's State of the Union speech in 2002 was "Like generations that
} 
whatever the cost may be... we shall never surrender." ${ }^{10}$ In 1964 Barry Goldwater boldly stated that "extremism in the defense of liberty is no vice." 11 This example illustrates that some sacred rhetoric is more successful than others; Goldwater was hoping to offer "a choice, not an echo," but he was not expecting that the choice would go so decidedly against him. One of the clearest invocations of sacredness in contemporary American politics is the NRA slogan "From my cold, dead hands." 12 The literal meaning of this phrase is that you will have to kill me in order to take my gun away, because I will not yield it. In symbolic terms, it is a clear statement of a sacred boundary.

The rhetoric of non-negotiable boundaries — the language of limits — is an important facet of American politics. The much-noted shift in contemporary political discourse from a politics of redistribution to a politics of identity has included the prominence of intense, unyielding, and non-negotiable claims that go far beyond the bounds of the religiously or traditionally sacred. Modern sacredness has come to comprise both the religious and secular sacred, grounded in pluralistic sources of authority that establish for different individuals and groups the limits of the tolerable and negotiable, the boundaries of the sacred. While a great deal of political psychology literature has emphasized that mainstream citizens are often ambivalent (Hochschild 1981, Feldman and Zaller 1992, Zaller and Feldman 1992, Cacioppo et al 1997, Alvarez and Brehm 2003), it is equally the case that much of the political rhetoric that citizens encounter is the opposite. It is unconflicted, extreme, and strident, taking positions that ignore

came before us, we will pay any price and bear any burden to make sure that this proud nation wins the first war of the 21 st century."

10 "We shall go on to the end, we shall fight in France, we shall fight on the seas and oceans, we shall fight with growing confidence and growing strength in the air, we shall defend our island, whatever the cost may be, we shall fight on the beaches, we shall fight on the landing grounds, we shall fight in the fields and in the streets, we shall fight in the hills; we shall never surrender." (Address to the House of Commons, June 4, 1940)

11 "I would remind you that extremism in the defense of liberty is no vice. And let me remind you also that moderation in the pursuit of justice is no virtue." (Republican Nomination Acceptance Speech, 16 July 1964)

12 The full version is "You can have my gun when you take it from my cold dead hands." See Charleton Heston's NRA Presidential Address in 2000, which not only concludes with the slogan, but also refers to the concept of sacredness elsewhere: "we know that there is sacred stuff in that wooden stock and blued steel" (c.f. that wooden cross and iron nails). 
compromise or negotiation, upholding the inviolability of a favored set of values while dismissing others.

The importance of sacred rhetoric is connected to three shifts in contemporary American politics - the culture wars, the rise of new social movements, and the significance of new media. Although some scholars question the extent of cultural balkanization among ordinary American citizens (see Williams 1997, Fiorina 2005), at the elite level there is overwhelming evidence of a large and growing division between advocates of progressive and traditional sources of cultural authority (Hunter 1991, 1994, Green et al 1996, Layman 1999, White 2003). This division reflects the decreasing centrality of tax policy and the increasing concentration of American politics on issues of morality and identity - the move from redistribution to recognition, from class to culture. Conservatives and liberals are decreasingly divided by income, and increasingly characterized by a split between the religious and the secular, rural dwellers and urbanites, clashing on abortion, gay marriage, guns, and public religiosity (see White 2003). Sociologists have characterized this same shift as the rise of New Social Movements, which work outside of the normal channels of party politics and have cultural rather than economic goals (compared to the 'old' social movement, i.e., the labor movement). Prime examples include the women's, peace, and environmental movements. ${ }^{13}$ Many of the same political issues and actors associated with new social movements also espouse sacred values. Social movement activists are prone to employ strategic framing of their arguments, including sacred rhetoric, in their effort to influence public thinking. ${ }^{14}$ As Claus Offe observes, these movements often take uncompromising public positions - "movements are also unwilling to negotiate because they often consider their central concern of such high and universal priority that no part of it can be meaningfully sacrificed" (Offe 1985, 831).

\footnotetext{
13 See Melucci 1985, Offe 1985, and Calhoun 1995. "Sometime after 1968, analysts and participants began to speak of 'new social movements' that worked outside of the formal institutional channels and emphasized lifestyle, ethical, or identity concerns rather than narrowly economic goals"; these movements are "concerned largely with values, norms, language, identities and collective understandings" (Calhoun pp. 173, 176).

${ }^{14}$ Much of the discussion of the ideational foundation of social movements revolves around the use of symbols and frames to influence society (see Snow and Benford 1992 and Zald 1996).
} 
Political communication scholars add to this description of contemporary politics the rise of new media and the relative decline in the importance of mainstream sources of news (Davis and Owen 1998, Barker 2002). Beyond the expansion of cable and network news (CNN and FOX), non-traditional sources of political information and opinion have taken root, especially talk radio and the internet, including web logs (blogs). The blogosphere is a particularly important source of citizen information and interaction outside of mainstream media, allowing citizens to be simultaneous producers and consumers of information (Davis 2005). The political significance of new media resides in the specialization of sources, allowing citizens to selectively restrict their consideration of opposing ideas, as well as in the increased stridency and extremism of views. Bloggers do not need to be measured or reasonable, and may face incentives to be neither. The combination of these phenomena - the culture wars, new social movements, and new media - have insured the prominence of sacred rhetoric in American politics. But what does it mean for democracy if, as Yeats lamented, "The best lack all conviction, while the worst / Are full of passionate intensity?"15 Or could it be that only passionate intensity and its expression can overcome the lethargy of contemporary citizen engagement?

In order to work out the political consequences of sacred rhetoric, I would like to begin by addressing a series of questions: What is meant by the sacred? How do we conceptualize sacred values and rhetoric in American politics? And what are the possible political advantages of moving an argument into the sacred realm? This will allow us in later chapters to examine these effects in detail and to address two further questions: How do we explain the mechanics of these influences, or the psychology of sacred rhetoric? And finally, What are the normative and partisan ramifications of sacred rhetoric for American democracy?

${ }^{15}$ William Butler Yeats, “The Second Coming” circa 1920. 


\subsection{THE SACRED AND THE MUNDANE: THE MEANING OF SACREDNESS}

By the sacred we mean something set apart for special reverence. The sacred is within the human world but nonetheless imbued with a transcendent quality; it is neither merely human, nor fully sublime, but is a bridge between the mundane realm of the material and the unobservable but nonetheless deeply felt realm of higher human values. This understanding of the sacred is drawn from three major social theorists - Durkheim, Eliade, and Berger - each of whom adds greatly to our understanding of this multifaceted concept. ${ }^{16}$ While the primary goal of each of these scholars was to explain the nature of religion (which is not our task), they each illuminate the idea of sacredness, a concept that is explicitly derived from religion but not limited to it. When we synthesize the views of these scholars, three aspects of the sacred emerge: 1) humans tend to divide the world into two distinct spheres of the sacred and mundane;2) things are made sacred by human labor, implying both the possibility of gradual change and a wide range in the choice of sacred objects; and 3) sacredness has not left the contemporary world.

\subsubsection{The Essential Division}

All three scholars agree that the sacred is understood as being exalted above the human or the material, apprehensible to humans but distinct from them. In Durkheim's phrase, "sacred things" are "things set apart and forbidden" (44); for Berger "by the sacred is meant a quality of mysterious and awesome power, other than man and yet related to him... The sacred is apprehended as 'sticking out' from the normal routines of everyday life" (25-26); in Eliade's language it is "the manifestation of something of a wholly different order, a reality that does not belong to our world" (11). The sacred is the ganz andere — the entirely other — that we can be with but not of.

\footnotetext{
16 These three scholars are emphasized because of their importance in the sociology of religion, but also because they explicitly discuss the concept of sacredness as distinct from religion. Many other works shed light on the concept, but I take three to be classic statements, beginning with Emile Durkheim's The Elementary Forms of Religious Life in 1912, followed by Mircea Eliade's The Sacred and the Profane in 1957, and Peter Berger's The Sacred Canopy in 1967, directly following his and Thomas Luckmann's The Social Construction of Reality, on which it builds.
} 
Durkheim famously argues that all individuals and societies divide their mental world into the two distinct realms of the sacred and non-sacred. ${ }^{17}$ These two domains "are always and everywhere conceived by the human intellect as separate genera, as two worlds with nothing in common" (36). "The two worlds are conceived of not only as separate but also as hostile and jealous rivals," such that "the mind experiences deep repugnance about mingling, even simple contact, between the corresponding things" (37). To read Durkheim is to gain the impression that the sacred and the mundane are not only distinct, but powerfully, permanently, and emotionally so, such that transgressions of the boundaries are immediately and unavoidably troubling. Eliade affirms this essential division, asserting that the "sacred and profane are two modes of being in the world, two existential situations assumed by man" (14).

But the two existential views are not co-equal. It is important to note that the sacred is meaningful, personal, in perhaps a better word, real in a way that most human objects are not. To understand this aspect of the sacred, it is important to take into account what could be called the ontological inversion of the Enlightenment, or the modern reversal of real and unreal. In the pre-enlightened view, it is the sacred that is real, and the mundane that is unreal. ${ }^{18}$ This may appear to be a reversal of our assumptions about the world - to us the observable, mundane world is real, while the unobservable realms of the sacred (along with religion, superstition, or even principles or values) are unreal, even if they are extremely meaningful. However, it is not

\footnotetext{
${ }^{17}$ There is some question about the best term for the non-sacred, or the residual outside the sacred realm. One possibility is material, though its technical opposite is ideational rather than sacred, and material objects often have a sacred quality. Another possibility is secular, but this is a misleading term, because its opposite is religious, and it bears repeating that the sacred is not coterminous with the religious, allowing for a significant realm of the secular sacred. Durkheim, Eliade and Berger prefer the term profane, but I find this to be inaccurate or at least limiting, as the profane is a more specific term referring to only those things that explicitly contravene the sacred, violating sacred boundaries. (See King 1968 at 32, "Classically speaking what is not sacred is profane; but in our time 'profane' connotes the antisacred rather than the merely nonsacred," quoted in Allen 1972 at 176.) I argue that the best term is the mundane, or the inoffensive world of the everyday, as opposed to the sacred or its explicit violation. Hence I would argue that it is more meaningful to discuss three identifiable concepts: the sacred, the mundane, and the profane. But the greater distinction is between the realm imbued with sacred concerns (both sacred and its opposite, the truly profane) and the mundane realm of the everyday.

${ }^{18}$ Eliade describes it as "an absolute reality, the sacred, which transcends this world but manifests itself in this world, thereby sanctifying it and making it real" (202). Establishing the sacred provides to potentially disconnected humans a point of reference - "an absolute fixed point, a center" (21). "The sacred reveals absolute reality and at the same time makes orientation possible; hence it founds the world in the sense that it fixes the limits and establishes the order of the world" (30).
} 
pre-modern people, but rather ourselves who did the reversing, in the Enlightenment inversion of real and unreal. By pre-Enlightenment assumptions, we cannot know much about a confusing environment. Therefore what we seem to observe is unreal; it is what lies outside of human apprehension that must be what truly exists and is most significant. It is our ignorance of the world that denies it reality; for that we must look elsewhere. But then the Enlightenment claimed the possibility of verifiable human knowledge. Hence now we can know things, and what we can know has become what we think of as real; nondemonstrable beliefs in the supernatural, gods, or God became unreal. But in the sacred worldview, not restricted by the Enlightenment inversion, the original view of real and unreal applies. And if the sacred is the most real, it is also the most meaningful and should be granted the most dignity and respect. The essential division into sacred and mundane is also a division into most and least important.

\subsubsection{The Creation of the Sacred: Many Objects, Slow Change}

It is of great importance to recognize that things are made sacred by human labor. While we may perceive the sacred as a preordained fact that is presented to us, this obscures that a choice of what to consider sacred was made by previous generations. As Berger phrases it, "whatever else the constellations of the sacred may be 'ultimately,' empirically they are products of human activity and human signification — that is, they are human projections" (89). Because sacredness is a collective choice made over time, this implies two important points: that $a$ wide range of objects can be made sacred, and that the objects imbued with sacredness can shift and change.

Durkheim observes that sacred things vary remarkably among cultures, such that "a rock, a tree, a spring, a piece of wood, a house, in a word anything, can be sacred" (35). ${ }^{19}$ It should be no surprise, especially given their collective nature, that political things - ideas, meeting places, historical events, leaders, national symbols or monuments - can be imbued with sacredness.

\footnotetext{
${ }^{19}$ See also Berger: "This quality may be attributed to natural or artificial objects, to animals, or to men, or to the objectivations of human culture. There are sacred rocks, sacred tools, sacred cows. The chieftain may be sacred, as may be a particular custom or institution. Space and time may be assigned the same quality, as in sacred localities and sacred seasons... The historical manifestations of the sacred vary widely" (25).
} 
Moreover, the sacred is not at all limited to the strictly religious. What appear to be fully civil or secular things can be sacred as well. Movements toward secularization may have lessened religion and religiosity in some societies, but not necessarily sacredness and sacred reverence. If religion fades but the impulse to hold something sacred does not, then the secular sacred may rise at the same time that the explicitly religious sacred declines. In this case, however, the sacred is not a given, but must be chosen from among other objects of collective significance. It is crucial to bear in mind that while sacredness derives from religious thought, it is in no way limited to religion, leaving a wide range for the secular sacred. This might encompass any number of thoroughly secular political positions or ideas.

But if sacred objects are in a sense chosen, how does this process work, which is to say how is the sacred made? Durkheim argues that the range of the sacred is neither small nor stable: "the circle of sacred objects cannot be fixed once and for all; its scope can vary infinitely" (35). The human act of splitting sacred from mundane and enforcing their separation creates and maintains the sacred distinction. Things "are made sacred by groups of people who set them apart and keep them bounded by specific actions; they remain sacred only so long as groups continue to do this. Humans acting collectively make and remake this quality of sacredness but then encounter it after the fact as if it had always been built into objects and was ready-made" (xlvi). This aspect of socially constructed things - that they appear to us to be objective reality - is discussed most clearly by Berger. Building on his classic with Thomas Luckmann (The Social Construction of Reality), he argues that social facts such as sacredness gain their objective quality by being created by one generation and then accepted by the next. This process of socialization "achieves success to the degree that this taken-for-granted quality is internalized" (24). Hence the qualities of society that we perceive as real, fixed, and enduring depend on the discussion that surrounds us; in this way "the subjective reality of the world hangs on the thin thread of conversation" (17).

This view of the sacred implies the possibility or even inevitability of change, but we must be careful of how we understand this process. It is important to not mistake it for being easily achieved or quickly reversible. Because social realities are constructed, this does not mean that they can be easily deconstructed. Berger and Luckmann do not argue that because 
things exist in our collective minds, we can simply change our minds and reconstruct reality, a view that can be described as naïve reconstructionism. Instead they explicitly argue that because social facts have become real to us, they are extremely resistant to change. ${ }^{20}$ This quality of "acquired objectivity" means that "once produced, this world cannot simply be wished away. Although all culture originates and is rooted in the subjective consciousness of human beings, once formed it cannot be reabsorbed into consciousness at will. It stands outside the subjectivity of the individual as, indeed, a world. In other words, the humanly produced world attains the character of objective reality" (9). The creation of a social reality such as a sacredness may be difficult to achieve but even more difficult to dismantle.

It may seem contradictory to argue that aspects of culture such as sacredness are created and therefore changeable, but nonetheless resistant to change. There seems to be no disputing Durkheim's claim that "culture must be continuously produced and reproduced by man. Its structures are, therefore, inherently precarious and predestined to change" (6). But this does not mean that they change quickly or through the efforts of one group. The forces moving a culture may be too large and varied for one group's efforts to make much of an impact. However, in order to be rhetorically effective a specific group need not change what is sacred as much as associate their views with what is already held as sacred. Sacred rhetoric may be effective primarily by connecting new things with old sacrednesses. In this sense it is not creating the sacred as much as extending it to new realms. Sacred rhetoric may not need to, and likely cannot, create the sacred anew, but it can connect a political position to an existing or latent sacredness. In this sense perhaps the sacred shifts more than changes. Later we will delve into the exact mechanisms by which invocations of the sacred are effective, but for now it is enough to note that the collective creation of the sacred, with its implications of wide choice and slow change, seems amenable to the influence of sacred rhetoric.

\footnotetext{
${ }^{20}$ See Berger and Luckmann 1966, part III. Because "man is capable of forgetting his own authorship of the human world," "it is experienced by man as a strange facticity, an opus alienum over which he has no control"; he "does not internalize the world as one of many possible worlds. He internalizes it as the world, the only existent and only conceivable world, the world tout court" $(89,134)$.
} 


\subsubsection{The Persistence of the Sacred}

The final facet of sacredness illuminated by these classic works is that the sacred has not left the contemporary world. On the contrary, the human impulse to recognize and revere a sacred difference seems alive and well, even when not recognized explicitly. Our inheritance of a sacred resonance ensures that "something of the religious conception of the world still persists in the behavior of the profane man, although he is not always conscious of this immemorial heritage" (Eliade 50). The pull toward sacredness suggests that "the man who has made his choice in favor of a profane life never succeeds in completely doing away with religious behavior; even the most desacralized existence still preserves traces of a religious valorization of the world" $(23){ }^{21}$ The objects of reverence may have shifted far from the clearly religious, but the act of reverence remains. If this is the case, then the realm of the secular sacred may be large and influential.

Moreover, contrary to many scholars' expectations, the secularization of the Western world is not complete nor perhaps even still occurring. In his 1999 The Desecularization of the World, Berger argues that "the assumption that we live in a secularized world is false" (2). "To be sure, modernization has had some secularizing effects, more in some places than in others. But it has also provoked powerful movements of counter-secularization" (3). Outside of Western Europe, organized religion remains not only well-organized, but by many metrics growing in population more often than declining. The proportion of Americans who state a belief in God is staggering (over $90 \%$ by most respectable surveys), while the proportion who believe that ghosts, spirits, or other aspects of the supernatural exist is almost as high. And it is not religion per se, but its remnant in the concept of sacredness that is our concern, whether in religious or secular forms. One way of conceptualizing the sacred in a more secular world is that while we can attempt to ignore sacredness, we can be reminded of it nonetheless. This reminder may occur when violations of the sacred - profanities - are presented to us. It may be the very

\footnotetext{
21 "Profane man cannot help preserving some vestiges of the behavior of religious man, though they are emptied of religious meaning. Do what he will, he is an inheritor" (Eliade 204). Therefore "even the most avowedly nonreligious man, in his deeper being, shares in a religiously oriented behavior" (211).
} 
profanity, not mundanity, of the modern world that instigates a counter-secularization. ${ }^{22}$ In this sense, sacred rhetoric could be effective not only by presenting a positive association with the sacred, but by pointing out a negative association with the profane.

Sacredness reveals itself as a seemingly simple concept that nonetheless has several nuanced aspects. Beginning with the question of what is meant by the sacred, we arrive at three important conclusions: that the sacred and the mundane are two distinct human realms, though the border between the two is porous, as things are made sacred by human effort, changing the objects imbued with sacredness, and that regardless of any secularizing trend, sacredness has not left the contemporary world. Taken together, these observations imply that through human intention - sacred rhetoric - some citizens may be influenced to alter their understanding or categorization of certain political issues, ideas, people, or events from one realm to another.

\subsection{SACRED VALUES AND SACRED RHETORIC}

So how do we understand the nature of sacredness in American politics? This study takes as a starting point the work of Philip Tetlock, building on his research agenda on sacred values and the psychology of the unthinkable - the human intersection of moral absolutes and secular trade-offs. Specifically, my aim is to expand upon the political ramifications of sacred thinking. I begin with an understanding of American belief systems that can be termed the Tetlock synthesis: most Americans are conflicted over basic value choices, while a smaller number of citizens hold specific values as absolute, or sacred. ${ }^{23}$ This description combines two interrelated aspects of Tetlock's writings: value pluralism (Tetlock 1986) and sacred values (Tetlock et al 1996, Fiske and Tetlock 1997, Tetlock et al 2000, Tetlock 2003). In terms of this synthesis, for

\footnotetext{
22 This implies that the process of counter-secularization, or the resurgence of religion in the modern world, is a direct reaction against the profanity spawned by a more permissive secular culture (counter-secularization $=$ $\downarrow$ sacred $\rightarrow \uparrow$ profane $\rightarrow \uparrow$ sacred).

23 "[S]acred values are those values that a moral community treats as possessing transcendental significance that precludes comparison, trade-offs, or indeed any mingling with secular values" (Tetlock 2003, 320).
} 
any given value or value pair (such as individualism versus communitarianism) citizens vary along a spectrum of internal value conflict, on which most Americans are characterized by value pluralism (adherence to conflicting values), some have increasing degrees of strong value preferences (less internal value conflict), and usually a minority hold any specific value as sacred (little or no internal value conflict). In this sense, internal value conflict is the opposite of sacredness; high internal value conflict allows for negotiability, while the lack of internal value conflict - moral clarity — is coterminus with absolute belief. Sacredness is the sense in which some things are not as negotiable, some rules not as bendable as others. They are inviolable, such that it is offensive to weigh them against other considerations or perhaps even to question their validity. They are special in a nuanced but meaningful sense, in a word, sacred.

A sacred value is a principle that is held to be absolute, resisting tradeoffs with other values. Sacredness is the invocation of absoluteness, or the adherence to specific values about which there is little or no question. This definition focuses on the defining trait of sacredness the degree of internal value conflict. Sacredness may have several other facets with important ramifications, but it can be defined by this core element.

Sacredness can be conceptualized at several different levels of analysis. In one sense, sacredness is an aggregate or social level variable that applies to values themselves. A given value may fall anywhere along a range from almost no one holding it as sacred, to a few people or groups, to an important segment (either in numbers or influence) of citizens who hold the value as sacred, to near-universal acceptance. ${ }^{24}$ In a second sense, sacredness is an individual level variable. The question in this case is not whether specific values are sacred to society as a whole, but instead whether they are to different individuals. The unit of analysis is the citizen rather than the value itself. In a third level of analysis, and the one on which we concentrate here, sacredness applies to language, or the sense in which a domain of thought is expressed in

\footnotetext{
24 This raises the question of what proportion of a population needs to hold a value as sacred for that value to be accorded sacred status by the culture as a whole. If a critical mass of a population thinks of a value as sacred, the few outliers become more likely to refrain from public statements or actions that would antagonize the majority. The spiral of silence and preference falsification perspectives both suggest that total agreement within a society is not necessary for the appearance of total agreement (see Kuran 1995). Sydney Tarrow describes this as the "costumes of consensus" (Tarrow 1998, p. 113).
} 
sacred or mundane terms. While it is necessary to understand the concept of sacred belief, it is the expression of this belief, or sacred rhetoric, that is our specific target. This study examines political rhetoric that holds values as sacred, compared to modes of expression that recognize a greater degree of internal value conflict and negotiability.

What this discussion points to is the flexibility within the value system of an individual, a culture, or a specific discourse, from conflicted to absolute. Whether sacredness is a continuous or a categorical variable within that spectrum is a question that needs further empirical clarification. Fiske and Tetlock suggest that sacredness is more categorical, especially in terms of Fiske's relational theory, which posits that different realms of thinking are discrete and incommensurable (Fiske and Tetlock 1997, 258; see also Fiske 1991). However, there is evidence that the sacred/non-sacred boundary is soft, in the sense that individuals can be framed into reducing sacred claims (Tetlock 2003). This highlights the distinction between sacred and pseudo-sacred values, or those for which citizens will employ sacred claims or rhetoric, but will compromise on nonetheless. I suggest as a starting point that we can distinguish among conflicted values (high levels of internal value conflict), negotiable values (for which citizens have some degree of preference but recognize the need for value trade-offs and willingly engage in them), pseudo-sacred values (for which citizens employ sacred rhetoric, but on which they will compromise nonetheless), and fully sacred values. The prevalence of hard boundaries between these categories (held by which groups of political actors in what numbers) is an important empirical question.

Research conducted by psychologist Jonathan Baron provides evidence that initial claims of sacred status sometimes do not hold up when citizens are pushed to clarify their views further (Baron and Leshner 2000). ${ }^{25}$ Baron makes the interesting argument that protected values are

\footnotetext{
25 Baron employs the term protected values, or values that "are protected from being traded off for other values" (Baron and Spranca 1997, p.1). His definition is essentially similar to what I describe here as sacred values, centering on absoluteness but also encompassing both non-negotiability and non-consequentialism: "The defining property of protected values is absoluteness" (Baron and Spranca 1997, p. 4); citizens hold that "the value should not be traded off, i.e., it is absolute" (6), because "protected values are different. They are treated as commitments" (5) (non-negotiability). Such values "apply to certain behavior "whatever the consequences"” (3) (nonconsequentialism). Baron also defines five other properties of protected values that derive from this status: (1) quantity insensitivity (the degree of violation is irrelevant to the reaction); (2) agent relativity (violations are judged
} 


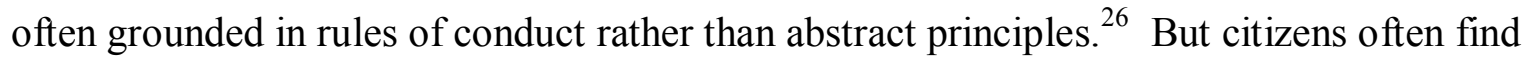
exceptions even to protected rules of conduct (or at least rules that they are willing to state should be protected). ${ }^{27}$ His finding that expressions of protected values are often not entirely sincere or absolute highlights the distinction between sacred values and pseudo-sacred ones. Even though expressions of protected values may be either truly sacred or merely pseudo-sacred, falling into the second category does not erase their political significance.

The distinction between sacred and pseudo-sacred values leads to the observation that sacred beliefs and sacred rhetoric may have distinct influences on democratic politics. While holding sacred values may influence how citizens engage in politics, the mere expression of sacred values in political rhetoric may also alter their behavior. We may not be able to distinguish between the sacred rhetoric that is sincere or strategic, but it may have the same influence regardless. And its effects may not depend on changing the distribution of sacred belief, but instead on activating existing beliefs or re-framing arguments in citizens' minds. For this reason, politicians and other opinion leaders may have an incentive to invoke sacred values, and to sacralize those that may not have been sacred before. Sacralization can be understood as the process by which the degree of sacredness of a specific value increases over time; the

by the degree of personal participation; hence protected values are asymmetric around commissions and omissions, an example of the omission bias (see especially Ritov and Baron 1999); (3) moral obligation (values are seen as universals, not cultural constructs); (4) denial (citizens engage in wishful thinking to avoid admitting a need for a trade-off (this is similar to what is described above as sacred blindness, which refers to refusing to notice evidence of sacrilege); and (5) anger at violations of the value, i.e. moral outrage.

${ }^{26}$ Protected values are expressions of "rules that prohibit certain actions" or "absolute deontological rules" connected to personal behavior (Baron and Spranca 1997, 2, 3). This is a direct denial of the Utilitarian tradition (a denial of the felicific calculus in favor of strict rules of conduct). It could be mistaken for a form of rule utilitarianism but is not based on a concern for outcomes, but is instead more likely the result of cultural transmission of norms, the cognitive need for simplicity, and other social mechanisms as "rules become detached from their justifications" (Baron and Spranca 1997, 14; see the interesting discussion of the possible origins of protected values on pp. 14-15). This perspective has important ramification about they type of things that are accorded sacred status. If it is the rule of conduct rather than the principle that is sacred, then the political ramifications may be very different. Following the rule "Though shalt not degrade the environment" is likely to allow a great deal that "Though shalt not tolerate degradation of the environment" would not allow. The description of sacred values as behavorial rules rather than abstract principles seems to fit some potentially sacred domains in American politics such as abortion, but may not fit as well with others such as gun rights.

27 Baron conceptualizes protected values as being self defined: "We define a value as protected for a subject when the subject says that the value should not be traded off, i.e., should be absolute" (ibid. p. 6). 
proportion of people who hold the value to be negotiable decreases while the proportion holding it to be pseudo-sacred or sacred increases. Sacralization (or desacralization) could be simply evolutionary, as social values change over time. Or it could occur in response to the intentional efforts of social movement activists or political leaders, what Eric Hoffer refers to as "religiofication - the art of turning practical purposes into holy causes." ${ }^{28}$ The sacralization of rhetoric by politicians may be a widespread phenomenon in electoral competition. In this sense, rhetoric and belief have independent effects and must be examined separately.

One way to describe the intersection of sacred rhetoric and American politics is to illuminate the boundaries of the sacred within different groups of political actors. Sacred boundaries are no doubt distinct for individuals, groups (forming some of the definitions of group membership and identity), and for society as a whole. These boundaries are constantly in flux, and the social conflicts over their limits form a great swath of contemporary political conflicts. One could certainly make the case that current American political divisions revolve around value conflicts that have sacred dimensions, including abortion, gay marriage, gun rights, military deployments, the death penalty, and environmentalism. This is the case with both sides of the abortion debate: pro-life advocates clearly hold the life of a fetus to be sacred, while some pro-choice advocates make seemingly sacred claims about the reproductive rights of women. The second sentence of Justice Blackmun's seminal opinion in Roe v. Wade recognizes "the deep and seemingly absolute convictions that the subject inspires" (410 U.S. 113, 1973). Gun rights advocates argue that the Second Amendment establishes a non-negotiable boundary. Many citizens hold that patriotism precludes much criticism of military policies during wartime, and especially criticism of military personnel (leading to the almost mandatory preface that one supports the troops even if one criticizes their deployment). The death penalty is for many people an example of a non-consequentialist value statement — it is not justified by a deterrent effect, but instead is upheld as a moral statement of the requirements of justice (often combined with the biblical injunction of blood for blood). ${ }^{29}$ Environmentalism is a clear case where

\footnotetext{
28 See Eric Hoffer, The True Believer, 1951, p.15.

29 "The issue is not revenge or retribution exactly, so much as moral order. The death penalty maintains its hold on the American conscience because of its intensely symbolic nature. Values count enormously in our lives. But it is essential to recognize that our adherence to the death penalty arises not because it provides proven tangible benefits
} 
a sacred assertion (protecting a specific species from extinction is an absolute requirement) can be challenged quickly by budgetary realities (how much money will we really spend before we reluctantly see the last animal of its kind?). Nonetheless, sacred rhetoric is often heard in regard to the preservation of natural wonders and endangered species. (And we witness remarkable financial commitments. India, for example, though a poor nation per capita, invests a large amount to ensure the survival of its tigers.)

The many possible examples of sacredness in political domains can be concluded with a current topic of much discussion - same sex marriage. For many citizens this question brings forth immediate feelings about the limits of acceptability. The Episcopal Church is currently contemplating a painful split over whether homosexuality will be accepted openly within the church hierarchy. Parishioners are being forced to examine and decide on their sacred boundaries: will they or won't they remain in a church with openly gay leaders? The degree to which the debate over homosexuality and its public status has become a major political topic and clear dividing line within American politics illustrates the political significance of sacred boundaries.

These examples highlight two concepts that may influence the political efficacy of sacred rhetoric: the underlying degree of conflict or consensus regarding a specific value, and whether only one or both sides of a conflict employ sacred appeals. There may be an important empirical distinction between sacred values that are held in consensus within a given society at a given time, and those that are conflictual (i.e. some hold the value as sacred while others do not, or even more significantly, some hold a value as sacred while others hold its opposite to be sacred). At the most basic level, some consensus sacred values such as the prohibitions against murder and incest may be near-universals among human societies (what Kant argued were categorical imperatives and Anthony Ashley Cooper argued were the products of an innate moral sense). But a consensus this broad seems limited to a small number of prohibitions. The larger number of values are likely to achieve a consensus only within a specific sub-culture. In contemporary America, a likely candidate for a consensus sacred value is constitutionalism, or the

like deterrence but rather from our belief that capital punishment makes an unequivocal moral statement" (Scott Turow, Ultimate punishment: A lawyer's reflections on dealing with the death penalty, 64). 
unquestionable authority of the Constitution as the final word in American politics. ${ }^{30}$ Imagine if any prominent politician openly suggested that the Constitution should be violated, and consider how long they would continue being a prominent politician. ${ }^{31}$ A clear example of this consensus value at work occurred during the 2000 election controversy between George W. Bush and Al Gore. Regardless of the early uproar, any further question of succession ended immediately when the Supreme Court made its ruling; as disliked and criticized as the ruling was, its authority was unquestioned. While some Democratic supporters continued to employ the rhetoric of illegitimacy, the issue of succession was effectively over. A sacred value like constitutionalism can often go unnoticed when a community is in such broad agreement that they forget about the possibility of dissent. But in few countries would a ruling by nine unelected, largely unknown people in robes immediately and definitively end a major controversy. That Americans find this to be normal is a testament to the degree to which constitutionalism is a sacred consensus value.

What may be more politically significant than consensus sacred values are conflictual ones. Given a political world of value pluralism — "the conception that there are many different ends that men may seek and still be fully rational, fully men" — conflict among values may be unavoidable (Isaiah Berlin Crooked Timber, p. 11). And the more one group expresses its sacred

\footnotetext{
${ }^{30}$ Constitutionalism can be defined as the unquestionable primacy of the constitution as the source of basic law. Donald Lutz defines it as treating the written document "as the summary of our political commitments and as the standard by which we assess, develop, and run our political system. To use a constitution in this way is the essence of constitutionalism" (Lutz The origins of American constitutionalism, p. 3). Rousseau argues in The social contract that all societies need a foundation myth (Book II, Ch 7). A constitution as the essence of a Founding and a symbol of that mythology can clearly gain sacred status. As "a bureaucratic form of the claim to moral authority" a constitution offers "new organizational vehicles for assessing national history against some standard of ultimate values. This helps assure political life of a sacred or quasi-sacred aspect so that politics is not merely a matter of force and fraud" (Markoff 1987, 168, 171). That constitutionalism in this sense is a mainstream article of faith in American society, as well as an aspect of perceptions of American expceptionalism, is evident in comments such as Peter Jenning's remark in an ABC news broadcast that "In no other society does such a document have the quality of a sacred text" (3 July 2003).

${ }^{31}$ An interesting exception to the general rule of public reverence for the constitution is the rhetoric of nineteenth century abolitionists, who vilified it for its acquiescence to slavery. The Constitution was "a covenant with Death and an agreement with Hell" (William Lloyd Garrison, Resolution Adopted by the Antislavery Society, 1843). For another example of Garrison's sacred rhetoric, see Salutatory of the Liberator (1831): "I am in earnest. I will not equivocate; I will not excuse; I will not retreat a single inch; and I will be heard!" Rather than a case of a sacred value clashing with a negotiable one, this seems to be the more unusual case of one sacred value (abolitionism) clashing with another (constitutionalism). The length and bloodiness of the struggles of the Civil War era can be understood as the product of such juxtapositions.
} 
commitment to a value but another group either refuses to recognize its sacredness, or worse, holds its opposite to be sacred, the greater the political consequences such clashes are likely to have. The degree of consensus or conflict at the aggregate level may have a great deal to do with the influence of sacred rhetoric in democratic politics.

Just as some political domains clearly have a greater sacred component than others, the two opposing sides of a given issue may have different degrees of sacredness as well. Sacred values can be thought of as being single-sided or double-sided. Abortion is likely an area where both camps have sacralized the underlying values. For those on the anti-abortion side, the life of the fetus is clearly a sacred value, not to be abrogated by less important things like the rights or desires of the woman. There is also a clear God-ordained backing for their view (a specific boundary sanctioned by a specific authority). But for those on the pro-choice side, the reproductive rights of a woman may have taken on a similarly sacred status. For both sides, at least for some or to some degree, their beliefs are non-consequentialist (other considerations do not matter compared to the rights of the fetus; other considerations do not matter compared to the reproductive rights of the woman). ${ }^{32}$ Political domains like abortion that are characterized by double-sided sacredness are likely to be highly contested, vitriolic, non-deliberative, and intractable, leading to unending political conflict. Abortion seems to fit this description. But neither side seems to have either a belief system advantage or a rhetorical advantage, as both have sacred beliefs and employ sacred rhetoric.

The opposite may be the case when only one side of the argument has been sacralized, or single-sided sacredness. If sacred rhetoric motivates political engagement, then the sacralized side should have a distinct political advantage. This ideational asymmetry may not only advantage the sacred side, but may also affect the nature of political struggle. A situation with two sides on offense creates a different environment than one on rhetorical offense and one taking a defensive posture. Both sides arguing values is different from one emphasizing values

\footnotetext{
32 This is in contrast to the great majority of Americans, who seem to think that some balancing is in order, as illustrated by the high numbers who favor legal abortion with some restrictions, and the high variability in survey responses when introducing different conditions based on the pregnancy's origins or the woman's situation.
} 
in strident tones and the other discussing consequences, statistics, and policy proposals in measured tones.

\subsection{THE POLITICAL RAMIFICATIONS OF SACRED RHETORIC}

If the observations made above are reasonably accurate - that it is a common practice to divide the world into the sacred and the mundane, even among modern thinkers; that the sacred is created, meaning that any number of objects may gain sacred status; that the secularization of Western society has far from eradicated the sacred, even fostering a significant realm of the secular sacred; and that the defining feature of sacred values and rhetoric is absoluteness - then what advantage is gained by convincing an audience to move a political position from one realm to the other?

About sacred things we think differently and care more. Both of these aspects have important political consequences, rooted in the sacred's defining feature of perceived inviolability. The sacred is not touched with impunity; its violation has consequences, whether divine, psychic, or social. The psychic consequences include reasoning and arguing about sacred political domains in a different way, as well as becoming more motivated to engage in politics. These two effects have important social consequences for the nature of civil society and the degree of citizen engagement.

The source of the influence of the sacred is its inviolability, which makes a sacred political position unquestionable and its opposition unconscionable. About such absolutes we reason differently. An acknowledged sacredness creates a fixed star by which to navigate a confusing world; once seen, this star is hard to extinguish. Public sacredness also puts good people in a corner, because people who are thought of as good do not question such things (which is a profanity), at least not without raising the public possibility that they are really not

good at all. This is of course the meaning of the parable of the Emperor's new clothes - if we believe we will be judged negatively for certain expressions, we will cease making them (even going to potentially extreme lengths, as in the denial of the emperor's nakedness). 
But this is not to say that the most important effect of sacred rhetoric is the indirect one of altering citizens' expressed preferences. The most clear effect is the direct one of altering citizens' way of reasoning and justification, or the process through which they arrive at their real preferences. The quality of inviolability is less influential on the content of an argument than it is on the process of reasoning. Sacredness does not depend on the political position taken or its ideological direction, as one can take a sacred stand against abortion just as one can take a nonsacred stand. The same applies to the anti-abortion side, or to stands both for or against the death penalty. Because sacred rhetoric is characterized more by the form of argument rather than its ideological direction, it may follow that its greatest influence is on citizens' process of reasoning. Sacredness is a cognitive process as well as an outcome. And it is on the method of reasoning that sacred rhetoric has its most discernable effects. Specifically, I argue that sacred rhetoric influences the form of reasoning employed by its hearers, shifting citizens away from consequentialist reasoning and toward absolutist reasoning. Employing more absolutist reasoning may or may not change the outcome of a citizen's judgment, but the importance of a reasoning shift does not rely on an accompanying shift in outcome. Moving toward a reasoning process that is more absolutist changes the character of political thought and public discourse. If the justifications people give in public are more absolute and less willing to acknowledge tradeoffs, then the character of public debate changes. The citation of authorities and the insistence on boundaries rather than an offering of evidence or discussion of consequences lead toward a clash of cultural authorities rather than reasoned agreement. Greater invocations of moral outrage engender a more strident form of politics. In this sense the process of reasoning alone is an important aspect of political discourse.

The second psychic and hence political consequence of sacred rhetoric centers on political motivation. About the sacred we simply care more and are therefore more politically motivated. The sacred intrudes on our consciousness in a way that the mundane does not; we feel deeper emotions in its presence and are more concerned about perceived violations. Profanity is more noted and remembered than simple error, falsehood, or failure to maximize. These feelings result in political and personal valorization. Because violation of the sacred is intolerable, rectifying such conditions becomes a noble, valorous act. And political engagement 
in this service not only enobles us in our own minds, but perhaps in the minds of those around us. Hence sacredness carries a social as well as internal pressure; violations create not only private disappointment, but public shame. The reinforcement is social as well as personal. It is worth noting that this may be driven by presentation management as well as real belief. As mentioned above, public sacredness creates an expectation of agreement because of the offensive (profane) nature of public dissent. This creates the incentive not only to care, but to appear to care.

Sacred and valorized ideas are therefore treated differently. They are given more reverence, respect, or dignity. They are, as Durkheim would phrase it, set apart. In addition to the divine command to observe sacred distinctions (as in Exodus 3:5: "Do not come near; put off your shoes from your feet, for the place on which you are standing is holy ground"), there is also the social command to respect others' boundaries and our collective rites. By valorizing such positions and their defense, sacredness allows citizens to construct personal meaning. And this meaning creates political motivation and engagement.

Both of these effects - that about the sacred we think differently and care more — deal with political persuasion. But they are not the usual form of persuasion that we consider, or what is thought of as attitude change. These effects are not changing minds, but changing forms of reasoning and levels of political engagement. This second consequence is most often referred to as an activation effect, or increasing political action by connecting citizens' previously held beliefs to their political meaning. But the other form of persuasion is less frequently considered. It could be called a reasoning or process effect rather than an outcome effect. One of the important contributions of this study is the identification of this form of political persuasion and its democratic influences.

Political engagement is the key not only to the nature of civil society and the vibrancy of democracy, but to the simple calculus of electoral success. If one party motivates its citizens to participate more than the other party does, this creates a significant partisan advantage. One part of this advantage is simply higher voter turnout, but the broader influence is an increase in political discussion. We do not only mean a greater volume of political conversation, but also a 
discussion of a different tenor - argument in a more strident, absolutist manner that reinforces sacred boundaries and the public pressure to observe them. The partisan advantage is not only a change in the level of political participation in terms of voting, donation, or activism, but also a change in the nature of political engagement, becoming less deliberative and compromising, more strident and unyielding. If one party employs sacred rhetoric to a greater degree than the other, it gains these electoral benefits - an absolutist advantage.

The proposed influences of sacred rhetoric can be summarized in these hypotheses:

\begin{abstract}
Hypothesis 1: $\quad$ Sacred rhetoric influences citizens' process of justification, increasing the degree of absolutist reasoning (a process or reasoning effect).
\end{abstract}
Hypothesis 2: $\quad$ Sacred rhetoric encourages political intensity and engagement (an activation effect).

Hypothesis 3: $\quad$ Sacred rhetoric is more prominent in Republican discourse, creating a partisan advantage.

These three hypotheses represent the democratic consequences of sacred rhetoric, or a shift in public discourse, an increase in political intensity and civic engagement, and an advantage for the party that expresses a greater degree of sacredness. These effects constitute important influences on the nature of civil society and public deliberation. They have significant ramifications for the health of American democracy, for the electoral prospects of the contemporary parties, and for our understanding of political belief and communication.

The following chapters address these empirical and normative concerns. Chapter two develops a more specific conceptualization of sacred values and sacred rhetoric, while chapter three addresses the broader normative questions. The second part of the study emphasizes the empirical findings, or the political consequences of sacred rhetoric. Chapter four delves further into the psychological foundations of sacred rhetoric and how this changes our understanding of political persuasion. Chapter five addresses the influence on political reasoning (hypothesis 
one), while chapter six discusses the activation effects on citizen engagement (hypothesis two). The final empirical chapter is a study of the partisan differences in the use of sacred rhetoric and the creation of an absolutist advantage (hypothesis three). But before we can discuss these empirical findings we need to address a series of questions about the conceptualization and measurement of sacred rhetoric, as well as the normative implications of the study, or the connections between sacred rhetoric and the competing perspectives on the origins of democratic health. 


\subsection{VALUES AND VALUE CONFLICT, SACRED VALUES AND SACRED RHETORIC}

In order to build a more specific conceptualization of sacred rhetoric, we can begin by clarifying the nature of two important constructs: values and value conflict.

\section{$2.1 \quad$ VALUES}

We can begin with the observation that values cannot be justified, yet we can justify nothing without them. All of our political judgments of right or wrong, better or worse, rely in the end on values, what Isaiah Berlin describes as "not means to ends but ultimate ends, ends in themselves" (Berlin 1992, p. 10). These ends can be thought of as normative backstops or terminal justifications. If we ask someone to explain a political position, and then press them to justify that justification, and continue in this fashion, the point at which they can go no further is a core value. $^{33}$ Hence values - the most reduced form of justification - can only be believed, not justified. The core divisions among belief systems cannot be defended rationally; for example, we cannot demonstrate either empirically or logically to someone who does not already agree with us that individualism is superior to communitarianism, or that secularism is superior to religiosity. Even the values of the Enlightenment (the dignity of the individual, the superiority of reason to received wisdom) cannot be justified by Enlightenment methods (empiricism and

\footnotetext{
33 "Values are backstops of belief systems. When we press people to justify their political preferences, all inquiry ultimately terminates in values that people find it ridiculous to justify any further" (Tetlock 1996, 26). This suggests not only a definition, but also a method of identifying core values.
} 
logic). ${ }^{34}$ Our fundamental values, the ultimate source of our political judgments and ideals, are irreducibly Romantic. I suspect that few conditions have as much fundamental political importance as the observation that we must rely on core values, but cannot justify them to others. And of course people rely upon different ones, which are sometimes incompatible. Hence the basis of our political judgments can be neither justified nor reconciled, leading in many cases to inevitable political conflict.

But their fundamental importance seems to make values more rather than less difficult to define. They also have an intuitive meaning in American discourse (e.g. "family values"), which can lead us to substitute a general cultural understanding for a clear social science definition. The contemporary emphasis on behavioralism has also made the study of values more difficult, as they are neither directly observable nor easily articulated, often remaining implicit rather than explicit in normal discourse. Nonetheless, definitions have emerged, first from social psychology and then from political science. Foundational definitions stress the role of values as motivators: "a conception of the desirable" (Kluckhohn 1951); "the dominating force in life" (Allport 1961); "an enduring belief that a specific mode of conduct or end-state of existence is personally or socially preferable" (Rokeach 1973). More recent psychological definitions stress the abstract character of values as "desirable, trans-situational goals" (Schwartz 1996) and "abstract trans-situational guides" (Rohan 2000). ${ }^{35}$ The major political science researchers on values (whom I would identify as Robert Lane, Stanley Feldman, Jon Hurwitz \& Mark Peffley, William Jacoby, and Phil Tetlock) ${ }^{36}$ have followed in emphasizing the abstract nature of values

\footnotetext{
${ }^{34}$ See footnote 4 supra.

35 This highlights an important distinction between values as organizing principles and attitudes as evaluations of specific objects, such as policy proposals. Rohan makes this distinction explicit: "I propose that the term attitude is used only for evaluations of specific entities. The term values can then be reserved for discussions of abstract transsituational guides" (Rohan 2000, p. 258).

${ }^{36}$ Lane 1962 and 1973, Feldman 1988 and 2001, Peffley \& Hurwitz 1987, Hurwitz \& Peffley 1985, Jacoby 2001, Tetlock 1986 and 1996. The state of political science knowledge regarding values can be summarized that we know how they differ from other ideational constructs (Rohan 2000); that the mass public employs them (Lane 1962); that they are organized in hierarchies (Peffley \& Hurwitz 1985); that they are the basis of policy attitudes (Hurwitz \& Peffley 1987) and candidate evaluations (Feldman 1988); what some of the principle values in American politics are (McCloskey \& Zaller 1984, Feldman 2001); and that value conflict is central to political judgment (Tetlock 1986, 1996).
} 
as "general principles" (Peffley \& Hurwitz 1985), "personal statements regarding the individual's priorities" (Hurwitz \& Peffley 1987), or "each individual's abstract, general conceptions about the desirable and undesirable end-states of human life" (Jacoby 2001). The consensus view seems to be that values are standing normative judgments of competing social ends, or in more psychological terms, trans-situational evaluative predispositions toward social end states. $^{37}$

\subsection{VALUE CONFLICT}

"Conflicts between ends equally ultimate and sacred, but irreconcilable within the breast of even a single human being, or between different men or groups, can lead to tragic and unavoidable collisions"

Isaiah Berlin (1970) Four Essays on Liberty, p. 102

Value conflict can be seen as the inevitable product of the condition that some values are incompatible with others. This condition and its role as a source of conflict is explained clearly by Isaiah Berlin in his Four Essays on Liberty and The Crooked Timber of Humanity. These works provide the philosophical basis for value pluralism: "it is what I should describe as pluralism - that is, the conception that there are many different ends that men may seek and still be fully rational, fully men" (Berlin 1992, p. 11). ${ }^{38}$ But values are not only multiple; some are inherently in conflict with others: "what is clear is that values clash," as "some among the Great Goods cannot live together" (ibid, p. 12, 13). Hence "in the end, men choose between ultimate values" (Berlin 1970, p. 171). For any given political value there is most often a directly opposed value — militarism versus pacifism, individualism versus communitarianism,

\footnotetext{
${ }^{37}$ One way to understand any epistemic construct such as values is to clarify how it fits in with other constructs within the spectrum of belief systems, and how it compares to the range of social science terms employed by other scholars. To avoid the digression here this is addressed in Appendix One on Belief Systems in American Politics and Political Science.

${ }^{38}$ See also Jon Elster (1983) Sour Grapes on the "plurality of ultimate values" (p. 38), and Joseph Schumpeter: "ultimate values - or conceptions of what life and society should be - are beyond the range of mere logic. They may be bridged by compromise in some cases but not in others" Capitalism, Socialism, and Democracy, p. 251.
} 
isolationism versus interventionism, etc. The degree to which we favor one, we automatically and inevitably oppose the other.

When considering value conflict, however, it is important to identify the level of analysis we have in mind. The principle form of value conflict may be intrapersonal, "as values may easily clash within the breast of a single individual" (Berlin 1992, 12). "So we must engage in what are called trade-offs - rules, values, principles must yield to each other in varying degrees in specific situations" (ibid., p. 17). For most people most of the time these trade-offs may seem reasonable, even if they are difficult or paralyzing (see Tetlock 1986). This defines a negotiable value. ${ }^{39}$ But some principles resist trade-offs and demand our absolute adherence - the definition of a sacred value. To a sacred thinker, the breach of that boundary is profane rather than merely a difference of opinion or a normal act of compromise. A sacred value as we have defined it is one for which there is no significant personal value conflict; we enjoy moral certainty rather than quandary, clarity rather than internal conflict.

Internal value conflict must be distinguished from interpersonal value conflict, which occurs when two clear-minded individuals see clearly in opposing directions. Two individuals who are both internally conflicted have no real stake in opposing each other, and may even be open to reasoning through their quandary together. On the other hand, it is the lack of internal value conflict that leads directly to conflict with others. And a short step away from conflict between individuals is conflict between groups within society, as like-minded citizens are drawn together and jointly oppose another group drawn together for the same reason. Sacred value clashes may be deeply connected to Gaetano Mosca's observation that people have an instinct for "herding together and fighting with other herds," creating divisions within society that "occasion moral and, sometimes, physical conflicts" (Mosca 1939, 163). This leads to one of the important conditions of value conflict, that the prevalence of internal value conflict is the

\footnotetext{
39 "The healthy person has multiple values, and he finds them often in conflict; his health is revealed in his toleration of the conflict and the means he chooses to reconcile the conflict, not in the way he makes all policy recommendations serve a single value, no matter how economical that might be for him" (Lane 1973, 102). I find this an interesting description of value conflict, though I am not sure that the connotation that sacred values are unhealthy has a strong foundation.
} 
obverse of the prevalence of social value conflict. For any given conjunction of values (e.g. religiosity versus secularism), a high level of internal value conflict among a large number of citizens leads to ambivalence at the individual level, which means low value conflict in the aggregate; on the other hand, a low degree of internal value conflict among a large number of people leads to greater intensity, which leads to a higher level of value conflict at the social level. This of course applies to conflictual and not consensus values - if almost all citizens are intent in the same direction (all secular or all religious) there is no conflict, which arises only when they are split in two different directions (some are unconflicted about secularism and others are unconflicted about religiosity). Figure 2.1 illustrates this relationship. Where personal value conflict is high and values are negotiable (the lower right corner of the diagram), social value conflict is low. As the prevalence of internal value conflict declines, the level of social value conflict rises, moving toward the lowest levels of personal value conflict and highest levels of social conflict, where we find conflictual sacred values. It is one of the interesting facets of value conflict that its manifestations at the personal and social level are intimately related, but in opposing proportions. 


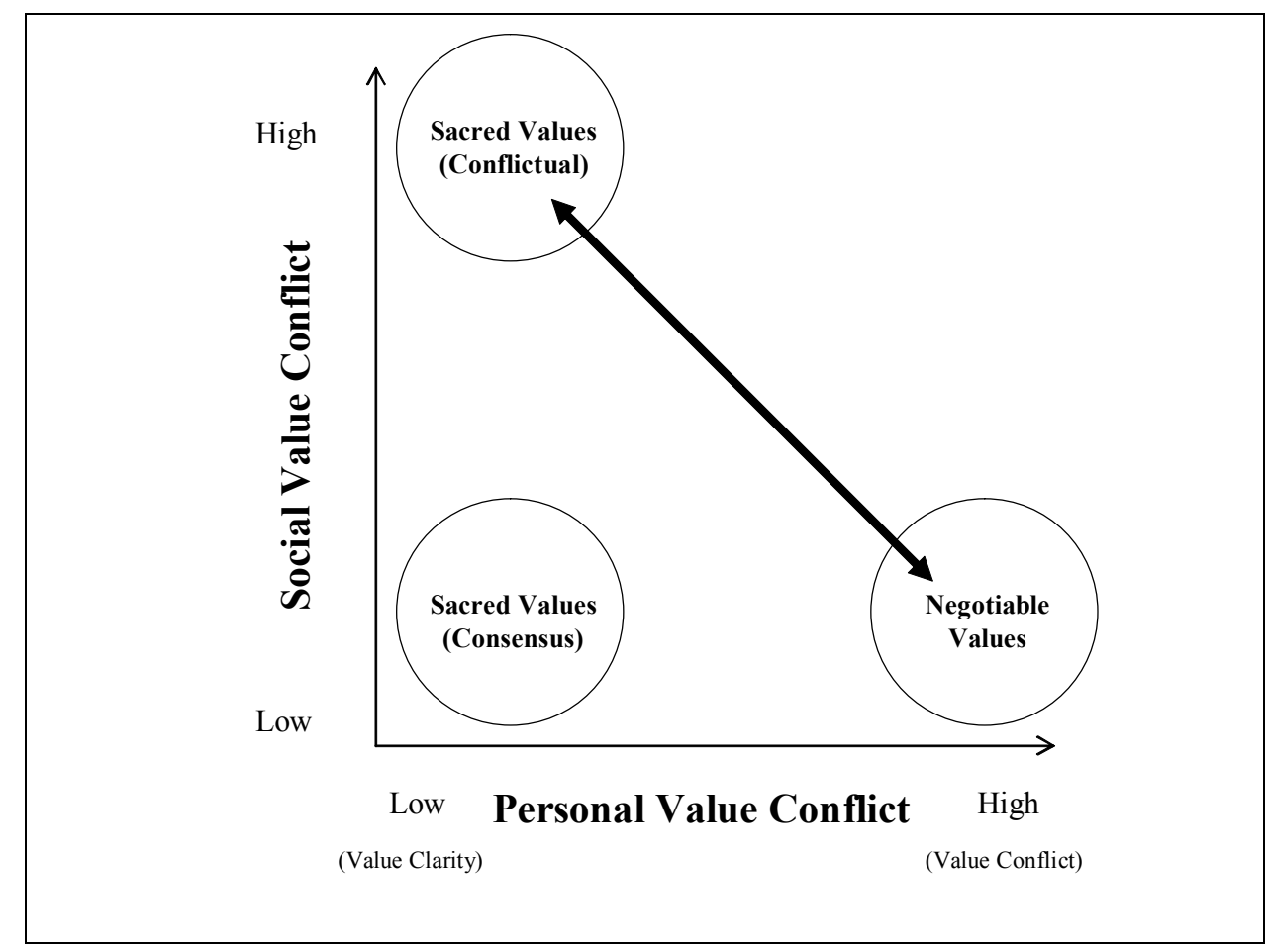

Figure 2.1 The Inverse Relationship Between Personal and Social Value Conflict

\subsection{SACRED VALUES}

In addition to the core element of the degree of value conflict or certainty - the degree of absoluteness - sacredness comprises several other important facets. One of these is noninstrumentality, or the primacy of reflexive values over calculated self-interest. By instrumentality we mean the difference between being motivated by values and being motivated by interests - the distinction between what is good and what is good for me. Instrumental thinking is borne of deliberate self-interest, while non-instrumental thinking is directed by principles. An important element of instrumentality is calculation - the degree to which we put mental energy into weighing the alternatives and consequences (the 'felicific calculus' of Bentham's Utilitarianism). In opposition to this is the degree to which we follow gut reactions, predetermined traditions, or what we know to be morally right, without the need for mental computation. Weber may have described this best in his distinction between "value rationality" 
and "instrumental rationality." The first is characterized by "a conscious belief in a value for its own sake," which is pursued "independently of its prospects for success," while the second is a clear-minded connection of means to ends, measured in terms of tangible self-interest (Weber 1978, p. 25). ${ }^{40}$ Instrumental thought is calculated and self-interested; non-instrumental thought is reflexive and value-driven. In this sense, the degree of instrumentality is the opposite of the degree of sacredness.

Another facet of sacredness is the degree of negotiability within a hierarchy of values. This can be conceptualized as a measure of the perceived degrees of freedom before something becomes simply unacceptable. Negotiability in this sense refers to an internal process, or bargaining within one's own mind, rather than external or literal negotiations with other parties. It is the willingness to give credence to opposing positions and to reconsider one's own position. A simple thought experiment should help illustrate this facet of sacredness: consider your place along a value dimension such as individualism versus communitarianism. You may be anywhere on the spectrum from believing that individuals should be self-sustaining with little help from government, to believing that society as a whole is fully responsible for each individual's welfare. Consider an economic redistribution policy such as greater taxation to fund universal health care, and what would be your immediate policy preference. Given resistance from those who prefer the opposite policy, to what degree would you be willing to accept a compromise? Would you recognize the validity of the opposing value, and perhaps most importantly, think it perfectly normal to do so? To the degree that you are comfortable making such trade-offs, individualism/communitarianism is a negotiable and not a sacred value.

Now consider the abortion question. Do you consider abortion on demand to be acceptable? If it is acceptable (or even necessary to preserve reproductive rights), would you draw a line at late term abortions? If you were offered a political compromise that would establish your favored position on the tax issue but the opposite of your position on abortion,

\footnotetext{
${ }^{40}$ A great deal has been written about the nature of instrumental and non-instrumental thought from the perspective of different disciplines and sub-disciplines. Here the word is meant to describe only the distinction between calculated self-interest and uncalculated adherence to principle — only one possible meaning of instrumentality, but I think the best available term for the distinction under consideration.
} 
would you find that compromise acceptable? What about the opposite proposition — the law would reflect your position on abortion, but the reverse on the tax issue? Would you find that agreement more palatable? The degree to which the first proposition (your view on taxes but not on abortion) is more difficult to accept than the reverse arrangement may reflect a greater degree of sacredness - a lower degree of negotiability — on the moral question of abortion compared to the economic redistribution question of taxes. Now consider something for which there is a near-universal social prohibition, such as incest. If a small sect living in a secluded area of your state were to promote the practice, and the majority party of the state legislature were considering erasing all legal prohibitions (perhaps in return for that group's support on a different issue on which they agree with you), would you feel this was something on which you could compromise? Or would you feel that no compromise could be made, and that no public or even symbolic endorsement could be tolerated? Whether a value is fully negotiable, resists negotiation or draws certain boundaries, or is clearly non-negotiable, is an aspect of sacredness. To engage in compromise regarding a sacred value, or even to consider doing so, may be seen as illegitimate. Holding a value as sacred entails denying the validity of the normal value trade-offs involved in policy compromises.

In addition to non-negotiability, another facet of sacredness is non-consequentialism. If a value or principle is sacred, then it stands on its own; it does not require the justification of positive consequences that derive from it, nor is it in any way invalid because of any negative consequences it might have. For example, if free speech is held to be sacred, the negative influences of certain types of speech are irrelevant. ${ }^{41}$ This facet of sacredness is also related to Weber's concept of "value rationality" or "value-rational social action," which is characterized

\footnotetext{
${ }^{41}$ If political expression is truly sacred, then the offense that my words create is not only outweighed by my right to say them, but the offense has no weight at all. In this view, a citizen who objects to my speech is more wrong to take offense than I am to give it, as they are not recognizing the sacredness of my free speech; they may object to what I am saying, but they are not defending to the death my right to say it. The ACLU has often taken a nonconsequentialist position on the First Amendment, an argument known as free speech absolutism (see Walker 1990). In this view, free speech means precisely that - all speech is protected absolutely and it is not legitimate to weigh speech against it consequences. A similar argument is made from the right of the political spectrum in regard to gun rights - the consequences of gun ownership (violent deaths) are not really relevant given that gun ownership is a sacred right. This approach has important ramifications for constitutional jurisprudence, because most Supreme Court decisions are grounded in balancing tests rather than absolute principles. If balancing is illegitimate from the start, this suggests an entirely different decision process.
} 
by pursuing a value "independently of its prospects for success." ${ }^{2}$ Consequences - either positive or negative - are not relevant if a principle is valid on its own terms. In this sense truly sacred values are non-instrumental, non-negotiable, and non-consequentialist — not to be calculated, compromised, or opposed with the logic of consequences.

Another facet of sacredness is the setting of boundaries. What is sacred is what establishes a limit to thought or behavior. Hence sacred rhetoric entails the language of limits one must not mention this; this kind of relationship is improper; this cannot be allowed; one must do this; one must not do that. Cultural relativism and value pluralism to the contrary, sacred thinking holds that some things are just not acceptable — delineating the boundaries of the sacred. ${ }^{43}$ But the boundary is likely not an idiosyncratic or random one; it is often a boundary sanctioned by an authority. In this sense an authority is a recognized source of legitimacy for a sacred claim. ${ }^{44}$ It provides the belief system necessary to reinforce a value's sacred status. The authority serves as an answer to the question of why we should accept something as sacred because $x$ says so. Lacking such an authority, a sacred claim is less likely to be persuasive or to maintain its hold. Consider, for example, a sacred claim that cannot answer the question of why it should be taken seriously. How long will it continue to hold force? In the face of contemporary value pluralism, sacred claims without authoritative backing are not likely to be

\footnotetext{
${ }^{42}$ See Weber Economy and Society p. 25 for a discussion of value rationality as opposed to instrumental rationality. See also Ulysses and the Sirens, in which Jon Elster describes the concept of binding, or precommitments limiting what one can or cannot do regardless of circumstances or consequences (Elster 1984). March and Olsen describe different forms of decision-making conforming to the logic of consequences (instrumentalism) and the logic of appropriateness (cultural norms) (March and Olsen 1989). All of these distinctions help illuminate the concept of non-consequentialism.

${ }^{43}$ See James Davison Hunter's definition in The Culture Wars: "the 'sacred' is that which communities love and revere as nothing else. The 'sacred' expresses that which is non-negotiable and defines the limits of what they will tolerate” (Hunter 1991, p. 322).

${ }^{44}$ See Marietta and Perlman 2000 on "authority systems, traceable to specific intellectual or cultural precursors, or authorities" (151). These "may be a reference to a person, a definitive published work, or an interpretation of a seminal thought... Our use of the term 'authority' as interchangeable with an intellectual legacy may be misconstrued because of its dual meaning - connoting both that a certain person or line of thought serves as an authority, and they assert authority over us... Once ingrained, however, the authority may be fully self-imposed, without any need for external support" (153, and n4).
} 
maintained. ${ }^{45}$ In this sense the sacred is not just a boundary, but a socially-reinforced boundary. One facet of the sacred is a specific boundary established by a specific authority.

Authorities could be described as "constellations of absolute presuppositions," to use Collingwood's and later Isaiah Berlin's phrasing. However, the degree to which adherence to an authority is truly absolute, or to which there are important exceptions, or to which one pays lip service but will nonetheless compromise, is a critical question. Of course the more legitimate and influential the authority, the more persuasive the sacred claim. For example, the Bible is a major religious authority and the Constitution a major secular one. The Book of Mormon on the other hand, is authoritative to some, but less so to others, while George Washington's warning against entangling alliances is often cited as a secular political authority, but is less authoritative than the Constitution. The degree to which an individual feels bound to the limit established by the authority is a measure of the degree of sacredness.

In addition to establishing the boundaries of what one will tolerate, sacredness can also influence the boundaries of what one will contemplate. Sacredness can entail taboos against even considering or discussing certain topics. Some options are simply not options to a sacred thinker. In the World War I tract Instincts of the Herd in Peace and War, William Trotter describes this effect in regard to the mass movements of that era: "To question it is for the believer to carry skepticism to an insane degree, and will be met by contempt, disapproval, or condemnation... there is a quality of feeling which tells us that to inquire into it would be absurd, obviously unnecessary, unprofitable, undesirable, bad form, or wicked."46 Taking this concept further, Mohammed Arkoun describes the distinction between thoughts that are thinkable and those that are unthinkable. ${ }^{47}$ Sacred boundaries

\footnotetext{
${ }^{45}$ By their very nature, value claims cannot rely on empirical evidence or logic for their backing, because "ethical values are not subject to verification" (Lane 1972, 182), and "are beyond the range of mere logic" (Schumpeter 1942, 251); see also Berlin Four Essays and Galston Liberal Pluralism. Because we cannot demonstrate empirically or logically that one value is superior to another or that one value is truly sacred rather than negotiable, such claims must rely strenuously on appeals to authority.

46 Trotter, 1916, quoted in James Harvey Robinson (1917) “The still small voice of the herd" Political Science Quarterly 32,2 p. 316.

47 Arkoun 1986, 158-9, cited in Kuran 1995, 176.
} 
are those that limit certain thoughts from consideration, or at least impose high costs to one's morality or decency if one does consider them. ${ }^{48}$ A contemporary example of this is the conflicting rhetoric surrounding the legitimacy of abortion, which can be illustrated by an anecdote about a family conversation concerning the pregnancy of a sixteen year old within a strong Catholic family. One of the older female relatives suggested that they should consider how having the child would influence the daughter's further education and future. The father immediately responded that they would not hear that — no talk of consequences could be tolerated about something that should only be considered in terms of right and wrong. This strikes me as a particularly cogent example of sacred non-consequentialism, or a boundary to framing things in the rhetoric or logic of consequences rather than principles. A similar phenomenon goes beyond the legitimacy of discussing certain subjects to the legitimacy of recognizing certain observations. Sacredness may be related to the denial of sacrilege, or the refusal to admit the existence of things that should not be the case - what could be termed sacred blindness. This could be described as cultivated ignorance for the sake of not having to think unpleasant thoughts, or for the sake of not having to face unpleasant social reactions. In either case, conflating normative and positive (it should be this, therefore it is this, and I will not pay attention to contrary evidence) may be an important ramification of sacredness. In this sense, the boundaries of the sacred may have an interesting breadth, extending from action to contemplation to observation.

A final facet of sacred values is moral outrage. This may be a strong and nearly unavoidable element of sacred belief, as the existence of the sacred almost automatically implies the existence of the profane. Holding a person, place, object, or belief as sacred implies that the desecration of that sacred thing, or perhaps even the expression of its opposite, is a profanity (Durkheim 1912). ${ }^{49}$ To the holder of a negotiable value, the expression of its opposite is merely a difference of opinion, perhaps an annoying but not a fundamentally offensive act. The abrogation of a sacred value, on the other hand, inspires moral outrage (Tetlock et al 1996, Fiske

\footnotetext{
48 See Tetlock et al 2000 for evidence of the social and internal sanctions imposed in response to transgressions against sacred values, including sanctions for just considering such transgressions (the mere contemplation effect).

49 A sacred thing is "the mandatory recipient of elaborated deference" (Durkheim 1912, xlvi); to not show that deference is profane.
} 
and Tetlock 1997, Tetlock et al 2000, Baron \& Spranca 1997). The public denigration (desecration?) of a cherished value results in a negative emotional reaction, which may require defensive public expressions or acts to cleanse. Hence holders of sacred values are likely to be publicly value-protective, defending the collective standing or reputation of a sacred value. Tetlock describes this as the Sacred Value Protection Model (SVPM), which predicts that the abrogation of sacred values leads to moral outrage and moral cleansing (Tetlock et al 2000). Acts of moral cleansing may only involve public statements, but I hypothesize that they also extend to political participation. Engaging in public acts of political engagement is a particularly powerful way of distancing oneself from the profane, as a statement both to others and to oneself. This raises the proposition that this form of political engagement is fundamentally symbolic, both in terms of its personal meaning and its public intent. Citizens do not need to intend to change public policy, or to think that their actions might do so, in order for the engagement to be meaningful. Symbolic politics and the skirmishes of the culture wars are often described as 'the politics of distraction,' but while they are clearly a distraction from policy proposals in other realms of the political agenda, this is missing the point that those issues are a distraction for people who place a high personal value on public symbolism. To sacred thinkers, collective symbolism is not a distraction from what is important, but instead it is an important political statement, both to others and to themselves. The influence of sacred rhetoric may be due to exactly this connection among moral outrage, public accountability, and political engagement.

\subsection{SACRED RHETORIC}

So how is sacredness expressed, or in other words, what distinguishes a sacred appeal from a non-sacred one? Sacredness does not depend on the political position taken or its ideological direction, as one can take a sacred stand against abortion just as one can take a non-sacred stand. The same applies to the anti-abortion side, or to stands both for or against the death penalty. We can understand sacred rhetoric as a form of reasoning, or a way of thinking through the relation between values and public policy opinions. This form of appeal makes an argument in a manner that sets a political issue apart, reasoning about it in a different way. Sacred rhetoric employs 
absolutist reasoning, while non-sacred or negotiable appeals employ more consequentialist reasoning. Absolutist reasoning is characterized by applying established principles or boundaries to a given situation, and then privileging these principles over the consequences of the decision. It may also entail citing specific authorities for the principle, and perhaps engaging in expressions of anger or moral outrage at perceived violations. Consequentialist reasoning, on the other hand, begins from the expected effects or outcomes of the decision and applies a give and take form of negotiation, with authorities seen as more pluralistic or non-binding, and expressions of moral outrage being more limited. One succinct example of the core difference is illustrated by two competing arguments for why one shouldn't steal - is it because it is wrong, or because crime does not pay ? $^{50}$ Both argue for the same result, but in a distinct fashion, one absolutist and the other consequentialist. ${ }^{51}$

We can define absolutist reasoning more clearly as being characterized by a combination of the following attributes:

${ }^{50}$ In the Cohen brothers remake of The Ladykillers, Professor G.H. Dorr sees his consequentialist reasoning defeated by the absolutist reasoning of his aged landlady when he tries to convince her to remain quiet about her discovery of the large sum of money that he has stolen. In his consequentialist view, the previous owner of the money was an evil institution (a gambling house), he will be donating half of the money to her favorite charity (Bob Jones University), and there is no victim, as the money will be replaced by the insurance company, without even a cost to the policy holders, each of whom will contribute only one cent. "Think of it," Professor Dorr argues, "one penny from those thousands upon thousands of people, so that Bob Jones University can continue on its mission." Her absolutist response is "It's wrong. And don't you be leading me into temptation. Its just plain wrong."

51 At this point we should note that there is a sense in which the distinction between absolutist and consequentialist reasoning is blurred: in the end, even a fully consequentialist position relies on a value judgment regarding the specific consequences at hand. But this reductionist approach ignores some key distinctions between the two modes of thinking and justification, which are noted by several prominent thinkers from Weber (1978) to March and Olsen (1989). Absolutist reasoning is a critique of actions or beliefs as valid or invalid in and of themselves.

Consequentialist reasoning, on the other hand, concentrates on states of affairs that result from such actions or beliefs. Hence one important distinction is whether we begin or end with values. In an absolutist approach, one chooses a value to exalt above others and begins there. A consequentialist approach only appeals to values at the very end, once the chain of consequences is complete. The value that one applies at this point depends on the nature of the consequences at hand. So both modes of reasoning deal with values, but one begins with values that are of one's choosing, while the other ends with values that one does not necessarily foresee. Perhaps a more important distinction between the two modes of argument is that in the one it is legitimate or even mandatory to weigh competing consequences and values, while in the second such weighing is illegitimate from the outset, identifying the person employing such reasoning as unethical or morally suspect. In this sense, additional information or facts are helpful or even crucial to consequentialist reasoning, but are at best a distraction (and may be detrimental) to absolutist reasoning. So while there is an important connection between absolutist and consequentialist reasoning, there are also crucial distinctions. It is an important normative point that all arguments reduce in the end to value justifications, but it is also an important empirical point that some arguments arrive there more quickly and immovably than others. 
1) Protected status: placing a value beyond question and set apart from trade-offs with other values.

2) Non-consequentialism: privileging values over costs or consequences.

3) Non-instrumentalism: rejecting calculated self-interest.

4) Non-negotiability: denial of the legitimacy of compromise.

5) Citation of boundaries: invoking a boundary of what is acceptable or tolerable.

6) Citation of authority: invoking the relevant authority for the boundary.

7) Moral outrage: referencing anger, especially at a boundary violation.

As opposed to sacred rhetoric, non-sacred or negotiable political rhetoric emphasizes consequences and outcomes; it cites figures and data rather than principles or authorities. It is phrased in the language of policy experts. It may well mention or invoke values, but it does so in a non-strident way. Most importantly, it employs consequentialist reasoning characterized by these attributes:

1) Relativism: implying value trade-offs or comparability with other competing values.

2) Consequentialism: invoking costs or consequences.

3) Instrumentalism: referencing calculated self-interest.

4) Negotiability: invoking compromise.

5) Denial of boundaries: denying the validity of a boundary.

6) Denial of authority: denying the validity of a known authority for the boundary.

7) Denial of moral outrage: denying the validity of moral anger.

This scheme provides us with a direct means of evaluating any given political appeal or justification. By taking note of each of the elements of absolutist or consequentialist reasoning present in a given argument, we can assign it a value from positive seven for an extremely absolutist argument (containing all seven absolutist elements) to negative seven for a strongly consequentialist argument. Take, for example, the following statement in favor of the death penalty:

The death penalty makes a clear moral statement about what we will and will not allow in our society. Heinous crimes cannot be tolerated. We must be clear about what sort of justice they require. Both the victims and especially their families are due the form of justice that both our religious and secular traditions call for. The Bible is clear about the demands of an eye for an eye, and the Constitution itself specifically mentions capital punishment as part of our legal system. The issue is not deterrence; it is the strongest possible statement of what outrages the community of what is allowable and what is not. 


\author{
Protected status \\ Non-consequentialism \\ Non-instrumentalism \\ Non-negotiability \\ Boundary \\ Authority \\ Moral outrage
}

\author{
Relativism \\ Consequentialism \\ Instrumentalism \\ Negotiability \\ Denial of boundaries \\ Denial of authority \\ Denial of moral outrage
}

This appeal invokes at least five elements of absolutist reasoning (protected status, nonconsequentialism, citation of a boundary, citation of authority, and moral outrage [marked in bold above], representing a 5 on the reasoning scale). Compare this to the following statement, also in favor of the death penalty:

The death penalty is our last line of defense against the most violent and dangerous criminals in our society. Some argue that capital punishment is not a deterrent to crime, but common sense tells you that at least some potential murderers will be stopped by the knowledge that they may be put to death. We must also protect society by removing the most vicious criminals from our midst, which cannot be done with certainty by imposing long prison sentences that later parole boards can lessen. Opponents argue that if one innocent man is executed then the system must be stopped. But how different is this from one innocent man who is held in prison for the rest of his life? We cannot stop from determining justice only because a mistake might rarely be made. Even if an innocent man is executed in the rare case of a mistake, this is more than balanced by the number of lives saved by making sure that the most vicious criminals cannot kill again.

Protected status
Non-consequentialism
Non-instrumentalism
Non-negotiability
Boundary
Authority
Moral outrage

\author{
Relativism \\ Consequentialism \\ Instrumentalism \\ Negotiability \\ Denial of boundaries \\ Denial of authority \\ Denial of moral outrage
}

While this appeal argues for the same policy as the first one, it does so in a consequentialist fashion, employing at least two elements of consequentialist reasoning and none of absolutist (-2 on the reasoning scale). This procedure for assessing the nature of reasoning can be applied to any given appeal or justification (and will be employed for the experimental study).

Consider the case of differing arguments in favor of gun possession. While one can take a consequentialist position in favor of guns, the more common arguments made by the NRA employ absolutist appeals, such as the following statement: 
The ability to keep and bear arms is a protected right of free citizens. The Constitution gave us that right because our forefathers knew that it must be preserved against future encroachments. It is this principle that counts. The $2^{\text {nd }}$ Amendment is no better or no worse than the other parts of the Bill of Rights. We must preserve it just as we must preserve First Amendment rights to free speech, and Fifth Amendment rights against self-incrimination. We should be angry at the efforts by false leaders to take away our long-standing freedoms, and refuse to allow ourselves to go

down the slippery slope of one concession after another. We cannot negotiate away our sacred rights.

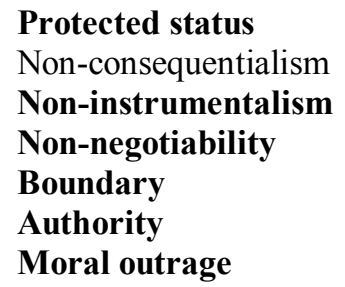

Protected status

Non-consequentialism

Non-negotiability

Moral outrage

\author{
Relativism \\ Consequentialism \\ Instrumentalism \\ Negotiability \\ Denial of boundaries \\ Denial of authority \\ Denial of moral outrage
}

This argument scores a six on the reasoning scale. Compare it to a more consequentialist way of making an argument in the same direction, which scores a -4 on the scale:

Citizens must be allowed to keep firearms in order to protect themselves. Allowing citizens to own guns is simply a matter of weighing the consequences of law-abiding citizens having them versus what would happen if solid citizens did not have guns. Having firearms may lead to some accidental deaths by those who do not store their guns properly or teach their children how to respect them. But the consequence of not upholding gun rights is the inability of citizens to protect themselves against criminals, as well as the increased boldness of criminals because they know that homeowners are not armed. This would result in a much larger number of deaths and a more violent society. It is simply not true that we can rely on the police to protect us. They do not, and we must be able to protect ourselves.

\author{
Protected status \\ Non-consequentialism \\ Non-instrumentalism \\ Non-negotiability \\ Boundary \\ Authority \\ Moral outrage
}

\author{
Relativism \\ Consequentialism \\ Instrumentalism \\ Negotiability \\ Denial of boundaries \\ Denial of authority \\ Denial of moral outrage
}

These two arguments make very different appeals for maintaining private gun ownership, and their influence may be quite different as well.

\subsection{SACRED RHETORIC IN SOCIAL MOVEMENTS}

The examples above come from the language of social movements, which are an important source of sacred rhetoric. Social movements may be one of the most common mechanisms 
through which sacred rhetoric influences American politics and enters partisan discourse. Moreover, this form of appeal may be inextricably connected to the nature of social movements themselves. I argue that in some ways it is difficult to fully understand one without the other. More importantly, their success may be mutually reinforcing; the success of a social movement increases the dissemination of sacred rhetoric, while the employment of sacred appeals may be one of the key factors in a movement's success.

Social movements can be understood most clearly in ideational terms - as explicit attempts to advance certain ideas or values. In this sense, social movements can be defined as collective attempts to employ ideas to change ideas. There is no doubt that social movements have a strong ideational component, but defining them in this way is not in the mainstream. ${ }^{52}$ This limits our understanding of what social movements do and the role of rhetoric in their success. A more useful definition of a social movement is cultural vanguardism attempting to bring about cultural change by influencing the dominant discourse. This gives us a clear view of the purpose and tools of social movements, as well as a clear definition of their success or failure: whether cultural change takes place. $^{53}$

Though not widely recognized, several strains of contemporary scholarship support this interpretation. These begin with McGee's 1980 article on the ideation rather than material

\footnotetext{
${ }^{52}$ For a more orthodox interpretation of social movements in terms of resource mobilization see Zald and McCarthy 1987. Approaches to social movements that emphasize resources, political opportunities, collective action problems, or cycles of contention generally focus on materialist rather than ideational foundations, ignoring the epistemic or cognitive nature of social movements. This may be part of the academic legacy of Marxism - a propensity to see change and causation in materialist terms, neglecting ideational approaches, what Fukuyama describes as "our disinclination to believe in the autonomous power of ideas," a product of "the ambient Marxism of the academy" (Fukuyama 1992).

53 This conceptualization also provides a clear distinction between social movements and interest groups, which are often confused. The target of social movements is the belief systems of society; the target of interest groups is government policy. Of course these may overlap: the pro-life cause involves both a social movement and interest groups, but this needn't be the case. The AARP is a decided interest group, with no discernable 'pro older Americans' social movement aimed at changing prevalent attitudes or social norms. An example of the reverse - a social movement without an interest group - would be the free love movement of the sixties. While it was clearly a movement aimed at changing social mores toward sexuality, I am aware of no interest group of free love advocates intent on changing government policy. In this sense, the two are distinct in conceptual and empirical terms, even though they often empirically overlap.
} 
foundation of social movements. As he describes it, "the issue was materialism versus idealism: The dispute was over what 'moves' in history - the material things which are our physical environment or the human ideas which mediate and interpret the facts of our experience" (McGee 1980, 238). Since then a more Hegelian view has emerged, of social movements as the vanguard of ideational change. As Bert Klandermans phrases it, "organizers are 'social reconstructionists'; they construct an alternative view of social reality" (Klandermans 1992, 8990). This is especially true of what have come to be described as New Social Movements, which have more cultural than economic goals and work outside of the normal channels of party politics. ${ }^{54}$ Prime examples include the women's, peace, and environmental movements. The ideational component of new social movements is especially clear, as are its connections to sacredness. Several of the issues in American politics that I have identified as espousing sacred values and employing sacred rhetoric are the same issues which are associated with new social movements, such as abortion, gun rights, peace, the death penalty, and environmentalism. As Claus Offe observes, these movements often take uncompromising (sacred?) positions "movements are also unwilling to negotiate because they often consider their central concern of such high and universal priority that no part of it can be meaningfully sacrificed" (Offe 1985, $831)$.

To the degree that scholars miss the ideational foundations of social movements, they also miss the crucial role of sacred rhetoric in the public sacralization of the movement's values and in encouraging citizen engagement to advance the movement's goals. Much of the discussion of the ideational foundation of social movements revolves around the use of symbols and frames to influence society (see Snow and Benford 1992 and Zald 1996). In this view, choosing the most influential "master frame" (Snow and Benford) is the key to influence and success. The most effective frame may be a sacred one. Movements that request little may be less successful than movements that request much. As Daniel Burnham, the Director and

\footnotetext{
54 See Melucci 1985, Offe 1985, and Calhoun 1995. "Sometime after 1968, analysts and participants began to speak of 'new social movements' that worked outside of the formal institutional channels and emphasized lifestyle, ethical, or identity concerns rather than narrowly economic goals"; these movements are "concerned largely with values, norms, language, identities and collective understandings"'(Calhoun 173, 176).
} 
innovator of the pathbreaking Chicago World's Fair of 1893, once said, "Make no little plans; they have no magic to stir men's blood."

The language of gun rights advocates — who have been remarkably successful in advancing their cause - is certainly framed in sacred terms: the common NRA slogan "You can have my gun when you take it from my cold dead hands" is one of the clearest statements in contemporary American politics of an absolute principle that refuses any sort of trade-off. The NRA takes a strong non-consequentialist position that the accidental or violent deaths that result from gun ownership are not germane to the issue, as the right to bear arms is a principle that transcends these concerns. It is inviolable. ${ }^{55}$ Whether the beliefs match the rhetoric in terms of true sacredness is an interesting empirical question. But I suspect that sacredness is not a part of the anti-gun position, which is clearly consequentialist. Accidental and violent deaths are the problem, which is about cause and effect rather than transcendent principle. Supporters of antigun positions must be convinced of negative consequences to be avoided rather than principles to be upheld.

This raises an interesting question about the comparative power of the pro and anti-gun positions. It is often assumed that the power of the NRA comes from their large coffers. An alternative hypothesis about the source of their power is the advantage gained by single-sided sacredness. The gun rights position may enjoy a belief system and rhetorical advantage over its detractors. This comports with two broad observations about the politics of issues characterized by single versus double-sided sacredness. Gay marriage, like abortion, is a back and forth battleground, with no clear advantage to either side. ${ }^{56}$ Gun rights, on the other hand, have little

\footnotetext{
55 Another way of phrasing this, as some gun advocates do, is that the higher order consequences of gun ownership in terms of maintaining individual freedoms and prevention of government tyranny outweigh the lesser order or temporal consequences such as a limited number of deaths (e.g. "the doorway to all freedoms is framed by muskets," Charlton Heston 2000 NRA meeting remarks). Free speech advocates employ the same logic in terms of the higher order consequences of free speech (individual freedom and the prevention of tyranny) that outweigh the lesser order or temporal consequences in terms of limited public disruption, threats to minorities (as in the Skokie case), or damage to national security (as in the Pentagon papers case).

56 Though one could argue that abortion is not really evenly split in terms of control over national policy, as the main thing in controversy - the simple legality of abortion - has gone to one side and not the other for over thirty years (with some back and forth about limitations and funding, but not over the main question of legality).
} 
electoral or for that matter constitutional challenge; the politics of gun rights weigh decidedly in their favor. This could be because of the power of the NRA as a lobby, but it could also in part be due to the form of belief system involved. A second observation is the comparative power of organizations on either side of the controversy. For abortion, both sides have prominent and well funded organizations (Operation Rescue on one side and NARAL on the other, to name only one example on each side). For guns, nothing matches the prominence and influence of the NRA; anti-gun organizations exist, but none are close to the NRA in status. ${ }^{57}$ This could be due to the particularities of these domains and their issue publics, but it could also in part be due to the existence of sacred arguments on one side but not the other.

\subsection{SACRED RHETORIC IN POLITICAL PARTIES}

Aside from the province of social movements, where do we find sacred rhetoric? Is it sprinkled throughout American political speech, or is it concentrated within specific domains or in the rhetoric of certain actors? In addition to these questions about contemporary American politics, it may be instructive to wonder how the current era compares to previous periods of American history. Are we more sacred thinkers now than in the recent past? While the historical questions would require a major study of the political rhetoric of other eras that is outside the scope of our empirical inquiry, it is nonetheless significant to note why sacred rhetoric may be an important characterization of our time. If we are living in a period of relatively prevalent sacred rhetoric, this may be because of the divided nature of our current politics, or as Brewer and Stonecash phrase it in their new book, our Split. The Culture Wars thesis argues that beginning in the later eighties or early nineties (though it is the ramification of changes occurring since the sixties), we have become a more culturally divided nation along progressive and traditionalist lines. To the degree that the culture wars thesis describes contemporary politics, we have shifted emphasis toward moral rather than economic questions. And sacred rhetoric is likely to be more prevalent

\footnotetext{
${ }^{57}$ The Brady Campaign to Prevent Gun Violence (formerly Handgun Control, Inc.) describes itself as "the nation's largest national, non-partisan, grassroots organization leading the fight to prevent gun violence," but it is dwarfed in membership and funding by the NRA.
} 
in the realms of morality and identity rather than economics and redistribution. Social welfare and economic redistribution questions are by their very nature monetized and therefore amenable to negotiated division. Moral questions, however, are more likely to be both indivisible and attached to deeply held principles. ${ }^{58}$ This may have not eradicated, but only added to the older economic division, which may have increased due to the recent wealth expansion among the upper strata of society. ${ }^{59}$ To these divisions we can add the more recent post 9/11 division over the response to Islamic terrorism. Hence we have three major divisions that map onto the current party structure (divided by the response to traditional culture, individual wealth creation, and warfighting). For these divisive reasons, along with the rise of New Social Movements and New Media as discussed above, we may well be living in a relatively sacred era.

But what can we say about the distribution of sacred rhetoric within our own time period? Perhaps one of the most important questions is whether it is employed equally by the two major parties. Is it the case that sacred rhetoric is more prominent on the right? Or do the sacrednesses of the left contribute to a substantial degree of sacred rhetoric for Democrats as well? More than just a matter of understanding partisan beliefs and tactics, this question has important ramifications for the electoral success of the competing parties. If one party employs a substantially greater degree of sacred rhetoric, then they will accrue the activation advantages of sacredness. In the close political environment of the current day, this may provide a critical marginal advantage for one party over the other. For this crucial question I advance the

\footnotetext{
58 "They are hard to resolve because, unlike quarrels over money, religious and ethnic quarrels are not easily solved by fractional relief, a redivision of the pie" (Lane 1972, 203). "Various political activities having to do with drugs, abortion, the teaching of evolution in public schools, prayer in the classroom, and religious observance as sanctioned by the government are fundamentally symbolic. That is, they are struggles over what activities - and hence what kinds of people - will be publicly defined as righteous, respectable, and worthy, and which will be bracketed in the opposite ways. ...Political participation tells who we are and what we stand for - to the world at large and to ourselves. Thus the stakes are very high, even when they have nothing to do with the kinds of interests allocated by lobbies and other 'economic' action" (Rule 1988, 40).

${ }^{59}$ It is important to note that the American economic division is not about having or not having wealth, but rather about the attitude toward wealth. Many Americans in the higher economic strata are now politically liberal and there is a strong base of economic individualists among poorer citizens, which is not coincidentally the base of Evangelism (this is the alleged conundrum of Thomas Frank's What's the Matter with Kansas?, but see Hunter 1991 and Barker 2000). Rather than haves versus have nots, it is a division over the attitude toward having.
} 
hypothesis that even taking into account some degree of sacredness on the left, Republicans do employ the greater degree of sacred rhetoric and gain the absolutist advantage.

A broader point is that identifying the prevalence and distribution of sacred rhetoric is an empirical question to be answered. We can speculate on the different facets of American politics, but ultimately they form a series of questions that need to be answered as part of a research agenda on the role of sacredness in democratic politics. Here we can address the central questions of the persuasive influence of sacred rhetoric and its partisan comparison. These questions have particular normative meaning for the operation and health of American democracy, points that we turn to in the following chapter. 


\subsection{SACRED RHETORIC AND DEMOCRATIC HEALTH}

So why study the role of sacred rhetoric in American politics? In addition to practical questions about the more effective forms of rhetoric for social movements and political leaders, I argue that sacredness is intimately connected to our current normative concerns about democratic politics. One focus of contemporary political science is the ongoing debate about the state of American democracy, or an interconnected set of ideas about the nature and origins of what could be termed democratic health. To what degree does our democracy match the different normative standards in which we traditionally believed or have more recently come to espouse? Several normative and empirical research agendas converge on the same central question of the degree to which our political system lives up to the norms of representation and citizen engagement to which it aspires, or the degree to which it is either healthy or malfunctioning. Different aspects of this conversation take divergent perspectives on the health of American democracy, the causes of its maladies, and the prescriptions for its improvement, but they are all part of what Skocpol and Fiorina describe as the general agreement "that social dynamics are closely intertwined with the health of democracy" (Skocpol and Fiorina 1999, p.12). The most prominent arguments are from the perspectives of civil society, social capital, and the literatures on participatory and deliberative democracy. Each argument emphasizes a different aspect of a healthy democracy, but there is a distinct area of overlap. In one sense or another, each of these discussions deals with the relation between democracy and political intensity. Sacred rhetoric influences citizens' political intensity, and the wide range of intensity is the centerpiece of the contemporary study of civil society.

I argue that the common ground in the conversation about the requirements of a healthy democracy is the question of the optimal distribution of political intensity, or the degree to which individual citizens are concerned about politics. This concept takes several forms in different 
aspects of the conversation, but what unifies the discussion across the varying perspectives is a root emphasis on the political motivation of citizens. Whether focusing on engagement within civic organizations, on direct political action, or on public discussion, each approach is concerned fundamentally with the underlying variance in citizen motivation. My argument is not that political conviction is the only variable in all of these approaches, but that it is central to each and provides a unified way of integrating them. Concentrating on political conviction and its origins as an underlying variable is a way to see the connections within a broad range of political science research and emphasize the importance of their joint discussion on the health of democracy.

While the concept of political conviction has several strong theoretical connections to democratic health, it nonetheless remains an underdeveloped concept. This is certainly true of its empirical description and measurement, but is also the case in regard to its theoretical impact. Most importantly, it is unclear whether the effects of political intensity are uniformly positive, even though "often those who discuss civic engagement speak as if all kinds of participation and activism were good (except perhaps totalitarian mobilization)" (Skocpol and Fiorina 1999, p. 19). ${ }^{60}$ Rather than the vices of apathy, we may wish to be concerned about those of extremism. A real detriment to democracy may be the strong, even violent, passions that curtail meaningful deliberation, discourage participation by moderates, make reasoned agreement difficult, or lead to political violence.

These observations can be summarized as a paradox of democratic health participation leads to health, but too much participation of the wrong kind may lead to dysfunction; political conviction leads to positive forms of participation, but too much conviction can lead to disruptive and detrimental forms of participation. The relation between sacred

\footnotetext{
${ }^{60}$ An important exception is the small but growing literature on "bad civil society," or citizen engagement within exclusive and intolerant organizations, especially those that advocate hate and bigotry. Chambers and Kopstein define these organizations as ones that deny the importance of reciprocity, or "the recognition of other citizens, even those with whom one has deep disagreement, as moral agents deserving civility" (Chambers and Kopstein "Bad civil society" 2001, 839). Fiorina describes the potentially negative affects of citizen participation even in mainstream organizations when it is conducted in an overly strident or intolerant fashion (Fiorina 1999).
} 
rhetoric and democratic health is the normative heart of this inquiry. If sacred rhetoric affects the degree and nature of citizens' political engagement, what does this mean for our democracy?

\subsection{THE NATURE AND ORIGINS OF DEMOCRATIC HEALTH}

In order to illustrate the distinctions as well as the underlying connections among the different perspectives on democratic health, a brief description of each approach may be useful. Civil society can be defined as the interaction among citizens that takes place in the public sphere, between the private realm of individuals and the government realm of the state. ${ }^{61}$ This encompasses explicitly political organizations such as protest groups or campaign volunteers, as well as ostensibly non-political organizations such as church groups or bowling leagues. The broad concept of civil society also connotes a high level of interaction, cooperation, and tolerance among an active citizenry. While civil society is the term for the web of citizen interactions or the ideal of the type of society envisioned, civic engagement is the term for the form of citizen action required for its realization. Social capital on the other hand denotes the level of trust and connectedness within society. In Making Democracy Work, Robert Putnam argues that the degree of social capital accounts for the differences in economic and political development among nations or regions, and in Bowling Alone he extends the argument to the United States, where he argues that social capital is in decline. ${ }^{62}$

The deliberative democracy approach argues that all forms of participation within the organizations of civil society are not created equal; the content of civic engagement matters. Deliberative theorists argue for the normative superiority of unrestrained discussion, leading

\footnotetext{
${ }^{61}$ For a summary of the civil society debates, see Skocpol and Fiorina 1999. They define civil society as "the network of ties and groups through which people connect to one another and get drawn into community and political affairs" (1999, p. 2).

62 On the nature of social capital see Coleman 1988 and Portes 1998; for the classic arguments for its decline see Putnam 1993, 1995, and 2000. The declining social capital argument is criticized on two different counts: 1) it is not declining (Ladd 1996, Lemann 1996), and 2) social capital is not connected to other desiderata, either theoretically or empirically (see Portes and Landolt 1996 and an especially cogent argument by Richard Florida 2000, chapter 15).
} 
toward reasoned agreement. In this view the requirement of democratic legitimacy is deliberation in public by members of all sectors of society. Grounded in the work of Jürgen Habermas, deliberative democracy emphasizes the importance of communication within the public sphere, the zone between the privacy of families and the official scrutiny of the state. ${ }^{63}$ Because deliberation exists within this realm, it relies directly on the organizations of civil society and the motivation of individuals to engage within them. Political theorists such as Amy Gutmann, Dennis Thompson, and Seyla Benhabib argue that the prevalence of value conflict is a major challenge for productive deliberation. ${ }^{64}$ In this sen 'se, sacred values and sacred rhetoric may have significant ramifications for the prospects of a more deliberative democracy. As distinct from the deliberative approach, advocates of participatory democracy emphasize direct political action within a system based on widespread participation among all sectors of society. ${ }^{65}$ Participation includes all facets of political action, as well as the extension of democracy into collective institutions such as the workplace. The essence of democracy in this view is total citizen participation, in the Rousseau tradition. While both deliberative and participatory democrats emphasize increased citizen involvement, the form of engagement is different. An important distinction between the participatory and deliberative traditions is that participatory democrats expect citizens to have recognized interests and fully formed opinions, while deliberative democrats emphasize the importance of the willingness to engage in discussion, rethink views, and find a consensus rather than a victor.

Other perspectives also add to the discussion of democratic health, including the literatures on elite democracy, citizen competence, and the culture wars. An older research tradition asserts the value of elitist or minimalist democracy, which advocates limited citizen

\footnotetext{
63 See Habermas 1984 Theory of Communicative Action, developed in more detail in his 1996 Between Facts and Norms. Other major works in this tradition include John Dryzek's 1990 Discursive Democracy and Robert Fishkin's 1991 Democracy and Deliberation.

64 See Gutmann and Thompson 1996, who argue that fundamental value conflict can be overcome through deliberation, and Benhabib 2002, who is not as sanguine on this point.

65 The seminal work in this tradition is Carole Pateman's 1970 Participation and Democratic Theory, followed in 1984 by Benjamin Barber's Strong Democracy.
} 
involvement. ${ }^{66}$ In this view, citizen apathy is a good sign, even a necessary feature of a smoothly running democracy. The current low rates of voter turnout can be taken as a sign that citizens have little to complain about and that the system is working well; high rates of involvement would be a sign that the polity was not doing well. The citizen competence approach examines the ability of democratic citizens to meet the demands of democratic citizenship (as defined by normative views of democracy). Competence includes such abilities as voting accurately or following political debates and applying core values to make reasoned decisions. Opposing camps argue that citizens make good decisions in the aggregate by employing heuristics, or that the lack of political knowledge and interest among citizens causes a poor relation between voters' values and public policies, allowing for the domination of politics by elites. ${ }^{67}$ The citizen competence approach highlights the ability or inability of citizens to comprehend political choices, but also emphasizes the degree of citizen motivation and belief. Some of the most promising recent developments in the field examine political values within the mass public and their connection to political behavior and motivation. ${ }^{68} \mathrm{~A}$ final approach is the culture wars, which is perhaps the most prominent description of the manifestation of value conflict at the aggregate level. James Hunter and others argue that American society has become increasingly divided along basic value dimensions, leaving us with a more conflictual and less deliberative society. ${ }^{69}$ Moreover, when participation is stridently conflictual and civic organizations form opposing camps, this may decrease rather than increase social cohesion.

\footnotetext{
${ }^{66}$ The most well known exponents of this tradition are Madison in the Federalist Papers (see especially Federalist 63), and Joseph Schumpeter in Capitalism, Socialism, and Democracy.

${ }^{67}$ This tradition began with Phil Converse's 1964 "Nature of belief systems in mass publics," and continued with any number of contributions, of which some of the more importance recent works are John Zaller's 1992 The Nature and Origins of Mass Opinion, and Sniderman, Brody, and Tetlock's 1991 Reasoning and Choice. For a summary of these arguments see Marietta (manuscript) "Citizen competence and democratic theory: Toward an integration of normative and empirical argument."

${ }^{68}$ Feldman 1988, Feldman and Steenbergen 2001, Jacoby 2001, 2006, Alvarez and Brehm 2003. Donald Kinder attributes this trend to "the widespread and apparently growing enthusiasm for principles as a way to understand American public opinion" (Kinder 1998, 811).

${ }^{69}$ See Hunter's 1991 Culture Wars, as well as his 1994 Before the Shooting Begins: Searching for Democracy in America's Culture War. Another excellent work on the state of value conflict within American society is John Kenneth White's The Values Divide 2003. See also Green et al 1996, Williams 1997, and Layman 1999.
} 
Table 3.1: $\quad$ Facets of the Democratic Health Debate

Research

$\underline{\text { Tradition }}$

Social

Capital

Civic

Engagement
Essential Argument

Declining social capital is detrimental to democracy

Associational activity strengthens democracy
Central Variable

Social trust and civic engagement
Form of Underlying Citizen Motivation

\begin{tabular}{clcc}
\hline $\begin{array}{c}\text { Civic } \\
\text { Engagement }\end{array}$ & $\begin{array}{l}\text { Associational activity } \\
\text { strengthens democracy }\end{array}$ & Civic engagement & $\begin{array}{c}\text { Civic motivation \& } \\
\text { political intensity }\end{array}$ \\
\hline $\begin{array}{c}\text { Deliberative } \\
\text { Democracy }\end{array}$ & $\begin{array}{l}\text { Democracy requires } \\
\text { deliberation in public }\end{array}$ & Public discussion & Political intensity \\
\hline $\begin{array}{c}\text { Participatory } \\
\text { Democracy }\end{array}$ & $\begin{array}{l}\text { Democracy requires } \\
\text { maximal participation }\end{array}$ & Political involvement & Political intensity \\
\hline $\begin{array}{c}\text { Elite } \\
\text { Democracy }\end{array}$ & $\begin{array}{l}\text { Limited citizen } \\
\text { involvement facilitates } \\
\text { efficient governance and } \\
\text { the protection of rights }\end{array}$ & Political involvement & Political intensity \\
\hline $\begin{array}{c}\text { Citizen } \\
\text { Competence }\end{array}$ & $\begin{array}{l}\text { Citizens may or may not } \\
\text { be able to meet the } \\
\text { demands of democratic } \\
\text { citizenship }\end{array}$ & $\begin{array}{c}\text { Political beliefs and } \\
\text { awareness }\end{array}$ & Political intensity \\
\hline Culture Wars & $\begin{array}{l}\text { Rising value conflict } \\
\text { and social division are } \\
\text { detrimental }\end{array}$ & $\begin{array}{c}\text { Political beliefs and } \\
\text { value systems }\end{array}$ & Political intensity \\
\hline
\end{tabular}

Each of these approaches is part of the larger conversation about the health of American democracy. Communitarian thinkers on both the left and the right are drawn to this essential question. Putnam famously argues that social capital in America has declined, with a host of negative consequences. A larger unanswered question is whether social capital and civic engagement are a uniformly positive good, as Putnam and others argue, or whether limited civic engagement is a good thing for democratic societies. In other terms, what degree of citizen engagement is optimal, and when does a society move from a state that is below optimal, to one 
that is optimal, and to something that is potentially above optimal? While the participatory democrats argue that greater direct political participation is the key to a healthy democracy, the deliberative democrats believe that the key is productive discourse in the public sphere outside of direct government organization. Again the optimal degree and kind of public activity is unclear. But the underlying variable at the heart of each of these debates is the degree of political intensity or political conviction within individual citizens. Understanding the origins of the motivation to engage, to participate, or to deliberate - in short, to care - is crucial to all of these research programs and to the broad discussion of civil society.

\title{
3.2 INTENSITY AND DEMOCRACY: A PARADOX OF DEMOCRATIC HEALTH
}

\begin{abstract}
"As one can readily see, intensity is almost a modern psychological version of natural rights... Unfortunately, intensity is not easy to define"
\end{abstract}

Robert Dahl (1956) A Preface to Democratic Theory, p. 90-91

In Dahl's terms, intensity is what determines the all important question of which majority will rule. ${ }^{70}$ Or as Bert Rockman phrases it, intensity is the currency of American politics. But despite its importance, intensity seems to have only a vague definition within contemporary political science. So what is this thing that theorists such as Dahl consider to be of such democratic importance but difficulty in discerning? One way of understanding intensity is the degree to which individual citizens are concerned about politics. It can be thought of as an individual's level of political commitment — not just their interest in following politics, but the depth or strength of their political feeling. Intensity in this sense is really an internal state, more a description of a feeling than a behavior. This highlights the important distinction between motivation and action, which we can separate into political intensity and political engagement the distinction between thought and action, caring and doing. Intensity we can then define as an individual's level of political passion, resolve, purpose, or zeal. The object of that passion could

\footnotetext{
${ }^{70}$ My use of the term political intensity is drawn from Dahl's classic Preface to Democratic Theory, in which he argues that in a polyarchal democracy, the distribution of political intensity is the key variable that determines both the specific majority that rules and the stability of the democratic system.
} 
be any number of political targets, such as a symbol, policy proposal, value, ideology, or group. How citizens act because of these motivations can then be thought of as their degree of political engagement. Motivation and action are of course highly interconnected, which is the entire point, but the larger question is the nature and origins of the motivation.

Because the variation in political intensity is the root concern of the different perspectives on democratic health, it provides a unified way of defining and comparing them. In this sense, each prescription for democratic health can be defined as a different proportion of citizens at the different levels of political intensity. This distribution can be plotted as a curve, with the level of intensity along one axis and the proportion of the population at each level of intensity along the other, as illustrated in Figure 3.1. The figure conceptualizes political intensity as varying from low to high (for ease of illustration intensity comprises four broad categories — apathy, political awareness, political conviction, and political extremism). Line $a$ represents a population that is evenly divided among the four levels of intensity (25\% fall into each group). This is of course just a baseline, to which we can compare the other possible combinations. Curves $b$ and $c$ represent different forms of dystopia. In curve $b$, almost the entire population is apathetic - a dysfunctional democracy in the view of most perspectives. Curve $c$ represents the opposite - a society comprised of extremists, leading to untenable levels of conflict and violence. 


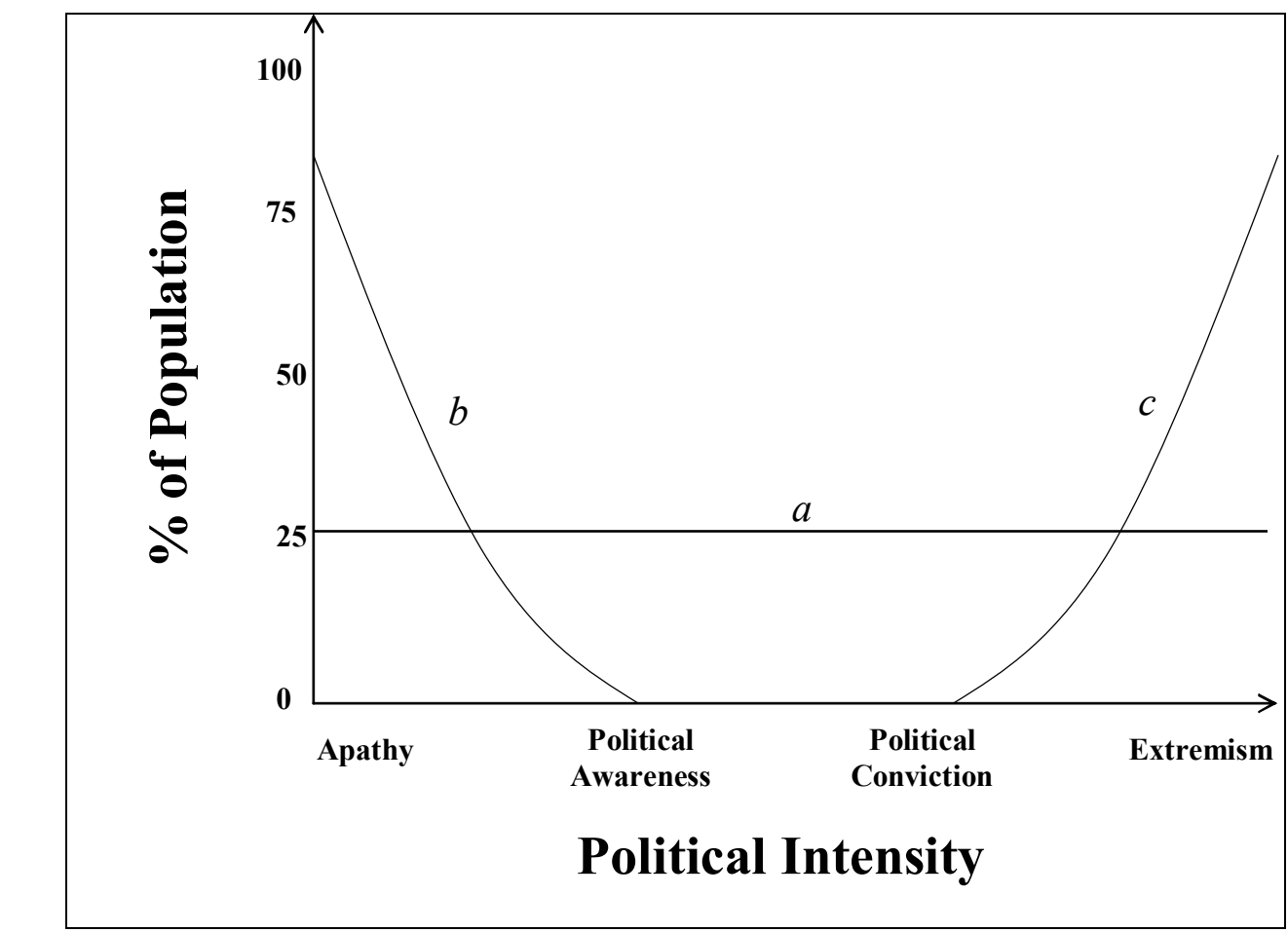

$a=$ baseline $\quad b=$ apathetic dystopia

$c=$ extremist dystopia

Figure 3.1: Democratic Health as a Function of Aggregate Intensity Levels

Conceptualized in this way, the competing prescriptions for democratic health can be diagrammed and compared. Figure 3.2 represents the normative visions of the deliberative democracy and participatory democracy perspectives, as well as the empirical descriptions of contemporary American politics according to the elitist and culture wars perspectives. Both deliberative and participatory democrats argue that the optimal society is one in which almost all citizens are in the middle range of political intensity - none are apathetic and none are so extreme as to curtail deliberation or lead to violence. I think, however, that the two optimal curves are not identical. Participatory democracy suggests a somewhat higher level of intensity, where all members of society are motivated to participate at several different levels of governance, guided by political beliefs and ideologies. The deliberative perspective seems to suggest a slightly lower level of conviction that encourages discussion, compromise, and seeking answers rather than already being sure of them. Hence curve $d$ representing deliberative democracy is centered on a slightly lower level of political intensity, while curve $e$ denoting participatory democracy is centered on a somewhat higher level. But both perspectives are 
clearly represented by steep bell curves grouped in the middle range of intensity. This is in marked contrast to the culture wars perspective (curve $f$ ), which argues that contemporary politics is characterized by high levels of both apathy and extremism, with fewer citizens in the middle (exactly the opposite of what is prescribed by the deliberative and participatory perspectives). In curve $g$, representing the elitist perspective, a great number of citizens are apathetic, with the number of citizens sharply declining as we move to higher levels of intensity. ${ }^{71}$ Defining the different perspectives on democratic health in this way highlights two conclusions - first, the various perspectives take contradictory positions on what constitutes a healthy democracy, and second, political intensity is the root construct in understanding the competing arguments.

\footnotetext{
${ }^{71}$ The elitist democracy curve represents a society in which $75 \%$ are apathetic, $15 \%$ fall into the political awareness category, $5 \%$ in political conviction, and $5 \%$ in extremism. The culture wars curve is $35 \%, 15 \%, 15 \%$, and $35 \%$ respectively. The specific numbers are not meaningful, but are simply reasonable representations of the arguments.
} 


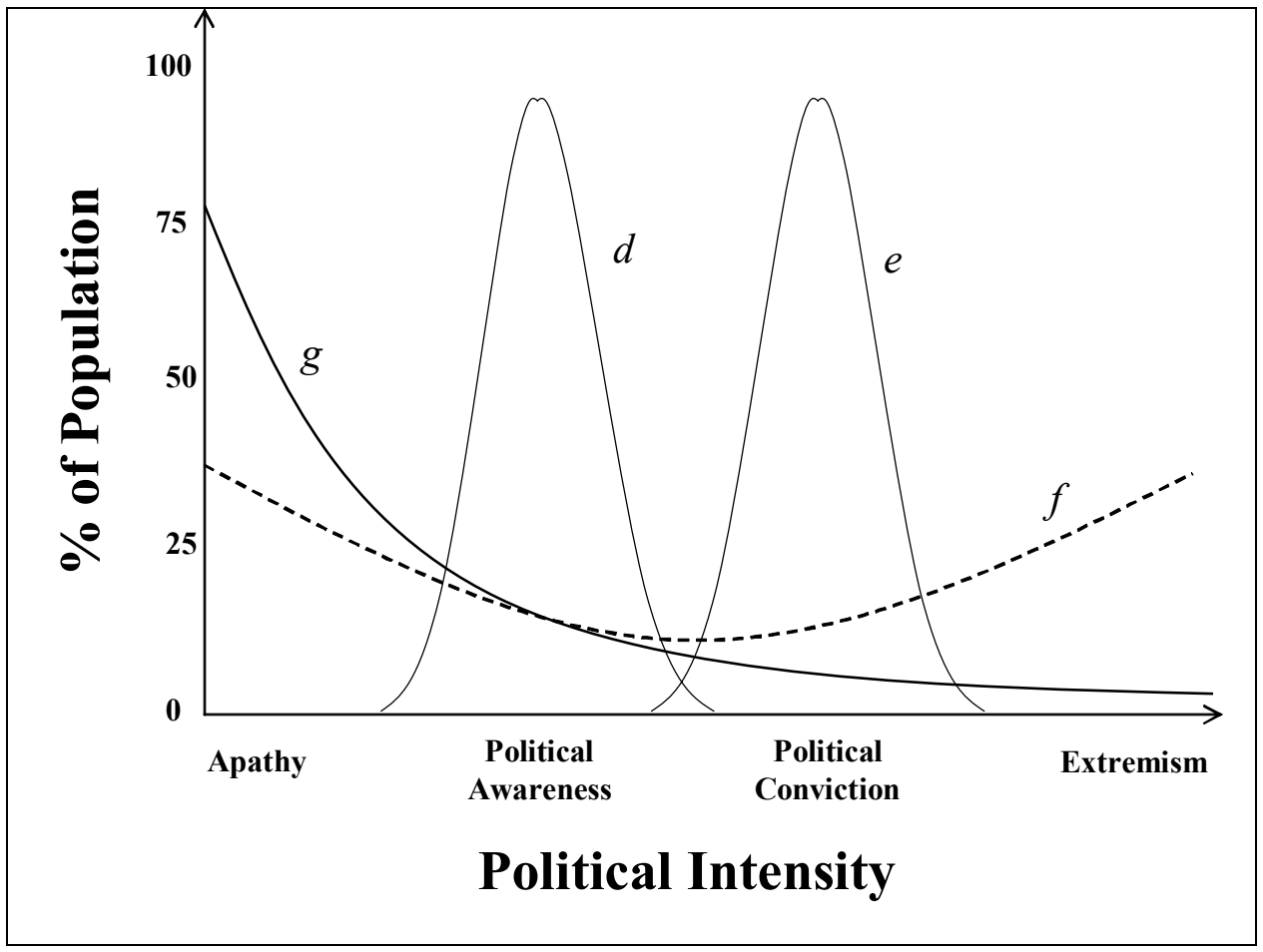

$d=$ deliberative democracy $\quad e$ =participatory democracy $f=$ culture wars $\quad g$ =elitist democracy

Figure 3.2: Normative Descriptions of Democratic Health

Conspicuously absent from the diagram is a curve representing the social capital perspective. This is because the social capital approach, and to a lesser degree the civic engagement view, emphasize social rather than political motivation. But the motivation to engagement in civic organizations is likely not the same thing as the intensity that motivates direct political action, though one of the difficulties in understanding the democratic health literature is that it often conflates and confuses two. The social capital approach argues that social engagement of a seemingly non-political nature has important political ramifications regardless of its intent. Like Adam Smith, Putnam argues that the pursuit of one's personal 
desires has an unintended positive effect in the aggregate. ${ }^{72}$ Theda Skocpol, on the other hand, argues that more often the importance of civic engagement is that it is self-consciously political. This is especially the case among women's groups, which for Putnam are more concerned with building social networks but for Skocpol are more concerned about building political influence (Skocpol 1999, pp 15-16). The existing literature does not make clear distinctions among forms of citizen motivation, especially in terms of which are solely beneficial and which may have negative as well as salutary effects. So far I have argued that citizen motivation (appearing in various forms) is the unifying variable of the different branches of the democratic health debates. An extension of this argument is that of the different facets of citizen motivation, political conviction is the most important. I argue that citizen motivation is conceptualized most effectively as the degree of political intensity, what could also be termed political conviction. This is the case because 1) political intensity is of greater theoretical importance, being the central variable for a larger section of the democratic health literature, and 2) engagement without belief, as opposed to engagement with belief, is both normatively and empirically faulty.

Distinctly political motivation is the central concern of the participatory democracy, deliberative democracy, elitist democracy, citizen competence, and culture wars approaches. The civic engagement tradition emphasizes both civic and political motivation. Only the social capital approach emphasizes civic motivation alone. Putnam makes a Smithian argument that it is not consciously political action that counts, but instead social action, guided by other personal motives, that has the important political effect in the aggregate. Social capital is in essence engagement without belief. The virtues of social capital are unity and comity — putting aside differences rather than emphasizing them. One way of defining high social capital is the lack of contention, in other words the lack of conflictual sacred values and the prevalence of consensus values. The prevalence of strong political beliefs is in this sense the opposite of social capital. This is supported by the different trends in post-World War II America emphasized by the social capital and the culture wars literatures. According to these two separate arguments, social capital

\footnotetext{
${ }^{72}$ While generally attributed to Smith in the Wealth of Nations (1776), the argument that private acts, even selfish ones, lead to the public good emerged earlier in Bernard deMandeville's Fable of the Bees (1714), which Smith cites dismissively but from which he cribs the argument nonetheless.
} 
has declined at the same time that political discord and division have increased. Moreover, civic engagement without reference to political belief is exactly what much of the citizen competence literature argues against! The lack of political ideology and attention among the American public is held to be the source of a stunted democracy and the means by which elite actors control policy regardless of the interests of the mass public (see especially Zaller 1992). In this sense, civic engagement without political engagement is no recipe for democratic health. In an empirical sense, engagement without belief may be a chimerical concept. Do social interactions increase within civil society without a concomitant increase in political intensity? In Skocpol's sense, it is often political interest that encourages even seemingly non-political organizations. Political values of one form or another are often the motivator for social organization. We do not always see elevated levels of civil society without elevated levels of political intensity; the second often accompanies the first because in part it motivates the first. The social capital approach clearly ignores the role of political intensity, and especially ignores the role of strongly held and sacred beliefs, which may be both prevalent and influential. For these reasons I argue that we can learn more about democratic health by concentrating on political rather than civic motivation.

Examining each of these perspectives on contemporary democracy gives us a way of understanding the concept of democratic health itself. Earlier in the chapter I defined democratic health as the degree to which our political system lives up to the norms of representation to which it aspires. Having illuminated the intersection of several different perspectives on democratic representation, we can now identify a more specific definition of democratic health: the health of democracy is the proximity of the empirical distribution of political intensity to the optimal distribution of political intensity endorsed by a specific normative perspective. Hence democratic health does not have one exact definition, as there is not one undisputed normative standard. But there is one uniform variable - political intensity - to which we can compare the various standards discussed above. This raises the possibility that the same empirical reality would have different normative implications, depending on which standard we apply. And indeed this is the case — what is healthy in one perspective is unhealthy in another, a predicament that bears further investigation. 
The relation between intensity and democracy can be summarized as a paradox of democratic health - political intensity leads to participation, but too much intensity can lead to disruption and violence; some participation leads to health, but too much participation by some may lead to apathy in others. This paradox in the positive and negative effects of political intensity is reflected in the contradictions in the democratic health literatures. I have already mentioned the tension between the social capital and citizen competence approaches - the first encourages citizen engagement in the absence of political belief, which is exactly what the second argues against. The participatory democracy tradition asserts that all forms of engagement are positive, but this contradicts the deliberative democracy, elitist democracy, and culture wars perspectives. Deliberation requires a commitment to only limited forms of conviction, allowing room for compromise and most importantly for respect toward opposing positions. In the deliberative democracy tradition, strong convictions are inimical to open discussion and the formation of consensus. Hibbing and Theiss-Morse even argue that it is specifically the exposure to conflict and discord that turns many Americans toward apathy and alienates them from our political institutions (Hibbing and Theiss-Morse 1995). ${ }^{73}$ While political convictions encourage participation for those who hold them, it remains unclear whether they discourage involvement by more moderate members of society. The elitist democracy and culture wars arguments remind us that strong conviction may have negative as well as positive results. Table 3.2 summarizes the influence of rising political conviction in the perspective of each of the seven research traditions. What is apparent from the table is that the normative influence of political conviction is not clear. From several perspectives rising citizen conviction cannot be a unitary good; instead there must be a point at which political intensity shifts from a positive to a negative influence.

73 This could be described as Gresham's Law applied to politics — bad participation drives out good. 
Table 3.2: Democracy and Intensity from Different Perspectives

$\underline{\text { Research Tradition }}$

Social Capital

Civic Engagement

Deliberative Democracy

The Culture Wars

\section{Positive or Negative Influence of Increasing Intensity}

Positive with some exceptions (leads to greater citizen engagement and social trust; except for intolerant, exclusive, or authoritarian organizations)

Positive with some exceptions (leads to greater citizen engagement; except for intolerant or authoritarian forms of participation)

Positive up to a point, then Negative (leads to greater citizen deliberation, but uncompromising and intolerant engagement is negative)
Participatory Democracy

Participatory Democracy

Elite Democracy
Positive (leads to greater participation, which is a unitary good)

Negative (increasing the quantity of participation lessens its quality, leads to demagoguery, and lessens the influence of more knowledgeable and tolerant elites)

\section{Citizen Competence Positive (increasing belief leads to citizen control)}

Negative (increasing conviction leads to division and conflict) 
This brings us to the normative relation between political intensity and democratic health. Is increasing political intensity always good for democracy? Or is it only positive up to a certain point before it becomes negative? If it does become negative, where is that point? And what is the origin of greater-than-optimal intensity? Figure 3.3 illustrates the different possible relationships and the crucial questions. Curve $a$ illustrates the assumption of much of the democratic health literature - a continuous positive relationship. Curves $b$ and $c$, on the other hand, illustrate a more complex relationship, with a theoretical turning point where intensity becomes a negative influence. The differences between curves $b$ and $c$ illustrate the two critical theoretical questions. Where is the turning point? And how far down does the curve descend in other words, how much of a negative influence is greater-than-optimal political intensity? The location of the turning point (represented by the asterisk in the diagram), is crucial to our understanding of the relation between intensity and democratic health. How high does political intensity have to be before it becomes a negative influence? What forms of intensity are too high?

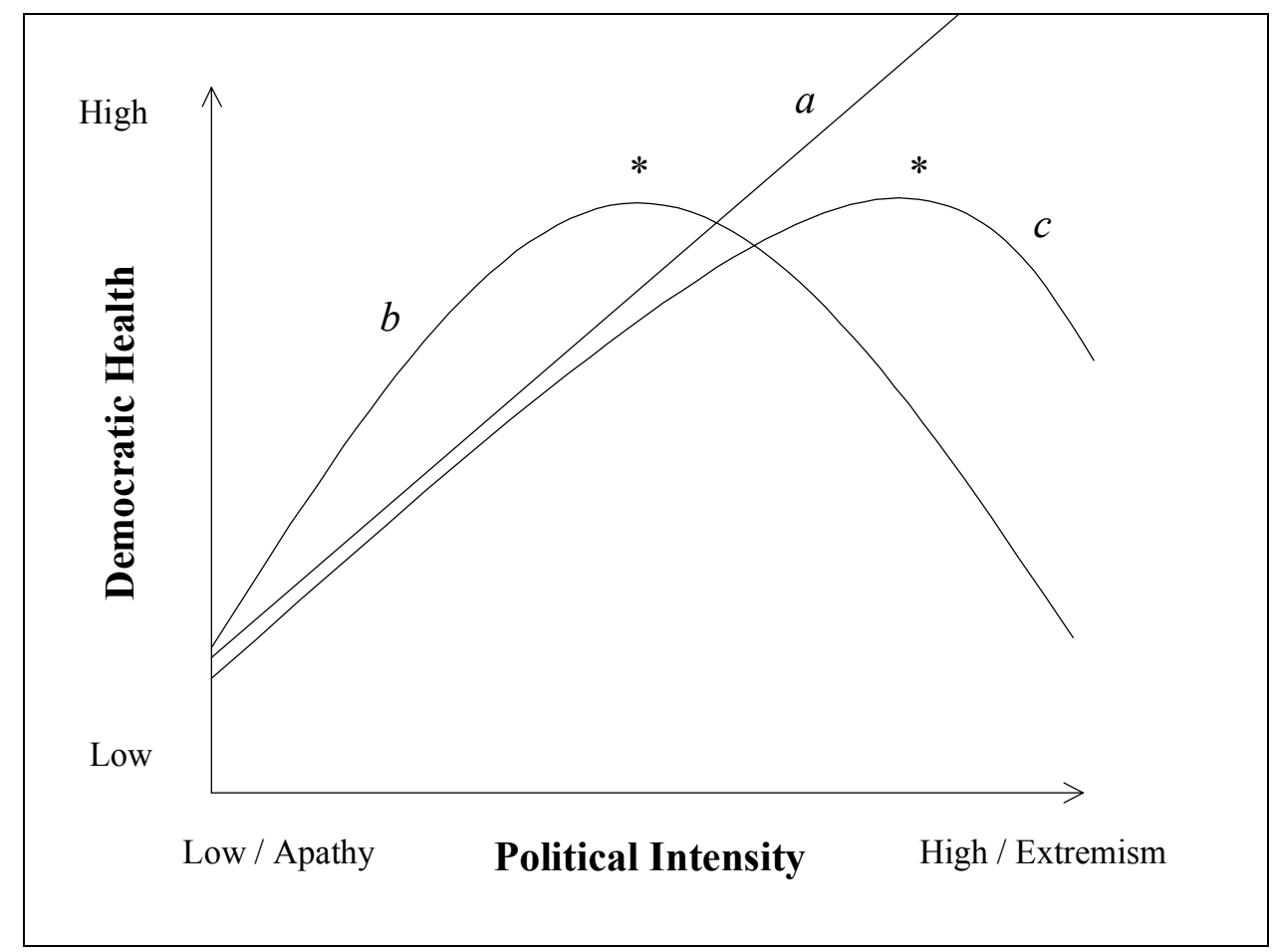

Figure 3.3: Intensity and Democratic Health 
So far I have argued that democratic health is dependent on the degree of political intensity; while intensity levels rising above apathy are beneficial, levels that get too high can be detrimental. But why do some citizens have greater political intensity than others? And when is political intensity too high? Answers to both questions may be related to the prevalence of sacredness within an entire polity or its internal organizations or groups. Hence by studying the employment of sacred rhetoric we may be able to learn a great deal about these facets of democratic health. The broad causal argument inherent in the democratic health literature is illustrated in Figure 3.4. Democratic health itself is the normative/theoretical variable under consideration, which each of the research traditions argues is dependent in one form or another on the variance in citizen engagement. However, it is the motivation to engage that is the more important and less developed construct. Hence the real underlying variable in the discussions of democratic health is not the variance in behavior, but the variance in motivation. Understanding the nature and origins of that variable is more theoretically important, as well as more challenging. This variance in citizen motivation I have identified as political intensity. Nonnegotiable beliefs and the boundaries of what citizens can tolerate or witness without negative emotional reactions are clearly strong motivators to political action. But the origins of this variable are even more of a mystery. While much of the literature in the democratic health debates deals with behavior (the range of civic and political engagement), our concern with sacredness concentrates on the language and means of persuasion that motivate such behavior. 


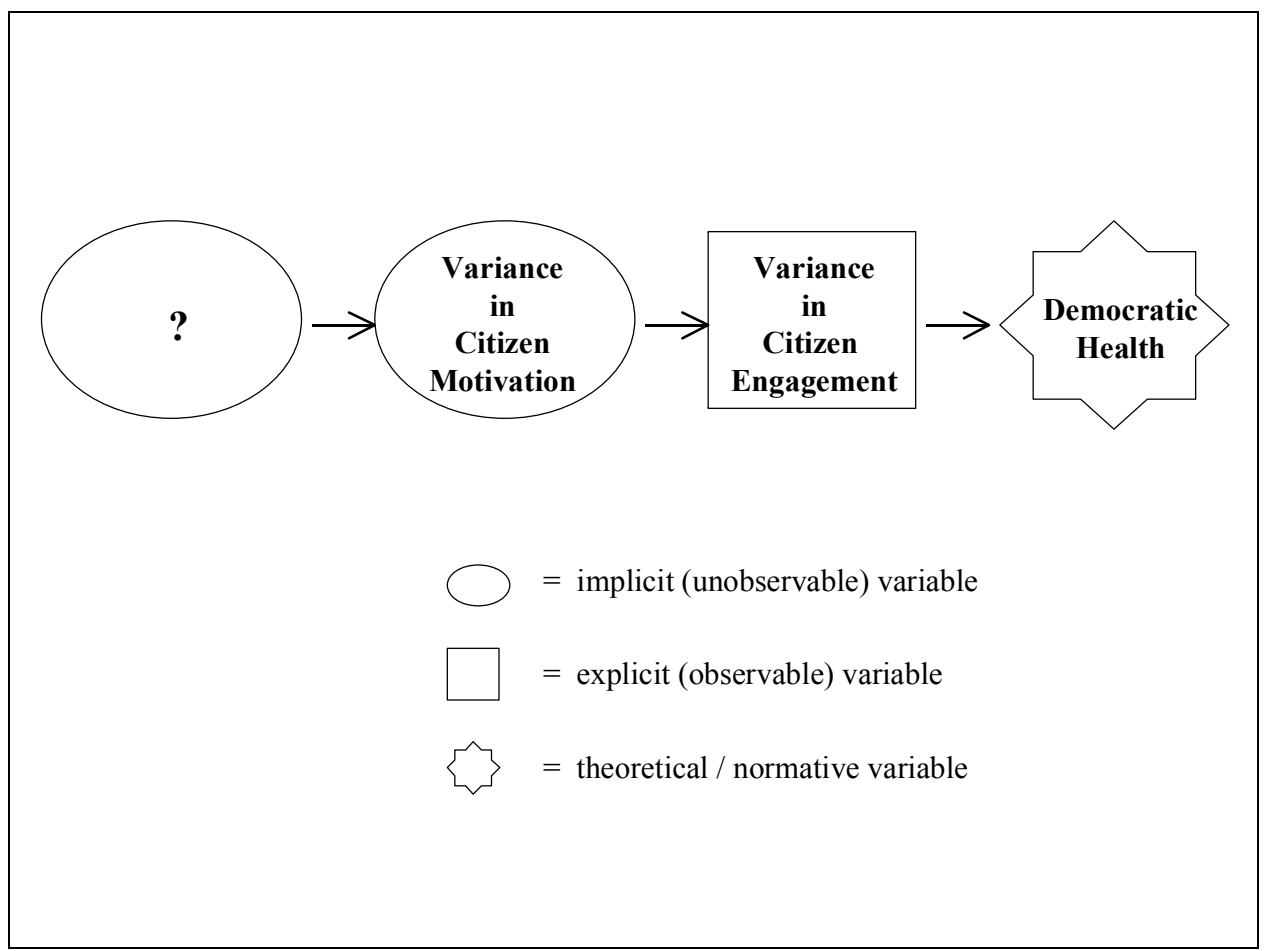

Figure 3.4: Origins of Democratic Health

A potential answer to the question of the limits of beneficial political intensity also highlights the importance of sacredness. As convictions become increasingly non-negotiable, the point at which they approach sacredness may be the point at which they become detrimental to democracy. The influence of sacred values on democratic health depends of course on which perspective on democratic health one is employing. It also depends on whether we are considering consensus or conflictual values; it is only conflictual values that could be seen as detrimental, as consensus ones lead to greater cohesion. One possible generalization is that consensus sacred values have a positive impact on democratic health, while the influence of conflictual sacred values is negative. Table 3.3 details the likely effects of both forms of sacredness in the perspective of the different research traditions. Consensus sacred values play a positive role from any of the perspectives, as they encourage mutual understanding, comity, and 
collective action. ${ }^{74}$ Conflictual sacred values, on the other hand, have potentially negative effects in the majority of cases. Only from the participatory democracy and citizen competence perspectives are conflictual sacred values a potentially positive influence. The social capital, civic engagement, deliberative democracy, elite democracy, and culture wars perspectives all suggest that the point at which convictions become sacred they become a negative influence.

Table 3.3: $\quad$ The Role of Sacredness in Democratic Health

\begin{tabular}{|c|c|c|}
\hline$\underline{\text { Tradition }}$ & Consensus Sacredness & $\underline{\text { Conflictual Sacredness }}$ \\
\hline Social Capital & Positive & $\begin{array}{c}\text { Negative } \\
\text { (lowers social cohesion) }\end{array}$ \\
\hline Civic Engagement & Positive & $\begin{array}{c}\text { Negative } \\
\text { (increases participation, but of } \\
\text { the wrong type) }\end{array}$ \\
\hline Deliberative Democracy & Positive & $\begin{array}{c}\text { Negative } \\
\text { (hinders deliberation) }\end{array}$ \\
\hline Participatory Democracy & Positive & $\begin{array}{c}\text { Positive } \\
\text { (increases participation) }\end{array}$ \\
\hline Elite Democracy & Positive & $\begin{array}{c}\text { Negative } \\
\text { (increases participation) }\end{array}$ \\
\hline Citizen Competence & Positive & $\begin{array}{c}\text { Positive } \\
\text { (increases belief) }\end{array}$ \\
\hline Culture Wars & Positive & $\begin{array}{c}\text { Negative } \\
\text { (leads to conflict) }\end{array}$ \\
\hline
\end{tabular}

74 "[W]ithout common ideas there is not common action, and without common action men still exist, but a social body does not" (Tocqueville, Volume II, Part One, Chapter 2, 407). 


\subsection{SACRED RHETORIC AND DEMOCRATIC HEALTH: THE CONSEQUENCES OF SACREDNESS}

All of the foregoing argues that expressions of sacredness and the operation of civil society are interconnected in both contradictory and complementary ways, suggesting that the nature and consequences of sacredness are deserving of further study. Sacred rhetoric is connected to the health of democracy in several fundamental ways: 1) sacred rhetoric encourages political intensity and engagement, influencing the degree of civic engagement; 2) sacred rhetoric encourages absolutist reasoning, influencing the nature of civic engagement, especially in regard to the nature of deliberation; and 3) the use of sacred rhetoric may advantage one political party over the other in electoral contests.

These effects are both empirically testable and normatively important. Through its influence on the degree and nature of civic engagement, sacred rhetoric may have simultaneously positive and negative effects, a complex legacy. The normative ramifications depend on whether sacredness is encouraging citizens to rise from a state of apathy or descend into a state of unreason; it is a complex, even paradoxical observation that intensity is simultaneously necessary and detrimental for democratic health. The third effect is a clearly partisan one, and our normative assessment of its meaning is a matter of ideological preference. But more importantly it is a question of how the competing parties communicate, influence, and succeed. Our point here is that any interest in their success should raise immediate concern about the mechanisms of their communication and influence. Table 3.4 illustrates the central ways that the political consequences of sacred rhetoric can be conceptualized, emphasizing their influence on both positive and negative political participation. This perspective leads both to testable propositions about the role of sacred rhetoric in civil society and important normative questions about the nature of American democracy. All of this suggests the importance of a research agenda on sacredness, intensity, and democratic health. What is the nature and influence of sacred rhetoric, and its relation to our visions of democracy? 
Table 3.4: Democratic Consequences of Sacredness

Democratic Effects of Sacred Rhetoric

$\underline{\text { Effect }}$

Positive Participation

Negative Participation
Sacred rhetoric activates citizens, encouraging political intensity \& engagement

Sacred rhetoric changes public discourse, increasing absolutist reasoning

\section{Partisan Effects of Sacred Rhetoric}

Advantages Republican Party

Republicans employ more sacred rhetoric, increasing political engagement by Republican voters 


\subsection{THE PSYCHOLOGY OF THE SACRED APPEAL}

Why would sacred rhetoric have effects that non-sacred rhetoric does not? The central contention is that the form as well as content of an appeal can affect how we react to its message. An example of the influence of rhetorical form is the reaction of American citizens to flag burning. John Markoff has suggested that the negative reaction to demonstrators who burn flags is due to the unnecessarily offensive nature of the act. If protestors had engaged in flag washing, symbolically cleansing the flag (and hence the nation) of its improper acts, they could have made a similar point without giving the same offense. But why was flag burning offensive in the first place? Because it is a profanity to many citizens, which did not allow them to see any effective political message beyond the desecration of a sacred symbol. The importance of this example is that the sacred element changed the impact of the message. Certain forms of rhetoric can either limit or increase the acceptability of an argument or act. An example of facilitating rhetoric is the use of the term 'harvest' in organ donation. "It's time to cut out the deceased's heart" puts a brake on the whole procedure, but "It's time to harvest the deceased's heart" invokes an entirely different reaction that allows it to proceed. ${ }^{75}$ Each of these examples makes the same point, that language and symbolism count. This is one facet of what we mean by persuasion, though we now recognize that interpersonal influence has several distinct aspects, some of which are more significant for the sacred appeal.

\footnotetext{
${ }^{75}$ This illustration was employed in remarks by Sir Zelman Cowen, former Governor General of Australia and Provost of Oriole College Oxford. He argued that harvesting is a metaphor from farming rather than butchering, thereby invoking growth rather than destruction.
} 


\subsection{CONTAGION}

"The sacred world is as though inclined by its very nature to spread into the same profane world that it otherwise excludes. While repelling the profane world, the sacred world tends at the same time to flow into the profane world whenever the latter world comes near it."

Emile Durkheim (1912) The Elementary Forms of Religious Life, p. 322

In The End of the Affair, we hear the complaint 'I've caught belief like a disease. I've fallen into belief like I fell into love." 76 Graham Greene is not alone in arguing that beliefs can be caught. Durkheim describes sacredness as a contagion, which imposes itself onto objects, ideas, and minds whenever the sacred comes into contact with the mundane. This process may require neither explicit effort nor an object of any specific character. If sacredness has settled in one locale, "it naturally spreads from the object to all the others it finds nearby - that is, to all that some cause has brought close to the first in the mind" (Durkheim 328). That cause may of course be sacred rhetoric. But the spread of the sacred may not require much effort or explicit argumentation because of "the extraordinary contagiousness that sacredness has. Far from remaining attached to the things that are marked with it, sacredness possesses a certain transience. Even the most superficial or indirect contact is enough for it to spread from one object to another" (322). Mere juxtaposition will do.

In this view, sacred beliefs "are like an oil slick; they spread to all the other mental states that occupy the mind" (328). As we discussed in chapter one, sacredness may grow in almost any field. ${ }^{77}$ By juxtaposing sacred elements with a given political cause or position, sacred rhetoric may lead its hearers to think of the new object in sacred ways. And what they think of it changes how they think about it. This represents a distinct way of conceptualizing political persuasion.

\footnotetext{
${ }^{76}$ Graham Greene, The End of the Affair, p. 182.

77 "We have seen that the sacredness of a being did not depend upon any one of its inherent characteristics... The causes of those feelings are entirely foreign to the nature of the object on which they eventually settle... By themselves, these emotions are not bound to the idea of any definite object" (Durkheim 1912, 328).
} 


\subsection{OUTCOME AND PROCESS: SEVERAL FACETS OF PERSUASION}

If we identify the different forms of persuasion in the political psychology literature, it becomes clear that most concentrate on outcome effects, or the final opinion that citizens hold or express. We can define persuasion broadly as simply any inducement of one individual's choices by another (Barker 2005). Its manifestations include attitude change, framing, priming, preference falsification, and activation. ${ }^{78}$ The most obvious form of persuasion is attitude change, or altering a citizen's opinion of a policy, candidate, or other object. But as Table 4.1 illustrates, several other aspects of political persuasion have more subtle influences.

\footnotetext{
${ }^{78}$ For prominent explications of attitude change, see Eagly and Chaiken 1993, for framing Nelson et al 1997, for priming Iyengar and Kinder 1987, or Krosnick and Kinder 1990, for preference falsification Kuran 1995, and for activation Finkel 1993.
} 


\section{Table 4.1: $\quad$ Forms of Political Persuasion}

$\underline{\text { Effect }} \underline{\text { Definition }} \underline{\text { Source }} \underline{\text { Type }}$

\begin{tabular}{c|c|c|c} 
Attitude Change & altering a policy choice or political opinion & $\begin{array}{c}\text { Eagly \& Chaiken; } \\
\text { Petty \& Cacioppo }\end{array}$ & Outcome \\
\hline Activation & $\begin{array}{c}\text { increasing political engagement in accord } \\
\text { with pre-existing beliefs }\end{array}$ & Finkel & Outcome \\
\hline $\begin{array}{c}\text { Preference } \\
\text { Falsification }\end{array}$ & $\begin{array}{c}\text { inducing changes in public expression } \\
\text { without changing underlying beliefs }\end{array}$ & Kuran & Outcome \\
\hline Framing & $\begin{array}{c}\text { shifting the weight given to different } \\
\text { considerations }\end{array}$ & Nelson & $\begin{array}{c}\text { Outcome \& } \\
\text { Process }\end{array}$ \\
\hline Priming & $\begin{array}{c}\text { introducing a new factor into consideration } \\
\text { Reasoning } \boldsymbol{S h i f t}\end{array}$ & $\begin{array}{c}\text { Krosnick; Kinder } \\
\text { shifting the form of reasoning or } \\
\text { justification employed }\end{array}$ & $\begin{array}{c}\text { Outcome \& } \\
\text { Process }\end{array}$ \\
\hline
\end{tabular}

Most of the time we are concerned about the effect of language on citizens' opinions, or the outcome of their political judgments. But we can make a distinction between effects on outcome, or a citizen's final position, and effects on process, or a citizen's form of reasoning. What do we make of a change in a listener's way of thinking that does not result in a change in attitude, that is, a difference in process but not in outcome? I propose that this can be termed a reasoning effect or a change in cognitive method, shifting the modes or forms of reasoning that citizens employ. But how stable is a citizen's form of reasoning? Are reasoning styles malleable, in the sense that exposure to different rhetorical forms can shift them? Or are cognitive methods more like cognitive habits, in the sense that citizens are likely to have a

\footnotetext{
${ }^{79}$ In this case the outcome is political action rather than belief; there is no outcome effect on opinion or attitude, but there is one on engagement.
} 
default mode of reasoning that they apply to most political domains regardless of recent influences? The degree to which a trait is malleable can be understood in two different empirical senses. The first is whether exposure to a specific treatment, such as a framed message or a particular form of rhetoric, can shift a citizen's thinking. The second is whether that shift is maintained over time or whether the citizen reverts back to their original position, and how quickly.

If we think through the ramifications of these two stages, there are important problems for this form of research and for the argument that messages are influential. The most glaring research problem is that most often we are only testing the first form of malleability — whether the treatment influences citizens in the immediate term. It is much more difficult to determine if the effects are lasting. But there is also a logical problem for this sort of argument. If citizens are not malleable in the immediate term, then the appeals seem to be ineffective. But if citizens are malleable, then the shift created is unlikely to be maintained for long because the citizen will be shifted again by the next message to come along. The catch-22 is that we can demonstrate that citizens are either immovable or that they are inconstant, bending with each new wind. What we really mean to suggest of course is that citizens are somewhere in the middle - they have some of the characteristics of a habit in the sense that they carry past influences with them, but these habits are not so ingrained that they cannot be moved by small increments. If sacred rhetoric or other forms of appeal have political importance, it is not because they affect citizens' decisions only at the time they are heard or immediately thereafter. Their importance relies on a longer term effect resulting from repeated exposures. For sacred appeals to have long-term importance, reasoning processes must be malleable enough to be influenced, but still have some of the character of a habit so that repeated incidences of this influence will accumulate into a long run shift. Repeated exposure to sacred rhetoric may shift a citizen's default process toward more absolutist reasoning. The more often a citizen is exposed to a particular form of reasoning, and the more normal, accepted, and expected it becomes, and the more likely they are to employ it.

A form of persuasion that entails both a process and an outcome effect is framing. Framing can be understood most clearly as the way in which differences in language change the 
relative weight given to competing considerations. ${ }^{80}$ The frequently cited studies conducted by Tom Nelson employ the example of the relative importance of free speech or public safety considerations when deciding whether to support an application by the Klu Klux Klan to hold a rally (Nelson et al 1997). While framing often affects the outcome of an individual's judgment, its direct effect is on how they weigh competing arguments. Several prominent studies have concluded that the wording of political or media messages can produce substantial framing effects (Nelson and Kinder 1996, Nelson et al 1997, Jacoby 2000, Druckman 2001, Barker 2002). The less understood question is the power or robustness of framing effects in the political arena. Studies of framing have shown that its effects are not based on simple accessibility, or the degree to which different arguments are readily available in a citizen's mind, but are instead dependent on the conscious weighing of alternatives (Nelson et al 1997). Hence framing is more or less effective depending on the degree to which the argument matches the audience's predispositions; listeners respond to cues that produce positive reactions, but reject cues that produce negative ones (Brewer 2001, Chong 1996, Druckman 2001a, Nelson et al 1997). In addition to individual differences such as value predispositions, framing is conditioned by contextual factors such as engaging in discussion with others or exposure to the competing frame (Druckman 2004). Because the effects of framing may be limited by these factors, we could summarize by saying that the power of framing is maximized when the recipient is exposed to the framed message repeatedly and without the opposing frame.

While in many cases, citizens will be exposed to both frames in regard to any particular political question, the ideological specialization of media and resulting selective exposure may mean that many citizens are increasingly only hearing one side of framed messages. The more

\footnotetext{
80 "[I] ssue frames affect opinion by selectively enhancing the psychological importance, relevance, or weight accorded to specific beliefs with respect to the issue at hand" (Nelson and Oxley 1999, p. 1043, italics in original). The terminology can be confusing because of the different use of the term 'framing' by political psychology, judgment \& decision making (JDM), and communication scholars. Framing as described here refers to issue framing, or what is sometimes called emphasis framing. This is distinct from equivalence framing, or when wording that is different but logically equivalent leads listeners to different decisions, as in the famous Kahneman and Tversky experiments (see the distinction made by Druckman $2001 \mathrm{~b}$ and 2004). Framing can also be distinguished from priming, which is the effect of inducing the hearer to remember or consider a given factor, whereas framing changes the weight given to one factor rather than another among considerations already in play. Priming can be particularly effective when media sources emphasize a single consideration, such as one aspect of presidential performance (Krosnick and Kinder 1990, see also Iyengar and Kinder 1987).
} 
the media become specialized, the more important framing effects should become. The circumstances of sacredness also lead to an interesting exception to the pattern of exposure to both competing frames. Political domains involving sacred values can be characterized as single-sided or double-sided, depending on whether only one or both sides of the issue have sacralized the underlying values in question. Just as some political domains clearly have a greater sacred component than others, the two opposing sides of a given issue may have different propensities toward sacredness as well. Abortion is likely an area where both camps have sacralized the underlying values. For those on the anti-abortion side, the life of the fetus is clearly a sacred value, not to be abrogated by less important things like the rights or desires of the woman. But for those on the pro-choice side, the reproductive rights of a woman may have taken on a similarly sacred status. For both sides, at least for some or to some degree, their beliefs are non-consequentialist (other considerations do not matter compared to the rights of the fetus; other considerations do not matter compared to the reproductive rights of the woman). The opposite case would be a political domain in which only one side of the argument has been sacralized, or single-sided sacredness. In political domains that are single-sided, citizens only hear one sacred frame. Citizens may hear opposing arguments phrased in negotiable rhetoric, but the particular effects of sacredness apply only to one side of the frame. Hence sacred appeals may be particularly effective in some political domains.

\subsection{THE REASONING EFFECT OF SACRED RHETORIC}

I hypothesize that the most powerful effect of sacred rhetoric is on citizens' cognitive method rather than on their final opinion, increasing their reliance on absolutist reasoning rather than persuading them to agree with the content of the message (Hypothesis 1). Sacred rhetoric may be no more persuasive than negotiable rhetoric on outcome (opinion), while having a substantial effect on process (the form of reasoning employed and the justifications given). Psychologists argue that humans have a strong natural propensity to be "cognitive misers," expending only the minimum amount of mental energy sufficient to the task at hand (Tversky and Kahneman 1974, Simon 1985). In this view citizens rely extensively on shortcuts or rules of thumb known as heuristics, especially in regard to decisions made with chronically low levels of information 
(Sniderman, Brody and Tetlock 1991, Popkin 1991, Rahn 1993, Lupia 1994). Political decisionmaking by most citizens definitely falls into this category given their scant political knowledge (Delli Carpini \& Keeter 1993, 1996, Friedman 1998, DeCanio 2000). In this sense, absolutist reasoning may be more efficient. Citizens do not have to weigh alternatives or consider competing consequences that are hard to verify. It is much less cognitively taxing to default to principles, rules, and norms that provide established judgments. The cognitive misery of citizens suggests that political reasoning would be prone to absolutism, and therefore that citizens should be vulnerable to sacred appeals.

This may be the case regardless of whether citizens agree with the message. One of the most important tests of the reasoning effect is whether the change in process applies to all listeners, even those who continue to disagree with the message. If only those who agree with the appeal are affected, then the role of sacred rhetoric is more limited. But if even listeners who oppose the appeal are still led to employ more absolutist reasoning, then the influence of sacred rhetoric is stronger and more pervasive. A process effect regardless of citizens' expressed opposition we can consider Hypothesis la.

\section{Hypothesis 1a: $\quad$ Sacred rhetoric increases absolutist reasoning even among listeners who disagree with the message.}

But we should consider how this could be moderated by the single or double-sideness of the issue. If the issue is double-sided sacred, then listeners have a ready default of absolutist arguments on either side. If they take up the absolutism of a message, they can apply it easily in the direction of their original inclination. However, if the issue is only single-sided sacred, then listeners who disagree with a sacred appeal do not have a ready example of absolutist arguments on the opposing side. For example, in the case of the environment, absolutist reasoning will not carry us very far on the anti-environment side. This position is grounded in consequentialist arguments about costs, both to taxpayers and to businesses. A sacred position against the 
environment is more difficult for most citizens to formulate. ${ }^{81}$ Because of this distinction, we can expect greater absolutist reasoning by those who disagree with a sacred appeal, but only in regard to double-sided political domains.

\subsection{THE ACTIVATION EFFECT OF SACRED RHETORIC}

Along with the process effect of greater absolutist reasoning, we could also expect an activation effect (Hypothesis 2). Activation would be considered an outcome effect, but the outcome is not a different opinion, but greater political engagement. This is driven by the connection of existing beliefs to their political significance. About sacred objects we not only think differently, but care more. Their violation is less tolerable, and political effort to rectify such a situation is valorized. A successful sacred appeal can therefore be expected to increase the perceived political importance of the issue at hand. Even though the citizen's opinion may remain the same, the issue itself is of greater note.

Activation can be conceptualized in several different ways. Along with the increased importance ascribed to a political issue, activation is reflected in greater political engagement such as the intention to vote, to engage in political discussions, and to participate in campaigns. Activation can also be observed in greater intensity of feeling toward one's own position and a decline in the perceived legitimacy of opposing arguments. If sacred rhetoric influences citizens who agree with its message and those who disagree, then we should see greater extremism on both sides. Even while not increasing attitude change in the intended direction of the message, sacred rhetoric may push opinions away from the center. Opinions should be more extreme, but in both directions. While I argue that the central effect of sacred rhetoric is on process rather than outcome, a related outcome effect that may occur is polarization rather than persuasion. If listeners are not on average moved toward the position espoused by the message any more than

\footnotetext{
${ }^{81}$ One could imagine an anti-environmental position that takes a sacred position in regard to property rights. So it is not that there is no possibility that the environment is double-sided sacred, but in usual political discourse it seems to be more single-sided. This is likely because the property rights arguments are more intellectual and known to academics on the right, but are not commonly employed by citizens.
} 
they are by non-sacred rhetoric, but some move more to one side while some move more to the other, then the net effect is not persuasion but polarization.

If "the contagious quality of sacredness" operates through sacred rhetoric, then we can expect significant persuasion effects, though not the ones we are most accustomed to examining (Durkheim 328). The most powerful influences should be on reasoning and activation, emphasizing process as well as outcome effects. The effect on cognitive method is a purely process effect, which the political psychology literature has previously ignored. This may be because its significance is less obvious. It is an effect on the nature of discourse rather than the direction of opinion. The manner of expression and the tone of political speech have much to do with the functioning of civil society and the health of American democracy. But to fully understand these effects and their political meaning, we need to examine the results of the sacred rhetoric studies. From here we move to the empirical evidence of the influence of sacred rhetoric. 


\subsection{FROM MY COLD, DEAD HANDS: THE REASONING EFFECT}

Not merely the content of political opinion but also its form of expression is meaningful for the health of American democracy. The positions citizens take affect our political decisions, but the justifications they offer affect the nature of public discourse. Reasoning that is absolute or inflexible allows little room for compromise or mutual agreement. This is particularly significant for the prospects of a more deliberative democracy. Deliberative theorists emphasize the importance of reciprocity, or the norm of employing political reasoning that is mutually justifiable. ${ }^{82}$ Reciprocity assumes that all citizens are equally motivated to come to an accord that is acceptable to all parties. A central requirement for this sort of atmosphere is a mutually agreed upon standard on which to base arguments, such as their consequences for public welfare. Hence the reasons for citizens' opinions can be as important as the opinions themselves in terms of their influence on the nature of political conflict and the functioning of civil society.

Sacred rhetoric may be particularly important in this regard because it is intimately connected to a specific form of reasoning. Sacredness does not depend on the political position taken or its ideological direction, as one can take a sacred stand against abortion just as one can take a non-sacred stand. The same applies to the anti-abortion side, or to stands both for or against the death penalty. We can understand sacred rhetoric as a form of reasoning, or a way of thinking through the relation between values and public policy opinions. This form of appeal makes an argument in a manner that sets a political issue apart, reasoning about it in a different way. Sacred rhetoric employs absolutist reasoning, while non-sacred or negotiable appeals employ more consequentialist reasoning. Absolutist reasoning is characterized by applying 
established principles or boundaries to a given situation, and then privileging these principles over the consequences of the decision. It may also entail citing specific authorities for the principle, and perhaps engaging in expressions of anger or moral outrage at perceived violations. Consequentialist reasoning, on the other hand, begins from the expected effects or outcomes of the decision and applies a give and take form of negotiation, with authorities seen as more pluralistic or non-binding, and expressions of moral outrage being more limited.

In this sense, sacredness is a cognitive process as well as an outcome. Because sacred rhetoric is characterized more by the form of argument rather than its ideological direction, it may follow that its greatest influence is on citizens' process of reasoning. And it is on the process of reasoning that sacred rhetoric may have its most discernable effects. Specifically, I argue that sacred rhetoric influences the form of reasoning employed by its hearers, shifting citizens away from consequentialist reasoning and toward absolutist reasoning. In order to test this proposition we must turn to the empirical evidence, which in this case suggests an experimental approach.

\subsection{SUBJECTS: AN EXPERIMENTAL APPROACH}

"If we are to talk about the human mind, let us start with human beings"

Robert Lane (1962) Political Ideology, p. 1

With these words Robert Lane starts his classic on American thought, Political Ideology: Why the Common Man Believes What He Does. Like Lane, our purpose is to understand a facet of political thinking — in this case how citizens respond to sacred rhetoric. Do human minds react to sacredness in the same fashion as they respond to other political appeals, or does sacredness have a distinct form of influence? It should be clear immediately that this is a fundamentally empirical question. In order to pursue it, we cannot assume away the nature of human psychology, either in motivation or mechanics. Most of the empirical evidence from Hume to

\footnotetext{
${ }^{82}$ See especially Guttmann and Thompson 1996, Chapter Two, on the role of reciprocity, and of course Habermas 1984 and 1996.
} 
Kahneman and Tvesrky suggests that humans cannot be described as purely rational creatures. Moreover, the workings of the mind are more a question than a given; human psychology is illuminated by empirical study rather than logical analysis. But an empirical approach nonetheless leaves a broad range of specific methods that could be employed. This highlights the essential role of epistemology in studying human minds.

Much has been made of the distinction between method-driven and problem-driven research, or the difference between beginning with a method and finding applicable questions, or beginning with a political question and applying the most appropriate means of illuminating it (Shapiro 2002). ${ }^{83}$ One way of clarifying the difference is the central role of epistemology, or the comparative origins of knowledge. This view is based on the perception that studying creatures imbued with free will and displaying great differences across time and space, whose interactions are complex, creates strong limitations on what we can claim to know. So the study of the differing origins and limitations of knowledge is quite important. A broad knowledge of both method and epistemology allows us to match the most appropriate methods to specific problems. However, this procedure requires more than a large $\mathrm{N}$ of methods, but also a knowledge of the epistemological foundations of the range of methods and where each specific approach falls in a comparative sense. In this way we can avoid the traps of method driven research and most clearly illuminate possible answers to the normative and empirical questions at hand.

Epistemology, or the study of knowledge claims, examines "the standards we use to know about the world and grounds we use to legitimate these foundations of knowledge"

\footnotetext{
83 "Empirical science is problem driven when the elaboration of theories is designed to explain phenomena that arise in the world. Method-driven research occurs when a theory is elaborated without reference to what phenomena are to be explained, and the theorist subsequently searches for phenomena to which the theory in question can be applied" (Green and Shapiro 1994, 194). Hence being problem-driven implies "starting with a problem in the world, next coming to grips with previous attempts that have been made to study it, and then defining the research task by reverence to the value added," while method-driven research is "detached from the great questions of the day and focused instead on what seems methodologically most tractable" (Shapiro 2002, p. 589-90). The distinction is often summarized in the hammer and nail metaphor, or alternatively, the lamppost problem. The first is the observation that someone with a new hammer looks for nails. The second is the cautionary tale of the drunk looking for his keys under a lamppost. When a good citizen who has stopped to help him asks if he remembers where he dropped them, he replies "I dropped them in the alley, but this is where the light is." The criticism of political science researchers is that we are often drunks with hammers.
} 
(Somers 1996, 53). Epistemology is synonymous with the old use of the term 'methodology,' meaning not a method, or even the study of method, but the study of the foundations of methods. ${ }^{84}$ Only through a grasp of epistemology can we be aware of the strengths and limitations of a specific method based on the type of knowledge it can produce. Perhaps more importantly, it allows us to know when to move to a different method or to compliment one approach with another.

Figure 5.1 is an attempt to clarify the different methods of empirical political psychology in terms of their epistemological foundations. The major insight of the diagram is that two different axes - the trade-offs between extensive versus intensive methods, and causal versus interpretivist methods - describe the major distinctions in what various methods offer in terms of their virtues and limitations in knowledge creation. Experimental approaches emphasize methods that allow for clear identification of causal mechanisms. This is the methodological approach closest to the hard sciences (see Hempel Philosophy of Natural Science). The opposite of causal methods are interpretivist methods, which emphasize deep understanding, phenomenology (the subjective perspective of individuals), and social science as an appreciation of the creation of human meaning. ${ }^{85}$ Another divide is between extensive methods (large numbers with less detail) and intensive methods (lower numbers with more detail). The arrows in the diagram represent tradeoffs; as we move toward one foundation of knowledge we move away from the other. Once we have these tradeoffs and configurations in mind, we can locate each specific approach in its comparative position among the constellation of methods. ${ }^{86}$

\footnotetext{
84 'Most of the literature introduced by the title 'Methods' (in the social, behavioral, and political sciences) actually deals with survey techniques and social statistics, and has little if anything to share with the crucial concern of 'methodology,' which is a concern with the logical structure and procedure of scientific inquiry. ...the profession as a whole is grievously impaired by methodological unawareness" (Sartori 1970,1033). Much of the confusion on this score results from a change in language in recent decades, such that 'methodology' has become synonymous in usage with 'method,' as in "which methodology do you plan to employ?," which is a nonsense usage in the old language. In the contemporary lexicon it is best to use the term epistemology for the study of knowledge claims.

${ }^{85}$ Interpretivist methods are difficult to explain briefly, as they are themselves relatively wordy, which is something of the point. They encompass ethnography and thick description, through mainstream history, including more traditional approaches to political science and more contemporary approaches to historical institutionalism (see Peters 1999).

${ }^{86}$ For a full description of this approach to social science, see Marietta (manuscript) "A note on method: The epistemology of political psychology."
} 


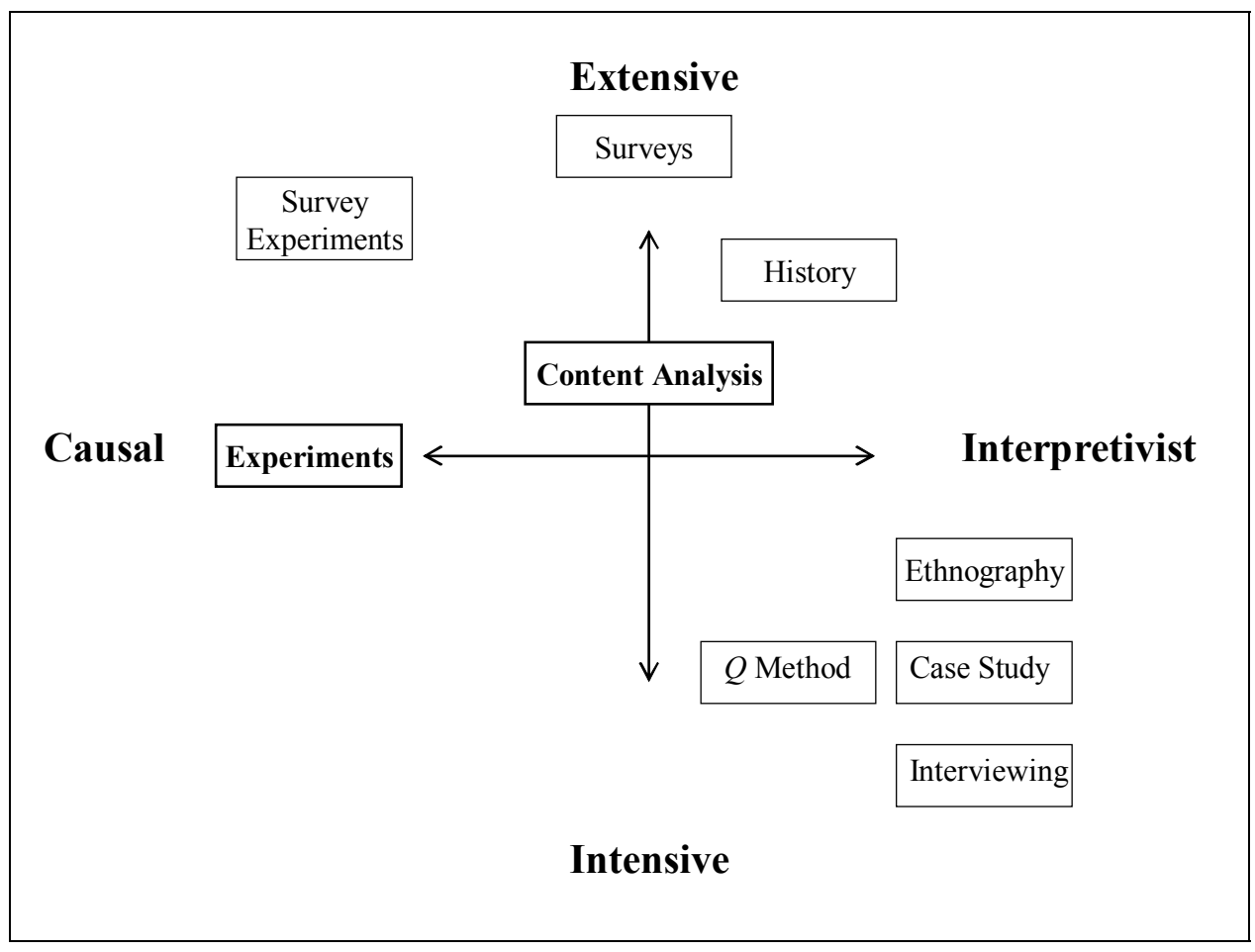

Figure 5.1: The Epistemology of Political Psychology 
Our explicit interest in this study is causation, or what are the effects of hearing sacred rather than negotiable appeals? This leads us toward experimental methods, which are most suited to this task. However, this is only the case when we can manipulate the causal variable. If, for example, we thought that income explained the variation in our object of study, we could not assign different citizens to different levels of wealth in order to observe its effects. Hence we could not be sure that it is wealth rather than another factor associated with it that is really the causal agent. In these cases we turn from experiments to more inferential methods, such as the statistical analysis of survey data, attempting to control for confounding variables. In our case, however, we can simply manipulate citizens' exposure to different forms of rhetoric, establishing a clear causal test.

The primary advantage of experiments is this ability to isolate causal mechanisms. This is accomplished through the establishment of a control group to compare to the treatment group, and the random assignment of subjects to one group or the other, removing selection bias and randomizing out other possible causal factors (Martin 1996, Kinder and Palfrey 1993). These procedures establish the internal validity that is the hallmark of experimental approaches. We can be sure that any observed differences between the control and treatment groups are due to the experimental manipulation, because the two groups are otherwise identical; the only difference between them is the one that we introduced. The associated disadvantage is the lack of external validity or generalizability to circumstance outside the lab. While experimenters strive to recreate or mimic real world conditions, only so much can be achieved. In our case, the corollary to real world political persuasion is strong; the rhetorical statements employed are similar to actual political appeals that citizens hear in the course of their daily lives.

It is important to note that on the intensive - extensive dimension illustrated in the table, we remain in the midrange. The experiments involve a more intensive analysis than most surveys, but do not approach the detail of the thorough interviewing in Lane's work. Moreover, we employ numbers of citizens into the hundreds in order to be able to apply statistical tests and assure that we have randomized out spurious influences. Again this is in the midrange between truly intensive and fully extensive approaches. The number of people is large enough to matter but small enough to manage. 
Which brings us back to the citizens under study: our experimental subjects. The first study employs students at the University of Pittsburgh, drawn from the Psychology Department subject pool, and the second sample comprises students at Colgate University, drawn from the student research pool of the Political Science Department. While the citizens in both studies are students, they represent a broader spectrum of Americans. Their representativeness relies not on the essential similarity between these students and other Americans, but on the essential similarity in how they react to political stimuli - in how their minds operate. One of the modern criticisms of laboratory experiments is the 'sophomores in the lab' effect (Sears 1986). The argument is that the narrow subject pool of college undergraduates may bias the results of contemporary psychology due to the unusual characteristics of that demographic, especially a susceptibility to peer pressure, less solidified attitudes, and political liberalism. Whenever any of these biases are related to the specific research question at hand we must be especially careful about our conclusions.

Of those three traits, the first is irrelevant for our manipulation, the second should not bias our specific question, and the third, if anything, biases results against our hypotheses, making the test more conservative. While some social psychology experiments regarding group dynamics and other public interactions may be biased by undergraduates' greater susceptibility to peer pressure, our experiments are done individually, without regard to group opinion. That students have less solidified attitudes than older Americans may seem at first to bias our results, but our test is not whether sacred rhetoric will persuade, but whether it does so more or less than negotiable rhetoric. If students are biased toward being persuaded, they should be more persuaded by both equally. Differences in the effects of the two forms of rhetoric should not be due to undergraduate biases. If anything, students should hold fewer sacred values than older citizens, and be less persuaded by appeals to sacredness. The third trait - greater political liberalism - should if anything bias students against sacred appeals and absolutist reasoning. If our third hypothesis is correct, that Democrats employ less sacred rhetoric than Republicans, we could assume that if there is a bias, it is toward liberals being less fond of sacredness and if anything less persuaded by it. On the whole, the specific character of the sophomores (and 
juniors, seniors, and fifth year students) in our lab should not determine our results, and an experimental approach is viable.

\subsection{THE EXPERIMENTAL DESIGN}

Our empirical test of the influence of sacred rhetoric relies on a straightforward experimental manipulation that allows us to compare the effects of sacred versus non-sacred rhetoric. I asked each of the participants to read and consider a brief political appeal and then respond to a series of questions about their opinions and justifications. For each political domain participants were randomly exposed to a sacred rhetoric, negotiable rhetoric, or control condition (which received no message at all). The sacred rhetoric statements contained at least five of the seven elements of absolutist reasoning described above, while the non-sacred statements contained several elements of consequentialist reasoning (see Appendix Two for the wording of the sacred and non-sacred appeals). Each appeal centered on a specific political domain within contemporary politics, but the choice of domains is an important facet of the experiment.

In order to make our tests of the effects of sacred rhetoric, we need to concentrate on a few specific political domains (rather than issue, attitude, or even value, I prefer the term 'domain' to connote simply an area of thought or political concern, within which a citizen may or may not apply those other constructs). Table 5.1 lists the prominent domains within contemporary American politics that regularly employ sacred rhetoric. Three different criteria seem important in winnowing down an appropriate sample on which to concentrate - the sidedness, obviousness, and source of authority for the potentially sacred values. In chapter one, we discussed the single or double-sidedness of political domains, which refers to whether only one or both sides of a political struggle have sacralized the underlying values. Domains that I suspect are double-sided include abortion, gay marriage, and the death penalty. However, several other domains I suspect are only single-sided, from either the left or the right. These include free speech, environmentalism, animal rights, and pacifism on the left, as well as gun rights, flag burning, and public religiosity (such as prayer in school and displaying the Ten Commandments) on the right. In terms of the focus areas of the study, it seems important to 
have some representation from each of these categories, perhaps two double-sided, one singlesided from the left, and one single-sided from the right. 
Table 5.1: $\quad$ Sacred Values in American Politics

Domain

$\underline{\text { Apparent Sidedness }} \quad \underline{\text { Obviousness }^{87}}$

Source of Authority

\begin{tabular}{|c|c|c|c|c|c|c|c|c|}
\hline & \multirow[b]{2}{*}{$\begin{array}{l}\text { Double- } \\
\text { Sided }\end{array}$} & \multirow{3}{*}{$\begin{array}{c}\text { Single } \\
\text { Left }\end{array}$} & \multirow{3}{*}{$\begin{array}{l}\text { Single } \\
\text { Right }\end{array}$} & \multirow{3}{*}{ Consensus } & \multirow{3}{*}{$\begin{array}{c}\text { More } \\
\text { Obvious } \\
\text { X }\end{array}$} & \multirow{3}{*}{$\begin{array}{c}\text { Less } \\
\text { Obvious }\end{array}$} & \\
\hline & & & & & & & Religious & Secular \\
\hline Abortion $^{88}$ & $\mathrm{x}$ & & & & & & $\mathrm{x}$ & \\
\hline Gay Marriage & $\bullet$ & & & & $\bullet$ & & $\bullet$ & \\
\hline Death Penalty & $\bullet$ & & & & & $\bullet$ & $\bullet$ & $\bullet$ \\
\hline The Environment & & $\bullet$ & & & & $\bullet$ & & $\bullet$ \\
\hline Free Speech & & $\mathrm{x}$ & & & & $\mathrm{X}$ & & $\mathrm{x}$ \\
\hline Post 9/11 Civil Liberties & & $\mathrm{X}$ & & & & $\mathrm{x}$ & & $\mathrm{x}$ \\
\hline Animal Rights & & $\mathrm{x}$ & & & & $\mathrm{X}$ & & $\mathrm{x}$ \\
\hline Pacifism & & $\mathrm{x}$ & & & & $\mathrm{x}$ & & $\mathrm{x}$ \\
\hline Gun Rights & & & $\bullet$ & & & $\bullet$ & & $\bullet$ \\
\hline Flag Burning & & & $\mathrm{x}$ & & $\mathrm{x}$ & & & $\mathrm{x}$ \\
\hline Public Religiosity ${ }^{89}$ & & & $X$ & & $X$ & & $\mathrm{X}$ & \\
\hline Constitutionalism & & & & $\mathrm{x}$ & & $\mathrm{x}$ & & $\mathrm{x}$ \\
\hline
\end{tabular}

${ }^{87}$ The degree to which political domains are more or less obviously sacralized influences whether our empirical tests are more liberal or conservative. To demonstrate effects within abortion politics means less about the role of sacred rhetoric than to find them within other domains such as the death penalty or gun rights. The less obvious cases provide a more conservative, and hence more meaningful, test.

${ }^{88}$ Abortion is the central topic of a broader domain characterized by the religious, ethical, and humanistic ramifications of interventions into human fertility, centering in one sense on the status of humans before they are born, and in another on public attitudes toward sexual mores. Stem cell research is a related issue that is focused more on the first root question. Sex education in schools and the distribution of contraception is another issue that centers more on the second concern.

${ }^{89}$ Public religiosity includes such issues as prayer in school, the "under God" controversy in the Pledge of Allegiance, evolution versus creationism in public schools, and the display of the Ten Commandments in courts. These could be thought of as separate domains, but they seem to share the same question of whether Christian values and symbols are excluded or given a noted place in public institutions. 
Another criterion is obviousness, or how clearly sacralized the domain is in contemporary politics. Some areas of political conflict have more clearly sacred connections than others. In choosing areas on which to focus, we would not want to avoid the obvious domains entirely, as they are politically important. But the argument should not rely only on obvious cases. Abortion may be the most clear and prominent example of a domain characterized by sacred values, but it may be too much so, providing only a narrow test of the role of sacredness. Less obvious examples provide a more conservative test, and if successful argue for a broader range of the influence of sacred rhetoric. Moreover, abortion has also received a great deal of scholarly attention. The third criterion is the source of authority, whether religious or secular. Because one of the important questions regarding the nature of sacredness is the division between the religious and secular sacred, as well as the role of an established and legitimate authority in backing up sacred claims, it would be unwise to concentrate solely on domains characterized by either religious or secular sources.

Balancing these different criteria leads us toward four specific domains: gay marriage, the death penalty, environmentalism, and gun rights. Gay marriage is potentially double-sided, more obvious, and clearly religious. It is also an important contemporary political issue, taking up a respectable portion of public issue-space. The sacred element of the anti-gay marriage position is seen both in terms of an established authority opposing the public legitimacy of homosexuality and in terms of drawing boundaries of the acceptable. Opposition to gay marriage is framed by its very nature as defining limits and roles - what are the boundaries of what we call marriage; what are the appropriate roles for men and for women; what is acceptable in public and what in private? Events like the ongoing split in the Episcopal church force people to decide what is and is not a transgression of their boundaries: will they or will they not stay in a church with publicly gay bishops? For the opposing side the sacred element is less clear, but still quite possibly influential. It is a different framing of limits, in this case the limits to bigotry and oppression. The potentially sacred value is inclusiveness, equal treatment, and nondiscrimination.

The three remaining domains are less obviously sacralized and therefore provide more conservative tests of the influence of sacred rhetoric. Another potentially double-sided domain is 
the death penalty, which has both religious and secular sources of authority on both sides of the question. Some opponents of the death penalty base their opposition on the Christian sanctity of human life. ${ }^{90}$ But advocates of the death penalty also cite a sacred religious authority, based on explicit Biblical sanction. ${ }^{91}$ Some anti-death penalty advocates take a more secular stand that killings by the state should be absolutely forbidden because they brutalize the state itself. ${ }^{92}$ But supporters of the death penalty also take a secular sacred position that the death penalty makes an unequivocal statement of right and wrong, of what is considered most heinous by our society, regardless of any deterrent or non-deterrent effect. ${ }^{93}$ In this sense the death penalty provides a domain with several different sources of religious and secular authority on both sides of the question.

The third domain is environmentalism, which is potentially single-sided from the left (the absolute requirement to save natural resources, wonders, or species). It is generally secular, though there are some religious foundations as well. ${ }^{94}$ The anti-environmental side seems to be more consequentialist than sacred. This may be because the motivation is not really an opposition to the environment, but is instead pro-economic development or pro-business, a

${ }^{90}$ Employing this reasoning, some anti-abortion advocates also oppose the death penalty on the same grounds, while other abortion foes do not. However, this is not necessarily a contradiction; foes of abortion who advocate the death penalty are opposed to the taking of innocent lives, which does not extend to those who have earned a death sentence.

91 The usual Biblical references are Genesis 9:6 "Whoso sheddeth man's blood, by man shall his blood be shed," Exodus 21:12 "He that smiteth a man, so that he die, shall be surely put to death" and Leviticus 24:17 "And he that killeth any man shall surely be put to death" (King James version). The phrase "shall be surely put to death" or a close variant is repeated at least 40 times in the first five books of the Bible.

92 Others also oppose the death penalty because of the possibility of errors, but this is a consequentialist and not a sacred argument.

${ }^{93}$ See note 33 supra.

94 These are grounded in the Noadic covenant to husband the earth (Genesis 9:1-2 "And God blessed Noah and his sons, and said unto them, Be fruitful, and multiply, and replenish the earth. And the fear of you and the dread of you shall be upon every beast of the earth, and upon every fowl of the air, upon all that moveth upon the earth, and upon all the fishes of the sea; into your hand are they delivered"). This is often interpreted to mean that we are under obligation to preserve that which God has given us; the resources of the earth are ours to employ but not to destroy, as they ultimately belong to God and have been given to us to husband. While this line of thought was prevalent in the early days of the conservation movement, more contemporary strands of environmentalism seem much more secular. 
distinctly consequentialist position. They are not in favor of destroying natural resources, but are simply not willing to pay the costs of their preservation, in terms of either government spending or forgone business revenues.

The final domain is of course guns, which is potentially single-sided from the right and secular. The language of gun rights is clearly sacred, invoking boundaries, authority, and absolutes. From their cold, dead hands to the invocation of a very slippery slope, gun advocates take some of the strongest secular sacred positions in American politics. Taken together, these four political domains provide us with a broad enough range to note differences, but a small enough group to examine in a single experimental session.

After considering the sacred or negotiable appeals, two of the most important questions for the participants were about their opinion on the issue and their justification for that position. The first question was simply "What is your opinion on [gay marriage, the death penalty, the environment, guns]?" Responses were along a seven point scale anchored by "Laws should be changed to allow gay marriages; Gay marriages should not be allowed," "The death penalty should be ended; The death penalty should be continued." "We need greater controls on damage to the environment; We do not need greater controls on damage to the environment." "Gun rights should be more limited; Gun rights should be more protected." The gauge of their form of reasoning for this opinion is based on their response to the open-ended question "Can you explain why you hold the view that you hold?" As described above, the seven facets of sacred rhetoric provide us with a scheme to gauge the number of elements of absolutist reasoning in these responses. By taking note of each of the facets of absolutist or consequentialist reasoning present in a given response, we can assign it a value from positive seven for an extremely absolutist argument (containing all seven absolutist elements) to negative seven for a strongly consequentialist argument. 


\subsection{RHETORIC AND REASONING}

We can test the causal connection between rhetoric and reasoning by examining this experimental evidence of the comparative effects of sacred and negotiable appeals. Table 5.2 illustrates the explicit hypotheses under examination, the measures for each hypothesis, and the empirical expectations that would confirm these psychological mechanisms. Table 5.3 displays the empirical results of the first experiment.

Table 5.2: $\quad$ Sacred Rhetoric Experiments, Hypothesis 1

$\underline{\text { Hypothesis }}$

\begin{tabular}{|c|c|c|c|c|c|}
\hline 1) & $\begin{array}{l}\text { Sacred Rhetoric } \rightarrow \\
\text { Greater Absolutist } \\
\text { Reasoning }\end{array}$ & Degree of Absolutist Reasoning ${ }^{95}$ & $\begin{array}{c}\text { Sacred } \\
\text { Rhetoric } \\
\text { Condition }\end{array}$ & $>$ & $\begin{array}{l}\text { Negotiable } \\
\text { Rhetoric } \\
\text { Condition }\end{array}$ \\
\hline 1a) & $\begin{array}{l}\text { Even Among Listeners } \\
\text { Who Disagree }\end{array}$ & $\begin{array}{l}\text { Degree of Absolutist Reasoning } \\
\text { (by dissenters only) }\end{array}$ & $\begin{array}{l}\text { Sacred } \\
\text { Rhetoric } \\
\text { Condition }\end{array}$ & $>$ & $\begin{array}{l}\text { Negotiable } \\
\text { Rhetoric } \\
\text { Condition }\end{array}$ \\
\hline
\end{tabular}

${ }^{95}$ Scale of consequentialist to absolutist reasoning, based on the participant's answer to the open-ended question "Please tell us more about your thinking on this question. Can you explain why you hold the view that you hold?" Answers range from -2 (consequentialist reasoning) to 3 (absolutist reasoning).

${ }^{96}$ This test is restricted to participants who disagreed with the direction of the appeal (i.e., responded from 1 to 3 on the seven point scale of opinion). 
An initial question is whether the sacred rhetoric manipulation was successful, in the sense that readers saw the ostensibly sacred appeal in that light and reconsidered their view of the topic. Citizens may use different terms for the distinction between sacred and non-sacred concerns, but the essence is that the domain is special in an important way that demands it be dealt with differently; it is determined by transcendental authority and is not up to majority vote. After their random exposure to a sacred or negotiable appeal, participants were asked for each topic "How would you describe [gay marriage, the death penalty, the environment, gun ownership]? A) It is the same as most political issues. It should be decided through the normal democratic politics of discussion and negotiation. Or B) It is not like most political issues. It is too important or sacred to be decided by the normal democratic politics of discussion and negotiation." Participants in the sacred rhetoric condition were significantly more likely in three out of four cases to choose option B, the indication of sacred status. ${ }^{97}$ In regard to the environment there is no discernable effect, but we see significant differences with gay marriage, the death penalty, and guns: $F=3.44(p=.065) ; F=9.96(p=.002) ; F=7.77(p=.006)$. This is initial evidence that the rhetorical manipulation was successful, leading citizens to alter their view of the domain in question, recategorizing it as sacred or set apart from normal domains.

The larger question is the influence of sacred rhetoric on reasoning (Hypothesis 1). It is important to note that the meaningful comparison is the group exposed to sacred rhetoric versus the group exposed to negotiable rhetoric, rather than the true control group. Comparing the sacred rhetoric group to a group exposed to no message does not address the real question at hand - whether sacred rhetoric has different influences than a non-sacred appeal that provides the same message but in a more measured and negotiable form. In other words, does the sacred rhetoric associated with the culture wars, new social movements, and new media have different effects than the usual political rhetoric of mainstream parties and politicians?

\footnotetext{
${ }^{97}$ The statistical tests employ an analysis of variance (one-way ANOVA), comparing the sacred rhetoric group to the non-sacred rhetoric group. This is a straightforward way of comparing the variance in categorization, reasoning, opinion, or other variables between the sacred rhetoric and non-sacred rhetoric groups.
} 
Table 5.3: $\quad$ Reasoning Effect Experimental Results ${ }^{98}$

Dependent

Variable
Double-Sided Sacred

Gay Marriage

Sacred v. Negotiable

Rhetoric

Issue Area

Death Penalty

Sacred v. Negotiable Rhetoric

\section{$\underline{\text { Single-Sided Sacred }}$}

Environment

Guns

Sacred v. Negotiable Rhetoric
Sacred v. Negotiable Rhetoric

\section{Hypothesis 1: Sacred Rhetoric Increases Absolutist Reasoning}

\begin{tabular}{|c|c|c|c|c|}
\hline Opinion $^{99}$ & $\begin{array}{l}F=1.32 \\
(p=.25) \\
(3.83,4.17)\end{array}$ & $\begin{array}{l}F=0.62 \\
(p=.43) \\
(4.60,4.39)\end{array}$ & $\begin{array}{l}F=0.80 \\
(p=.37) \\
(2.58,2.43)\end{array}$ & $\begin{array}{l}F=0.99 \\
(p=.32) \\
(3.87,4.16)\end{array}$ \\
\hline $\begin{array}{l}\text { Absolutist } \\
\text { Reasoning }\end{array}$ & $\begin{array}{c}\mathbf{F}=\mathbf{9 . 3 7} \\
(\mathbf{p}=\mathbf{. 0 1}) \\
(.95, .56)\end{array}$ & $\begin{array}{c}\mathbf{F}=\mathbf{1 5 . 9 3} \\
(\mathbf{p}=\mathbf{. 0 1}) \\
(.45,-.03)\end{array}$ & $\begin{array}{c}\mathbf{F}=\mathbf{1 6 . 5 6} \\
(\mathbf{p}=\mathbf{. 0 1}) \\
(-.16,-.51)\end{array}$ & $\begin{array}{c}\mathbf{F}=\mathbf{8 . 3 7} \\
(\mathbf{p}=\mathbf{. 0 1}) \\
(.99, .62)\end{array}$ \\
\hline
\end{tabular}

\section{Hypothesis 1a: Even Among Listeners Who Disagree}

\begin{tabular}{|c|c|c|c|c|}
\hline $\begin{array}{c}\text { Reasoning By } \\
\text { Those Who } \\
\text { Disagree }^{100}\end{array}$ & $\begin{array}{c}\mathbf{F}=\mathbf{5 . 3 5} \\
(\mathbf{p}=\mathbf{. 0 2}) \\
(.58, .17)\end{array}$ & $\begin{array}{c}\mathbf{F}=\mathbf{6 . 6 1} \\
(\mathbf{p}=\mathbf{. 0 1}) \\
(.36, .-06)\end{array}$ & $\begin{array}{l}\mathrm{F}=0.39 \\
(\mathrm{p}=.53) \\
(-.16,-.25)\end{array}$ & $\begin{array}{c}F=0.52 \\
(p=.47) \\
(.18, .00)\end{array}$ \\
\hline
\end{tabular}

\footnotetext{
${ }^{98}$ Results are F statistics derived from a one-way analysis of variance (ANOVA), comparing the sacred rhetoric treatment to the negotiable rhetoric treatment. All statistically significant results are in bold $(\mathrm{p}<.05)$. The numbers reported below the $\mathrm{F}$ statistics are the means of the dependent variable for the sacred and non-sacred groups respectively. $\mathrm{N}=237$.

${ }^{99}$ Seven point scale, where lower scores are more ideologically liberal.

100 This test is restricted to participants who disagreed with the direction of the appeal (i.e., responded from 1 to 3 on the seven point scale of opinion). $\mathrm{N}=107,72,48$, and 137 respectively. Positive results indicate that even listeners who disagreed with the content of the message were influenced by its form, shifting them toward absolutist reasoning.
} 
At the outset it should be noted that sacred rhetoric is not more persuasive than nonsacred rhetoric in the sense of altering policy opinions to a greater degree. After reading the political appeals, participants were asked their views on each topic, as described above. Opinions on gay marriage, the death penalty, the environment, and guns were not altered more on average by sacred appeals than by negotiable ones. Instead, the distinctive influence of sacred rhetoric is on the process of reasoning. The most important finding of the experiment is that compared to negotiable political rhetoric, sacred appeals shift the listeners' reasoning style toward absolutism. After reading the political appeals, participants were asked "Please tell us more about your thinking on this question. Can you explain why you hold the view that you hold?" Their responses (which averaged 42 written words) were coded for their form of reasoning in the fashion described above, resulting in a scale from +7 (employing each of the facets of sacred reasoning) to -7 (employing each of the facets of negotiable reasoning). ${ }^{101}$

A few examples should serve to illustrate the sort of results obtained (quotations are in the citizen's own language, including grammatical errors):

\section{Gay Marriage:}

"Well I recently got saved and am into church. The Bible says woman and man, not woman and woman. I think it is gross and unacceptable. Homosexuality is a choice, and a very wrong one at that." (Scale $=3$ [boundary, authority, moral outrage])

"I hold my view because I don't feel that marriage is so sacred that it should only be one man one woman. People get married and divorced so quickly now that marriage is not such a traditional and holy thing. Besides, if a gay couple got married, how could that affect me one way or another?" (Scale = -2 [denial of boundary, instrumentalism])

"I believe that as individuals we should have the right to marry who we want to. According to the constitution this is supposed to be the land of the free. We as a people do not have to answer for another persons sins [sic]. Let them marry." (Scale $=3$ [protected status, citation of authority, non-instrumentalism])

\section{Death Penalty:}

"I believe in the principle "An eye for an eye" (Scale = 1 [citation of authority])

\footnotetext{
101 The coding of these responses was carried out separately from subjects' other responses in order to maintain blind coding procedures.
} 
"I think the death penalty should be used - and used often. If we just let murderers sit in jail for a life sentence how is that going to stop others from murdering." (Scale $=-1$ [consequentialism])

"I do not believe in the death penalty. Yes the Bible says an eye for an eye but it also says though [sic] shalt not kill. What as individuals gives us the right to decide if he should die, leaving there [sic] blood on our hands. What if yrs down the road they find that the person didn't do it - you can't bring him back. But if sentenced to life with no parole he could be released." (Scale $=-3$ [denial of authority, relativism, consequentialism])

We find consistent and strong evidence that exposure to sacred rhetoric increases the degree of absolutist reasoning. In all four domains there is a statistically significant and substantively influential effect $(F=9.37[p=.002], F=15.93[p=.001], F=16.56[p=.001], F=$ $8.37[\mathrm{p}=.004])$. We can state with confidence that there is a strong effect of sacred rhetoric on reasoning process.

\subsection{DISAGREEMENT AND ABSOLUTIST REASONING}

But how pervasive is the reasoning effect? One of the important questions about sacred rhetoric is whether the reasoning shift applies to all listeners, or only those who agree with the message. If listeners who oppose the appeal are still influenced toward employing more absolutist reasoning, then the influence of sacred rhetoric is more significant (Hypothesis 1a). To test this hypothesis, I limited the sample to those who disagreed with the statement and again tested for differences between the sacred and non-sacred groups. For example, in regard to the anti-gay marriage statements, I selected only participants who gave opinions in favor of gay marriage (a 1,2 , or 3 on the seven point scale). The same procedure was applied to the death penalty, environment, and guns. In two out of four domains, citizens who were exposed to sacred rhetoric but disagreed with its message still employed absolutist reasoning at higher rates than those exposed to non-sacred rhetoric $(F=5.35[p=.023], F=6.61[p=.011])$. Their form of argumentation was significantly affected even though they continued to dispute the appeal itself. This is particularly strong evidence that sacred rhetoric influences the reasoning process of its listeners, even while not changing opinions - or even despite blatant disagreement. 
Had we not been considering the single or double-sidedness of the issues, it might appear that sacred rhetoric is ineffective half of the time among those who disagree. Because the effect is in evidence only in regard to gay marriage and the death penalty but not the other two domains, this could suggest a weak or partial effect. But on reflection, the effect should be moderated by the nature of the domain. We can expect greater absolutist reasoning by those who disagree with a sacred appeal, but only in regard to clearly double-sided political domains. The likely single-sided nature of the pro-environment and gun rights positions provides a persuasive reason that we should not expect absolutist reasoning among those who disagree with the sacred appeals in regard to these domains. Both opposing arguments are grounded in consequentialist positions - the one because of the deaths resulting from gun ownership and the other because of the loss of economic output caused by environmental regulation. Hence the lack of result in the gun and environmental domains, but a strong effect in the case of gay marriage and the death penalty provides strong support for the argument. The finding that sacred rhetoric affects reasoning processes within double-sided domains even among listeners who disagree with its message is particularly strong evidence of its influence.

\subsection{THE IMPORTANCE OF POLITICAL REASONING AND PUBLIC JUSTIFICATION}

The psychological importance of the findings is that a specific form of political appeal - sacred rhetoric - has a distinct effect on citizens' reasoning process even in the absence of persuasive influence on aggregate opinion. The effect of sacred rhetoric is on the reasons offered rather than the opinions held, an influence on public discourse rather than public opinion. In sum, sacred rhetoric increases the prevalence of absolutist reasoning based on principles and authorities, boundaries and moral anger, while decreasing citizens' reliance on arguments grounded in consequences for public welfare. These effects are robust in the sense of being effective even among listeners who disagree with the direction of the message. Because effects on reasoning process are more subtle than direct persuasion effects, they may be overlooked by political researchers concentrating on political opinions. But process rather than outcome effects represent a significant and underappreciated facet of political persuasion. 
Differences in reasoning process may be significant because they could lead to differences in opinion, but they are significant in and of themselves because they change the ways that citizens justify their positions. One of the most important ramifications of sacred rhetoric may be for democratic deliberation and the nature of public discourse within civil society. Communication within the public sphere requires a commitment to only limited forms of conviction, allowing room for compromise and most importantly for respect toward opposing positions. ${ }^{102}$ Intransigent positions and absolute convictions are inimical to open discussion and the formation of consensus. Political theorists such as Amy Gutmann, Dennis Thompson, and Seyla Benhabib argue that the prevalence of fundamental value conflict is a major challenge for deliberative democracy. The expressions of intransigent values can only increase the difficulties of deliberation and consensus. To be clear, it is not just the extremity or content of sacred rhetoric that is significant, but also its form of expression. Not only opinions but also their justifications affect the nature of public discourse. Reasoning that is absolute, inflexible, or strident allows little room for negotiation, compromise, or mutual agreement.

In some senses, the reasons a citizen gives for an opinion are as important as the opinions themselves. The mode rather than content of an argument determines if public debate is civil or strident, negotiable or intractable. In this sense consequentialist and absolutist reasoning have very different influences, especially for the deliberative norm of reciprocity, or employing political reasoning that is mutually justifiable. Reciprocity requires that all citizens are equally motivated to come to an accord that is acceptable to all parties. A central condition for this sort of atmosphere is a mutual standard on which to base arguments, such as their consequences for public welfare. Hence consequentialist reasoning is a much stronger basis for a deliberative public culture. Absolutist reasoning, on the other hand, begins from foundations that are far from mutually agreeable. Starting from cultural authorities as a foundation for an argument means that a citizen can accept either one side's authorities or another's; no compromise is possible. Absolutist positions that insist on the primacy of certain principles leave little room for conciliation. In order to win adherents their advocates can only become more strident, more

102 See Habermas 1984, 1996. 
shrill, more insistent. The difference in the prevalence of the two forms of reasoning is a difference in the nature of our public culture. 


\subsection{SACRED RHETORIC AND CIVIC ENGAGEMENT: THE ACTIVATION EFFECT}

The shift from mundane opinion to sacred value not only signals a change in how citizens reason, but also a change in how they engage in politics. The sacred shift engendered by absolutist rhetoric may have important consequences for American democracy, increasing citizen engagement at the same time that it lowers the capacity for deliberation. In this chapter we examine the empirical evidence for the activation effect of sacred rhetoric, grounded in the psychology of the sacred.

\subsection{SACRED MOTIVATION}

Why some citizens engage in politics more than others is central to understanding democratic representation, but the motivation to participate has never been especially clear. If we listen to the more rationalist approaches, differences in participation are tied to disparities in the calculated benefits to be received. In Anthony Down's famous formulation, the profit to be found in political knowledge or engagement for most people is quite low, which explains the persistence of both political ignorance and apathy (Downs 1957). The collective action problem can be overcome by offering citizens exclusive benefits for participation, as famously suggested by Mancur Olson (1965). But the few who seem to have made it to the end of The Logic of Collective Action note that Olson makes a clear distinction between economic interests and those that are guided by other motives. In regard to value-driven politics, "the theory is not at all sufficient where philanthropic lobbies, that is, lobbies that voice concern about some group other than the group that supports the lobby, or religious lobbies are concerned. In philanthropic and religious lobbies the relationships between purposes and interests of the individual, and the purposes and interests of the organization, may be so rich and obscure that a theory of the sort developed here cannot provide much insight... Where non-rational or irrational behavior is the 
basis for a lobby, it would perhaps be better to turn to psychology or social psychology than to economics for a relevant theory" (Olson 1965, 160-1).

The role of sacred motivation may provide much more traction in explaining the politics of belief. More importantly, political engagement relies on the connection between belief and a call to individual action, which it is up to the potentially successful politician or social movement leader to make clear. If we concentrate not merely on the question of what motivates citizen engagement, but on motivations that can be influenced by political activists, we arrive at the role of rhetoric. Rational incentives to participate are mostly outside of the control of political leaders or social movement entrepreneurs. Other potential explanations for the differences in participation also center on mechanisms that are also largely out of the control of political actors, including resource availability (citizens who are more affluent in money and time are more likely to participate), or social norms of participation (citizens who see voting or other forms of participation as a social duty are the ones who are most active). On the other hand, it is language that is the province of political movements. It is the choice of language, symbol, and frame that is within their control and may be their best avenue of influence.

One powerful rhetorical influence open to political actors may be the shifting of the sacred in the minds of citizens. Interestingly, Olson himself identifies two alternative explanations for citizen engagement that dovetail perfectly with the role of sacred rhetoric and motivation: an individual gave time or money to a cause "because he got an individual, noncollective satisfaction in the form of a feeling of personal moral worth, or because of $a$ desire for respectability or praise" (ibid., italics added). The psychology of the sacred suggests that these are the two key mechanisms that lead to engagement - valorization and cleansing. Participation in the service of the sacred is valorized, increasing our sense of dignity, righteousness, or honor. And participation allows us to morally cleanse any disquieting or disreputable affiliation with a sacred violation. As Olson suggests, this is not merely a personal but also a public act. Political participation allows us to establish or re-establish our moral standing, both private and public. For these two reasons sacred status offers the combination of carrot and stick to encourage civic engagement - the benefit of personal valorization and the detriment of contamination if one does not morally cleanse. 
Anti-sacred acts or opinions are not merely wrong; they are a violation. If sacred rhetoric can create this shift in citizens' minds, from seeing political opposition as ordinary wrongheadedness to perceiving it as an indecent act, then participation grounded in valorization and moral cleansing should follow. Rectifying a violation allows us to improve our self-mage, creating personal meaning and identity through a political act. In the Sacred Value Protection Model (SVPM), Tetlock argues that exposure to violations of sacred values will lead citizens to "engage in symbolic acts of moral cleansing designed to reaffirm their solidarity with their moral community" (Tetlock et al 2000, 855). Previous experiments reveal that this effect is not limited to literal acts or opinions that violate sacred boundaries, but is triggered by mere contemplation. Citizens who even considered whether boundaries such as legalizing prostitution or selling human body parts should be violated were more likely to both express moral outrage and to seize opportunities to engage in moral cleansing such as volunteering for an organ donation campaign (ibid.). The mere contemplation effect is a powerful suggestion that sacred rhetoric alone may be a powerful agent of influence, given the peculiar psychology of the sacred.

\subsection{THE ACTIVATION EFFECT}

To test the activation effect, it is important to see if sacred rhetoric leads to greater citizen engagement across the spectrum of political action. Table 6.1 illustrates the different measures and expectations for each of our tests. These can be divided into effects on citizen intensity (the extremity of opinions, perceived importance of the issue, and perceived legitimacy of opposing arguments), as well as effects on citizen engagement (the intent to vote, to engage in political discussions, to attempt to convince others of your position, and to contribute to political campaigns). 
Table $6.1 \quad$ Sacred Rhetoric Experiments, Hypothesis 2

\section{Hypothesis}

Measure

\section{$\underline{\text { Expectation }}$}

\begin{tabular}{|c|c|c|c|c|}
\hline \multirow{7}{*}{$\begin{array}{l}\text { Sacred Rhetoric } \rightarrow \\
\text { Greater Intensity \& } \\
\text { Engagement }\end{array}$} & Extremity of Opinion ${ }^{103}$ & $\begin{array}{c}\text { Sacred } \\
\text { Rhetoric } \\
\text { Condition }\end{array}$ & $>$ & $\begin{array}{l}\text { Negotiable } \\
\text { Rhetoric } \\
\text { Condition }\end{array}$ \\
\hline & $\begin{array}{l}\text { Perceived Importance } \\
\text { of the Issue } \mathrm{e}^{104}\end{array}$ & $\begin{array}{c}\text { Sacred } \\
\text { Rhetoric } \\
\text { Condition }\end{array}$ & $>$ & $\begin{array}{l}\text { Negotiable } \\
\text { Rhetoric } \\
\text { Condition }\end{array}$ \\
\hline & $\begin{array}{l}\text { Perceived Legitimacy of } \\
\text { Opposing Arguments }{ }^{105}\end{array}$ & $\begin{array}{c}\text { Sacred } \\
\text { Rhetoric } \\
\text { Condition }\end{array}$ & $<$ & $\begin{array}{l}\text { Negotiable } \\
\text { Rhetoric } \\
\text { Condition }\end{array}$ \\
\hline & Intent to Vote ${ }^{106}$ & $\begin{array}{c}\text { Sacred } \\
\text { Rhetoric } \\
\text { Condition }\end{array}$ & $>$ & $\begin{array}{l}\text { Negotiable } \\
\text { Rhetoric } \\
\text { Condition }\end{array}$ \\
\hline & Intent to Engage in Discussion ${ }^{107}$ & $\begin{array}{c}\text { Sacred } \\
\text { Rhetoric } \\
\text { Condition }\end{array}$ & $>$ & $\begin{array}{l}\text { Negotiable } \\
\text { Rhetoric } \\
\text { Condition }\end{array}$ \\
\hline & Intent to Convince Others ${ }^{108}$ & $\begin{array}{c}\text { Sacred } \\
\text { Rhetoric } \\
\text { Condition }\end{array}$ & $>$ & $\begin{array}{l}\text { Negotiable } \\
\text { Rhetoric } \\
\text { Condition }\end{array}$ \\
\hline & Intent to Contribute ${ }^{109}$ & $\begin{array}{l}\text { Sacred } \\
\text { Rhetoric } \\
\text { Condition }\end{array}$ & $>$ & $\begin{array}{l}\text { Negotiable } \\
\text { Rhetoric } \\
\text { Condition }\end{array}$ \\
\hline
\end{tabular}

\section{2)}

\section{Sacred Rhetoric $\rightarrow$ Engagement}

${ }^{103}$ This is tested by folding the opinion scale, such that moderate opinions are the low end of the scale and extreme opinions the high end $(4=0 ; 3$ or $5=1 ; 2$ or $6=2$; and 1 or $7=3)$.

${ }^{104}$ Four point scale: 1 = Not at all important; Somewhat important; $3=$ Important; 4 = Very important.

${ }^{105}$ Seven point scale of legitimacy of opposing arguments, derived from "Opponents of same-sex marriage argue that it would degrade traditional marriages. How legitimate is that argument?" (Opposing argument is tailored to each domain [see appendix]). 1 = Legitimate; $7=$ Not Legitimate.

${ }^{106}$ Seven point scale derived from "How likely are you to vote in the next national election?" (1=Very Unlikely, $7=$ Certainly)

${ }^{107}$ Seven point scale derived from "How likely are you to engage in political discussions in the next campaign season?" (1=Very Unlikely, $7=$ Certainly)

${ }^{108}$ Seven point scale derived from "How likely are you to try to convince someone you know to support your political views during the next national campaign?" (1=Very Unlikely, $7=$ Certainly)

${ }^{109}$ Seven point scale derived from "How likely are you to contribute money to a candidate who supports your views during the next campaign season?" (1=Very Unlikely, 7=Certainly) 
While we noted earlier that sacred rhetoric does not produce a decided shift in opinion in the direction of its argument, it may polarize opinion by increasing intensity in both directions simultaneously. If sacred rhetoric increases absolutist reasoning by both those who agree with its message and those who disagree, then we should see greater extremism on either side. Sacred rhetoric pushes opinions away from the center while increasing their reliance on authorities, boundaries, and absolutes. This emphasis should also increase citizens' perceptions of an issue's importance and its centrality to their political conclusions and actions. And opposing views, by contrast, should be granted less legitimacy. The greater the degree that one's values are absolute and unquestionable, not to be weighed against competing concerns, the less one has to view opposing positions with any respect. Sacred rhetoric is likely to lessen the perceived legitimacy of challenges to a sacred position because of its appeals to absolutism and non-consequentialism. These appeals represent an extreme form of framing effect, as they do not just lessen the weight assigned to the opposing values or consequences, but argue that they have no weight at all. ${ }^{110} \mathrm{~A}$ successful absolutist argument changes the reasoning process from one of weighing competing considerations against each other into one of identifying the appropriate principle and isolating it from consequentialist challenges. A successful non-consequentialist appeal gives listeners a basis for eliminating all concern for the ramifications of their position; the principle is all and the consequences emphasized by the opposing side are nothing. Sacred rhetoric should be accompanied by more extreme opinions, opposition to which is seen as increasingly illegitimate, about issues that are increasingly important.

\footnotetext{
${ }^{110}$ Framing as it is usually understood presupposes a weighing process (which might pit consequence $x$ versus consequence $y$, or consequence $x$ versus value $z$, or even two values against each other). This form of framing argues that the process of weighing is itself illegitimate.
} 
Table 6.2 Activation Effect Experimental Results, Intensity ${ }^{111}$

\section{Dependent \\ Variable}

\section{Extremity of \\ Opinion}

Importance

$\mathrm{F}=1.58$

$F=7.82$

$(p=.01)$

$(1.77,1.45)$

\section{Issue Area}

$$
\begin{array}{r}
\mathbf{F}=\mathbf{4 . 4 6} \\
(\mathbf{p}=\mathbf{. 0 3}) \\
(2.69,2.44)
\end{array}
$$

$(\mathbf{p}=.01)$

$(1.96,1.47)$

\section{Double-Sided Sacred}

$$
\begin{aligned}
& \mathrm{F}=0.61 \\
& (\mathrm{p}=.44) \\
& (2.91,3.11)
\end{aligned}
$$

$$
\begin{gathered}
\mathbf{F}=\mathbf{5 . 9 7} \\
(\mathbf{p}=\mathbf{0 2}) \\
(3.52,4.11)
\end{gathered}
$$

\section{Single-Sided Sacred}

\section{Environment}

Sacred v. Negotiable Rhetoric

$\mathrm{F}=0.29$

$(\mathrm{p}=.59)$

$(-.16,-.25)$

$F=11.08$

$(\mathbf{p}=\mathbf{. 0 1})$

$(1.92,1.49)$

\section{Guns} Rhetoric
Sacred v. Negotiable

$$
\begin{aligned}
& F=6.93 \\
& (p=.01)
\end{aligned}
$$$$
(2.56,2.18)
$$

$(\mathrm{p}=.74)$

$(2.66,2.70)$

$(2.56,2.18)$

$\mathbf{F}=\mathbf{3 . 3 3}$

$\mathrm{F}=0.24$

$(\mathrm{p}=.06)$

$(\mathrm{p}=.62)$

$(3.86,4.21)$

${ }^{111}$ Results are F statistics derived from a one-way analysis of variance ANOVA, comparing the sacred rhetoric treatment to the negotiable rhetoric treatment. All statistically significant results are in bold $(p<.05)$. The numbers reported below the $\mathrm{F}$ statistics are the means of the dependent variable for the sacred and non-sacred groups respectively. $\mathrm{N}=237$. 
If we compare the extremity of citizens' opinions when exposed to sacred and non-sacred rhetoric, in three out of four domains the sacred group has more extreme opinions toward both sides (only opinions on the environment do not show polarization) $(\mathrm{F}=13.46[\mathrm{p}=.001], \mathrm{F}=7.82$ $[\mathrm{p}=.006], \mathrm{F}=11.08[\mathrm{p}=.001]) .{ }^{112}$ Fewer citizens remain in the middle, while there are both more people strongly in favor and more strongly opposed to the sentiment of the appeal. The effect of sacred rhetoric is to polarize its listeners, creating a more divided and more strident environment.

Table 6.2 also demonstrates the influence of sacred rhetoric on the perceived importance of the issues discussed. Participants were asked "How important to you is [gay marriage, the death penalty, the environment, guns] as a political issue?" In two out of four domains, sacred rhetoric increased perceptions of the importance of the issue $(\mathrm{F}=4.46[\mathrm{p}=.033], \mathrm{F}=6.93$ $[\mathrm{p}=.009])$. After reading the political statements, participants were asked about the legitimacy of opposing arguments. ${ }^{113}$ Citizens exposed to sacred rhetoric were significantly more likely to consider the opposing arguments to be less legitimate in two out of four domains ( $F=5.97$ $[\mathrm{p}=.015] ; \mathrm{F}=3.33[\mathrm{p}=.061])$. Each of these facets of intensity - the extremity of opinion, the perceived importance of the issue, and the perceived illegitimacy of opposing arguments - are increased by exposure to sacred rhetoric. ${ }^{114}$

In order to test aspects of political engagement as opposed to intensity, I conducted a second experiment designed to focus on these effects. In this experiment, participants were randomly selected to receive either sacred or negotiable messages for all four domains, rather than randomizing each exposure. If the exposure to sacred or negotiable rhetoric were mixed as in the first experiment, we could not determine an overall effect on participation, but in this

\footnotetext{
112 This is tested by folding the opinion scale, such that moderate opinions are the low end of the scale and extreme opinions the high end $(4=0 ; 3$ or $5=1 ; 2$ or $6=2$; and 1 or $7=3)$.

113 "Opponents of same-sex marriage argue that it would degrade traditional marriages. How legitimate is that argument?" Responses were along a seven point scale anchored by "Legitimate" and "Not Legitimate." The wording for other domains was: "Opponents of the death penalty argue that it does not deter crime; Opponents of environmental controls argue that it lessens economic growth; Opponents of gun rights argue that gun ownership leads to more violent deaths."
} 
fashion the causal influence is clear. After reading the arguments, participants were asked how likely they were to vote, to engage in political discussions, to try to convince someone they know to support their political views, and to contribute money to a candidate who supports their views during the next campaign season.

${ }^{114}$ While each of the tests was not upheld in each of the domains, there is a clear pattern of increasing intensity. The three measures (extremity, importance, and legitimacy) in the four domains create a total of twelve separate tests, in which there are statistically significant effects in seven out of twelve cases. 
Table 6.3 Activation Effect Experimental Results, Engagement ${ }^{115}$

\section{Dependent}

Variable

Total

$\mathrm{F}=0.68$

$(\mathrm{p}=.41)$

$(5.93,6.14)$

$\mathbf{F}=\mathbf{6 . 1 9}$

$(\mathbf{p}=.01)$

$(5.28,5.99)$

$F=8.94$

$(p=.01)$

$(3.99,4.96)$

Convince

Intent to

Contribute
$\mathrm{F}=1.94$

$(\mathrm{p}=.17)$

$(2.41,2.84)$

\section{$\underline{\text { Agree }}^{116}$}

$\mathrm{F}=0.20$

$(p=.66)$

$(6.32,6.47)$

$F=5.24$

$(\mathbf{p}=\mathbf{. 0 3})$

$(5.50,6.47)$

$F=13.49$

$(p=.001)$

(3.64, 5.71)

$\mathbf{F}=\mathbf{2 1 . 1 6}$
$(\mathbf{p}=\mathbf{0 0 1})$
$(2.18,4.41)$

\section{$\underline{\text { Disagree }}$}

$\mathrm{F}=0.94$

$(\mathrm{p}=.34)$

$(6.48,6.14)$

$\mathrm{F}=0.29$

$(\mathrm{p}=.59)$

$(5.61,5.87)$

$\mathrm{F}=0.03$

$(\mathrm{p}=.88)$

$(4.61,4.70)$

$\mathrm{F}=2.13$

$(\mathrm{p}=.15)$

$(3.00,2.27)$

115 Results are F statistics derived from a one-way analysis of variance ANOVA, comparing the sacred rhetoric treatment to the negotiable rhetoric treatment. All statistically significant results are in bold $(\mathrm{p}<.05)$. The numbers reported below the $\mathrm{F}$ statistics are the means of the dependent variable for the sacred and non-sacred groups respectively. In the first round of experiments, each political domain was randomly sacred or non-sacred, so the final questions regarding intent to participate would not be related to the overall exposure to sacred rhetoric. The second round was designed to test these effects by exposing participants to only sacred or non-sacred rhetoric for all four domains. $\mathrm{N}=136$.

116 This test is restricted to participants whose opinion agreed with the direction of the argument in at least three out of the four domains $(\mathrm{N}=38)$. The disagree test is identical in the opposite direction $(\mathrm{N}=44)$. 


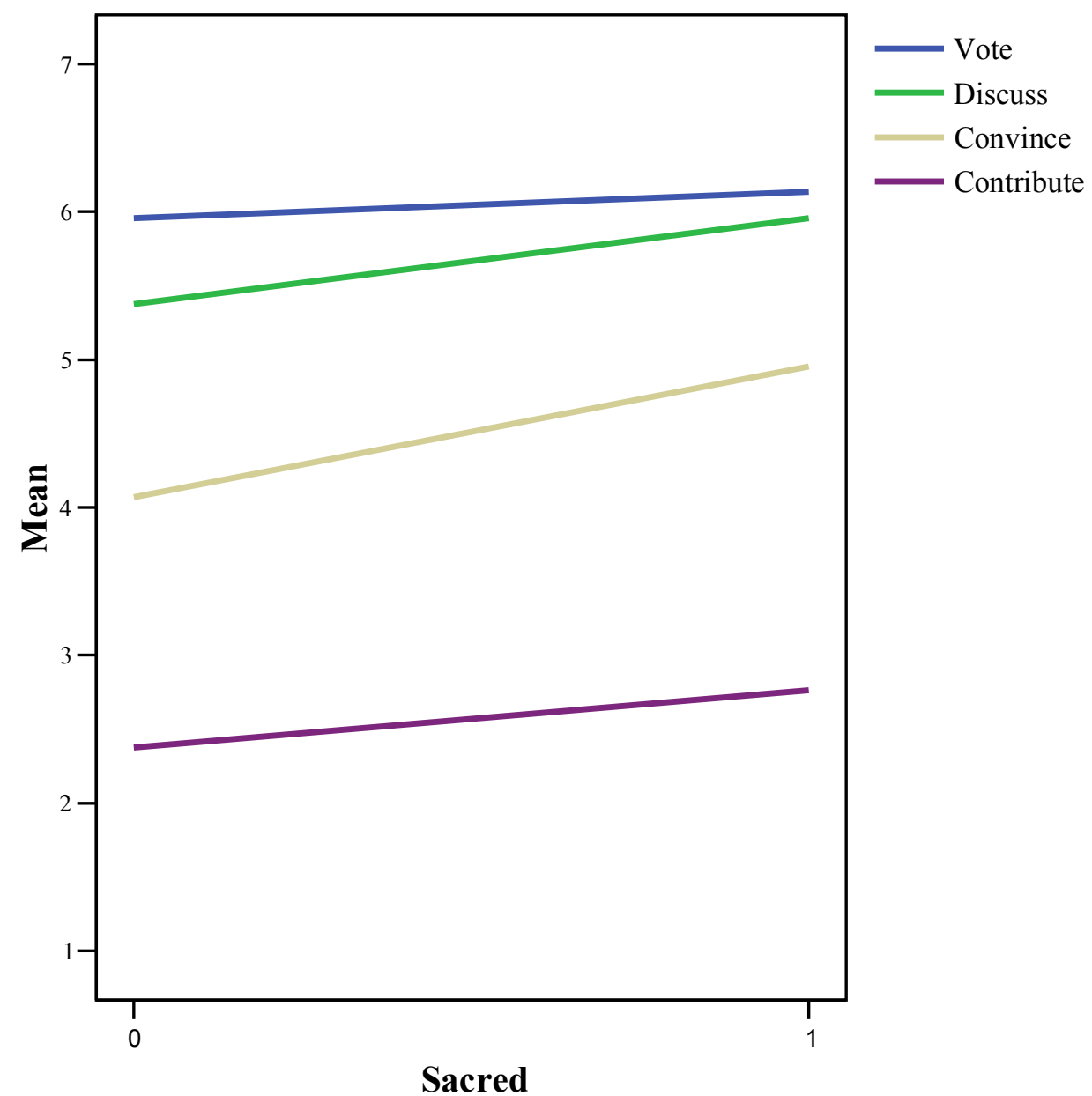

Figure 6.1 Activation Effects of Sacred Rhetoric ${ }^{117}$

${ }^{117}$ Diagram indicates the average difference between the negotiable (0) and sacred rhetoric (1) conditions for citizens' intent to engage in each of the four facets of political activity. Responses are gauged along a seven point scale from "Very Likely" to "Certainly" for the intent to vote, discuss politics, convince others, and contribute to campaigns. The difference between the sacred and mundane conditions for voting is .21 (5.93 to 6.14), for discussing .71 (5.28 to 5.99), for convincing is .97 (3.99 to 4.96) and for contributing .43 (2.41 to 2.84). 
As illustrated in Table 6.3, we find significant effects of sacred rhetoric in two of the four aspects of civic engagement. Figure 6.1 provides a clear demonstration of the significant influence on citizens' intent to discuss politics (moving on average from 5.3 to 6.0 on a seven point scale), and to convince others to see things their way (4.0 to 5.0 on the scale). As we can see in the figure, the differences for voting and contributing were also higher in the sacred rhetoric condition (by .2 and .4), but these increases were not statistically significant. The figure also provides a strong indication of why we do not find similar effects for the intent to vote: respondents are already clustered at the top of the scale, with over half of the participants in each condition recording a seven on the scale. Whether true or not, survey and experimental participants generally claim that they intend to vote, not allowing enough variation for the rhetorical influence to show an effect. But for both discussing politics and attempting to convince others, exposure to sacred rhetoric has a strong effect.

\subsection{THE BACKLASH QUESTION}

But is there a backlash effect? Does sacred rhetoric activate only citizens who support its cause, or does it also activate those in opposition? If a sacred appeal is equally motivating to those who are impressed and those who are annoyed, there may be no net benefit for its advocates. The overall level of political engagement would rise, but the partisan advantage of political activation is lost. In order to test this possibility, we can split our sample into those who are highly in agreement with our appeals and those who are in dissent. For the four domains, I identified the participants who agreed with at least three of the four appeals. In the group that agreed with the messages, the influence of sacred rather than negotiable rhetoric is the same in regard to their intent to discuss politics and greater in regard to their intent to convince others. Moreover, while the influence of sacred rhetoric on the intent to contribute to campaigns was not statistically significant in the whole sample (moving up only .4 on the seven point scale), in the group more in agreement with the messages it jumped over two points on the scale, from an average of 2.2 to 4.4 , an extremely statistically significant difference. On the whole, sacred rhetoric has remarkable effects when we concentrate on citizens who resonate with its message. However, in the group that largely disagreed with the appeals, there were no effects at all within all four 
forms of political engagement. The numbers employed in these tests were necessarily small $(\mathrm{N}=$ 38 and 44, respectively), meaning that we cannot have the same degree of confidence in these findings. But the disparity between the agreeing and disagreeing groups is so striking that it is highly suggestive that the activation effects are contingent on agreement. The initial evidence at least indicates that a backlash effect is unlikely.

\subsection{SACRED RHETORIC AND PARTICIPATORY DEMOCRACY}

The activation effect of sacred rhetoric provides an insight into the role of principled belief in political thought and motivation. While citizen engagement is often seen as a matter of socioeconomic status and resources - those with greater education, wealth, and time participate more in politics - this ignores the potentially important connections between political engagement and sacred belief systems. Regardless of the consistent performance of SES variables in statistical analyses of participation, the increasing levels of education and wealth within the American public in recent decades have not led to higher levels of citizen engagement during that same time period. Resource-based approaches certainly provide some insight into our political process, but they shed more light on why some citizens can have more influence, rather than the process of how some choose to do so but most (even most in the higher SES ranges) do not. And they do not begin to account for which domains and from what perspectives citizens engage in politics, in other words, what citizens are thinking. Studying participation from the perspective of citizen belief addresses a clear lack of emphasis in contemporary scholarship. ${ }^{118}$ Regarding the crucial question of who has influence in democratic politics, for each given issue it may be the people who care the most rather than those who have the most resources.

But sacred rhetoric is not only an advantage to the partisans who employ it. It has a broader effect of engendering a more participatory democracy. One of the more striking features

\footnotetext{
118 See Kay Schlozman's review of current research on citizen participation, which notes that "the literature on participation tends to give short shrift to the role of deeply held political convictions in animating political activity" (Schlozman 2002, 459).
} 
of American politics is the sheer lack of interest among our citizens. In the battle for the public's attention, immediate personal lives are more compelling than remote politicians; the pursuit of happiness in a market economy is more absorbing than public policy. In Robert Weissberg's phrase "the Home Shopping Network inevitably trumps C-SPAN" (Weissberg 2001, 276). Anything that cuts through the publics' inattention, increases their political intensity, and leads to civic engagement is likely to be seen as beneficial by some democratic theorists. But sacred rhetoric has a more complex effect. It increases participation at the same time that it decreases deliberation. This normative contradiction is further complicated by disparities in the use of sacred appeals by different political groups. As we shall see in the final chapter, sacred rhetoric creates a partisan advantage as well as a normative democratic quandary. 


\subsection{THE ABSOLUTIST ADVANTAGE}

The significance of value language may be more clear to rhetoriticians than to politicians. In their classic text on rhetoric (Thinking and Speaking: A Guide to Intelligent Oral

Communication) Otis Walter and Robert Scott conclude with this "moral law" of speaking:

Always act to provide conditions most favorable for mutual understanding between yourself and all concerned.

Speaking, if it is to be ethical, must create conditions favorable to the expansion of symbolism and mutual understanding and influence. We define ethical rhetoric as the discovery of the means of symbolism which leads to the greatest mutual understanding and mutual influence.

The highest values have the highest consequences. When we use these values in speaking, we may enable man to transform himself and his society. To this end, speaking must commit itself if it is to serve us best.

Walter \& Scott 1962, p 231, italics in original

A clear example of language that commits itself is sacred rhetoric. And as we have seen, this language has certain advantages in the fractured communication process between ideological elites and an inattentive public. But sacred rhetoric may be understood and employed by some politicians more than others. The question of this chapter is whether there is a partisan distinction in the use of sacred rhetoric. Is it simply the case that Republicans are the more sacred party, given their propensity for religious foundations and traditional sources of authority? Or do Democrats have their own sacrednesses, also employing the language of limits? Some initial evidence indicates that within certain specific domains, it is the Democrats who are the more rhetorically sacred party. But on the whole, Republicans employ a decidedly more sacred form of discourse. The larger question is whether this creates a significant electoral advantage. 


\subsection{SACREDNESS IN PRESIDENTIAL RHETORIC: THE 2000 BUSH — GORE DEBATES}

To evaluate the comparative degree of sacredness across the breadth of party rhetoric would be a daunting task. Even limiting our inquiry to recent years, the total amount of political speech is staggering, including the party convention speeches, presidential addresses and their rebuttals, news conferences, political advertisements, campaigns for several offices at national and more local levels, as well as many other forums. Even a fair assessment of who really represents each party would be difficult to limit convincingly. Rather than claim to represent a cross section of party language, it may be more advisable to choose a quintessential form of competing party rhetoric and limit ourselves to one clear example. For this task, the presidential debates may be the most meaningful test of partisan differences. They are a straightforward case of attempted persuasion, pitting the two party leaders in direct competition. They take place on a national stage, and perhaps have more direct influence on voters than any other single exchange between the parties. They are also not limited to a single event, but take place in three consecutive broadcasts, separated by extensive commentary and analysis. Moreover, this forum is one of the only cases of an explicit simultaneous comparison of the two parties, when they face and question each other directly, rather than the more usual form of partisan rhetoric in which citizens hearing only a single appeal at a time from one side or the other, such as a political advertisement, presidential news conference, or party convention. The 2000 Bush - Gore debates are especially significant because of their historical timing. They represent an important watershed in political eras and perhaps in party rhetoric: the end of the Clinton era, the return to Republican dominated national politics, and the increasing influence of Evangelism within the Republican party. The Bush - Gore debates represent a viable test of partisan rhetoric in their attempt to persuade, their visibility and impact, their historical timing, and their direct comparison of the two parties.

As a means of party comparison, the debates also offer an additional advantage. Mainstream party politicians may be likely to employ less sacred rhetoric than more fringe politicians or the elements of the party more attached to social movements or interest groups. Concentrating on the two party leaders when facing each other provides a conservative test of the 
party differences in sacredness, expressions of which are likely to be more muted in the presidential debates than other elements of party rhetoric. By contrast, if we were to compare the speeches at the respective party conventions, we would likely find a greater difference in rhetorical styles. By concentrating on the presidential debates we can make a meaningful and conservative test of the differences in the two parties.

\subsection{THE ROLE OF EXPLICIT RELIGION}

Before we examine the differences between the two party spokesmen in their use of sacred rhetoric, it is important to avoid a conflation between sacred rhetoric and references to religion. Citations of religious authority may be an important subset of sacred rhetoric, which could make it appear that Republicans employ more sacred rhetoric simply because they employ more references to God. But the first invocation of God by either party is not until the second debate; it is by the Republican, but only in the traditional "God bless" at the end of his closing statement. Bush's final words at the close of the third debate invoked a slightly different variation: "Should I be fortunate enough to become your president, when I put my hand on the Bible, I will swear to not only uphold the laws of the land, but I will also swear to uphold the honor and the dignity of the office to which I have been elected, so help me God. Thank you very much." This of course was a reference to the previous Democratic president's indiscretions as well as an invocation of traditional religious values. By contrast, Gore did not employ the traditional invocation of God's blessing — a mainstay of presidential rhetoric — in any of his three closing remarks.

But what about religious references in the main body of the debates? They appear in the predictable areas, but by both men. In response to a question in the third debate about public morality and Hollywood, Bush mentions faith-based schooling: "I think that afterschool money ought to be available for faith-based programs and charitable programs." But on this topic Gore was not to be outdone, especially given the history of his wife Tipper's efforts to encourage parental warning labels: "Tipper and I have four children. And God bless them, every one of them decided on their own to come here this evening." The religious reference was not even directly related to the topic, but it is unlikely a coincidence that God was invoked in the 
exchange on this particular topic, even if just in passing. This was Gore's only specific mention of God in the debates.

Religious references also came up regarding some less predictable topics, specifically guns and the environment. Responding to a gun control question in the second debate, Bush argues that "gun laws are important, no question about it, but so is loving children, and character education classes, and faith-based programs being a part of after-school programs. Some desperate child needs to have somebody put their arm around them and say, we love you." Invocations of religion in regard to the environment may be more predictable given the biblical foundations of American environmentalism. In this case the reference was from Gore: "In my faith tradition, it is, it's written in the book of Matthew, 'Where your heart is, there is your treasure also.' And I believe that, that we ought to recognize the value to our children and grandchildren of taking steps that preserve the environment in a way that's good for them."

But invocations of religion are somewhat limited. In all three debates, the total number of explicit mentions of God equals four, ${ }^{119}$ faith equals three, ${ }^{120}$ the Bible equals two, ${ }^{121}$ and Jesus equals zero (some of these overlap; the total number of explicit religious references is seven, five from Bush and two from Gore). This is clearly not the religion-soaked rhetoric of much of American politics, especially compared to previous eras. The word 'Bible' appears only once, only one biblical quote is offered, and Jesus is ignored. This is an unusual paucity of God

\footnotetext{
119 Bush (end of Debate 2): "I'm asking for your vote, and God bless"; (beginning of Debate 3, regarding the death of Missouri governor Mel Carnahan): "I, too, want to extend my prayers and blessings, God's blessings on the families whose lives were overturned"; (end of Debate 3): "Should I be fortunate enough to become your president, when I put my hand on the Bible, I will swear to not only uphold the laws of the land, but I will also swear to uphold the honor and the dignity of the office to which I have been elected, so help me God. Thank you very much."

Gore (Debate 3 re: morality \& Hollywood): "Tipper and I have four children. And God bless them, every one of them decided on their own to come here this evening."

${ }^{120}$ Bush (debate 2 on guns): "faith-based programs being a part of after-school programs"; (debate 3 on morality): "I think that afterschool money ought to be available for faith-based programs and charitable programs."

Gore: reference to Matthew quoted in the text above.

${ }^{121}$ Bush: reference to swearing in on Bible quoted above.

Gore: reference to Matthew quoted above.
} 
compared to the rhetoric of the Founders, the abolitionists (and the entire Civil War era), the Progressive era, or the civil rights movement, not to mention the contemporary rhetoric of many social movements. ${ }^{122}$ But both mainstream party candidates avoided much more than perfunctory references and traditional formulations. The Republican candidate holds the lead in citing religious authority, but Republican sacred rhetoric is in no way limited to or dominated by religious rhetoric.

\section{3 “THAT WONDERFUL NOTE OF DISAGREEMENT”: CONTRASTING PARTISAN STYLES}

"On that wonderful note of disagreement, we have to stop here" was the moderator's way of bringing the first debate to a close. Jim Lehrer was referring to the candidates' clash over public funding of political campaigns, but their 'note of disagreement' perhaps describes rhetorical styles more than simple policy difference. To see the rhetorical difference between the two candidates, we need only compare their closing sentences of the final debate, the last impression each made on the viewers:

Gore: "We've made some progress during the last eight years. We have seen the strongest economy in the history of the United States. Lower crime rates for eight years in a row. Highest private home ownership ever, but I'll make you one promise here. You ain't seen nothing yet. And I will keep that promise."

Bush: "Should I be fortunate enough to become your president, when I put my hand on the Bible, I will swear to not only uphold the laws of the land, but I will swear to uphold the honor and dignity of the office to which I have been elected, so help me God. Thank you very much."

Both candidates offered promises, but they are commitments of a very different nature. The first is to reach certain results or consequences, while the second is to uphold certain values and boundaries. Gore's promise dealt with the economy, crime, and home ownership — personal

122 It is worth noting that this may be different in the context of intra-party debates. Democratic candidates may well place less emphasis on religion, while it is plausible that Republicans would speak in more religious terms while attempting to appeal to their own base. Bush's most famous reference to God took place in the December 1999 Iowa debate against John McCain, when in response to the question, "What political philosopher or thinker do you most identify with and why?" Bush responded, "Christ, because he changed my heart." 
standards of living — while Bush's dealt with public dignity — personal values. His entire concluding statement can be understood as a series of simple value and limit statements: "there is a big difference between big federal government and somebody who is coming from outside Washington who will trust individuals"; "a promise made will be a promise kept should I be fortunate enough to become your president"; "I don't think the surplus is the government's money. I think it's the people's money." Contrary to Jim Lehrer, the two candidates did not always disagree on policy, but they did contrast in their style of rhetoric.

One way to illustrate this difference is to compare the degree of sacred rhetoric employed by each candidate throughout the debates. To examine this I conducted an analysis of the three debates, employing the same strategy used to discern sacred rhetoric in the experiments discussed earlier. ${ }^{123}$ Because the debates are divided into a series of exchanges on distinct topics, this allows us to examine the degree of sacredness in each exchange. For each candidate for each question, I recorded the use of any of the seven facets of sacred rhetoric:

1) Protected status: placing a value beyond question and set apart from trade-offs with other values.

2) Non-consequentialism: privileging values over costs or consequences.

3) Non-instrumentalism: rejecting calculated self-interest.

4) Non-negotiability: denial of the legitimacy of compromise.

5) Citation of boundaries: invoking a boundary of what is acceptable or tolerable.

6) Citation of authority: invoking the relevant authority for the boundary.

7) Moral outrage: referencing anger, especially at a boundary violation.

As well as their opposite forms of negotiable rhetoric:

1) Relativism: implying value trade-offs or comparability with other competing values.

2) Consequentialism: invoking costs or consequences.

\footnotetext{
${ }^{123}$ For this test we move away from the causal methods of the experiments toward more direct empirical observation. But we do not need to go the other extreme of interpretivist methods such as ethnography or even historical analysis (though these could be other useful ways of approaching the topic). In our case, we have an explicit definition of the elements of sacred rhetoric, which we can distinguish and observe. This leads toward a content analysis, or an empirical method for counting and comparing the use of distinct words, phrases, or ideas within a given discourse. This method resides in the middle range between causation and interpretivism. Moreover, the approach allows for a quantitative gauge, which introduces a more specific means of comparing the difference between parties.
} 
3) Instrumentalism: referencing calculated self-interest.

4) Negotiability: invoking compromise.

5) Denial of boundaries: denying the validity of a boundary.

6) Denial of authority: denying the validity of a known authority for the boundary.

7) Denial of moral outrage: denying the validity of moral anger.

This creates a scale from a possible -7 (employing each element of negotiable rhetoric) to +7 (each element of sacred rhetoric). The results ranged from negative three to positive five, with a great deal of variation across issue areas. 
Table 7.1 Sacred Rhetoric in the 2000 Presidential Debates

\section{$\begin{array}{llll}\text { Topic Bush } & \text { Gore Difference Reversals }\end{array}$}

DEBATE 1

\begin{tabular}{|c|c|c|c|c|}
\hline Social Security & 2 & -1 & 3 & \\
\hline Oil Supply \& Environment & -2 & 0 & -2 & $*$ \\
\hline Abortion & 4 & 1 & 3 & \\
\hline Yugoslavia & -1 & -1 & $\mathbf{0}$ & \\
\hline Use of Force & -1 & 1 & -2 & $*$ \\
\hline Domestic Political Philosophy & 2 & -2 & 4 & \\
\hline Education & 1 & -1 & 2 & \\
\hline Unexpected Events & - & - & - & \\
\hline Financial Crises & 0 & 1 & 1 & \\
\hline Social Security & 2 & -1 & 3 & \\
\hline Character & 3 & -1 & 4 & \\
\hline Closing Statements & 3 & -2 & 5 & \\
\hline AVERAGE: & 1.2 & -.5 & 1.9 & \\
\hline
\end{tabular}

\section{DEBATE 2}

\begin{tabular}{|c|c|c|c|c|}
\hline U.S. Power & -1 & 3 & -4 & $*$ \\
\hline Racial Profiling / Hate Crimes & 1 & 1 & $\mathbf{0}$ & \\
\hline Gay Marriage & 3 & -1 & 4 & \\
\hline Guns & 2 & -3 & 5 & \\
\hline Health Insurance for Kids & 0 & -2 & 2 & \\
\hline Environment & 0 & 2 & -2 & * \\
\hline Credibility & - & - & - & \\
\hline Closing Statements & 2 & -2 & 4 & \\
\hline AVERAGE: & 1.0 & -.3 & 1.3 & \\
\hline
\end{tabular}

\section{DEBATE 3}

\begin{tabular}{|c|c|c|c|}
\hline HMOs & -1 & -1 & $\mathbf{0}$ \\
\hline Drug Prices & -1 & -1 & $\mathbf{0}$ \\
\hline National Health Care & 2 & 0 & 2 \\
\hline Educational Accountability & 3 & -2 & 5 \\
\hline Teachers & 2 & -2 & 4 \\
\hline Middle East & 2 & 1 & 1 \\
\hline Military Preparedness & 0 & -1 & 1 \\
\hline Guns $-\cdots$ & 2 & -1 & 3 \\
\hline Family Farms & 1 & -1 & 2 \\
\hline Inheritance Tax & 4 & 0 & 4 \\
\hline Morality \& Hollywood & 2 & -1 & 3 \\
\hline Youth Apathy & 2 & 0 & 2 \\
\hline Inclusiveness & 2 & -1 & 3 \\
\hline Taxes & 2 & -1 & 3 \\
\hline Capital Punishment & 1 & -1 & 2 \\
\hline Keeping Pledges & - & - & - \\
\hline Closing Statements & 3 & -1 & 4 \\
\hline AVERAGE: & 1.6 & -.8 & 2.4 \\
\hline \multirow[t]{3}{*}{ TOTAL AVERAGE: } & 1.4 & -.6 & 2.0 \\
\hline & \multicolumn{2}{|c|}{ Average Without Democratic Reversals: } & 2.6 \\
\hline & \multicolumn{2}{|c|}{ Average of Closing Statements: } & 4.3 \\
\hline
\end{tabular}


Table 7.1 illustrates the results of this analysis for each of the three debates. The most important finding is that Republican appeals do entail a greater degree of sacred rhetoric. For each exchange, Bush's language averaged 1.9 more elements of sacred rhetoric than Gore's in the first debate, 1.3 in the second, and 2.4 in the third. The overall average was 2.0 more elements of sacred rhetoric for Bush in each exchange. This is clearly a statistically significant difference, even though the numbers involved are relatively small (a total number of 34 meaningful exchanges). ${ }^{124}$ When we compare only the candidates' closing statements - the most prepared language of the debates - the difference is even more stark, with Bush employing an average of 4.3 more elements of sacred rhetoric. While it is clear that Republican rhetoric was more sacred on the whole, this was not the case with every topic nor was there always a great difference. The issue areas where Bush displayed the more decisive difference were predictably the moral issues (abortion, gay marriage, character, and public morality), but also issues of principled disagreement such as guns and taxes. The exchanges involving the inheritance tax and public school accountability entailed some of the greatest distinctions in rhetorical style due to Bush's invocation of strong boundaries, limits, and standards compared to Gore's discussion of policy consequences.

To understand these differences it is important to move beyond the raw data to examples of their competing rhetoric. One of the best ways to compare the candidates is not in their answers to questions chosen by the moderator or audience members, but in their closing statements, which they have had ample time to prepare and to phrase in their preferred fashion. Below are the closing statements from the first debate. They are printed in full because they illustrate major differences in the candidates' rhetorical styles. Especially illustrative passages are in bold.

Bush: "Thank you, Jim. Thank the University of Massachusetts and Mr. Vice President, thank you. It has been a good, lively exchange. There is a huge difference of opinion. Mine is I want to empower people in their own lives. I also want to go to Washington to get some positive things

\footnotetext{
${ }^{124} t=5.02$, which with 33 degrees of freedom represents a $p$ level of .001 , or a $99.9 \%$ chance that Bush and Gore employ different levels of sacred rhetoric. Three of the exchanges were excluded from the analysis because they were in response to fluff questions, producing no meaningful response. These were on whether the candidates could handle unexpected events, whether they had credibility, and whether they would keep their pledges if elected. The answers offered by both candidates were essentially yes, yes, and yes.
} 
done. It is going to require a new spirit. A spirit of cooperation. It will require the ability of a Republican president to reach out across the partisan divide and to say to Democrats, let's come together to do what is right for America. It's been my record as Governor of Texas. It will be how I conduct myself if I'm fortunate enough to earn your vote as President of the United States. I want to finally get something done on Medicare. I want to make sure prescription drugs are available for all seniors. And I want seniors to have additional choices when it comes to choosing their health care plans. I want to finally get something done on Social Security. I want to make sure the seniors have the promise made will be a promise kept, but I want younger workers to be able to manage some of their own money, some of their own payroll taxes in the private sector under certain guidelines to get a better rate of return on your own money. I want to rebuild our military to keep the peace. I want to have a strong hand when it comes to the United States in world affairs. I don't want to try to put our troops in all places at all times. I don't want to be the world's policeman, I want to be the world's peacemaker by having a military of high morale and a military that is well-equipped. I want anti-ballistic missile systems to protect ourselves and our allies from a rogue nation that may try to hold us hostage or blackmail our allies and friends. I want to make sure the education system fulfills its hope and promise. I've had a strong record of working with Democrats and Republicans in Texas to make sure no child is left behind. I understand the limited role of the federal government, but it could be a constructive role when it comes to reform, by insisting that there be a strong accountability systems. My intentions are to earn your vote and earn your confidence. I'm asking for your vote. I want you to be on my team. And for those of you working, thanks from the bottom of my heart. For those of you making up your mind, I would be honored to have your support."

Gore: "I want to thank everybody who watched and listened tonight because this is indeed a crucial time in American history. We're at a fork in the road. We have this incredible prosperity, but a lot of people have been left behind. And we have a very important decision to make. Will we use the prosperity to enrich all of our families and not just a few? One important way of looking at this is to ask who are you going to fight for? Throughout my career in public service, I have fought for the working men and women of this country, middle-class families. Why? Because you are the ones who have the hardest time paying taxes, the hardest time making ends meet. You are the ones who are making car payments and mortgage payments and doing right by your kids. And a lot of times there are powerful forces that are against you. Make no mistake about it, they do have undue influence in Washington, D.C. and it makes a difference if you have a president who will fight for you. I know one thing about the position of president, it's the only position in our Constitution that is filled by an individual who is given the responsibility to fight not just for one state or one district or the well-connected or wealthy, but to fight for all of the people, including especially those who most need somebody who will stand up and take on whatever powerful forces might stand in the way. There is a woman named Winifred Skinner here tonight from Iowa. I mentioned her earlier. She's 79 years old. She has Social Security. I'm not going to cut her benefits or support any proposal that would. She gets a small pension, but in order to pay for her prescription drug benefits, she has to go out seven days a week several hours a day picking up cans. She came all the way from Iowa in a Winnebago with her poodle in order attend here tonight. I want to tell her, I'll fight for a prescription drug benefit for all seniors and fight for the people of this country for a prosperity that benefits all."

Bush opens with "there is a huge difference of opinion." This may be true, but there is also clearly a substantial difference in style of argument. When given free choice of words, unconstrained by a questioner and with ample opportunity to prepare, Bush begins with a value 
statement: "I want to empower people in their own lives." In other words, individualism is paramount, such that government is not to be trusted compared to individual decision-makers. Gore, on the other hand, opens quite differently. His first lines are "I want to thank everybody who watched and listened tonight because this is indeed a crucial time in American history. We're at a fork in the road." In other words, what happens next is what counts the most; it is the direct consequences of our actions we should consider. Especially now, when the consequences are high. "We have this incredible prosperity, but a lot of people have been left behind. And we have a very important decisions to make. Will we use the prosperity to enrich all of our families and not just a few?" The consequences are instrumental. How will these decisions affect your individual wealth and place in society? It is consequences and their instrumental meaning that should determine your vote.

Later in the debates Gore continues to focus on instrumentalist appeals and the logic of consequences. One of his clearest appeals to instrumental calculation appears in the third debate on the subject of taxes:
"Look, this isn't about Governor Bush, it's not about me. It's about you... If you want somebody who believes that we were better off eight years ago than we are now and that we ought to go back to the kind of policies that we had back then, emphasizing tax cuts mainly for the wealthy, here is your man. If you want somebody who will fight for you and who will fight to have middle-class tax cuts, then I am your man. I want to be. Now, I doubt that anybody here makes more than $\$ 330,000$ a year. I won’t ask you, but if you do, you're in the top $1 \%$."

\begin{abstract}
On the topic of presidential character, Gore also attempts to shift the conversation to consequentialism: "You may want to focus on scandal. I want to focus on results." In this exchange, Bush cites moral outrage and appropriate boundaries of conduct:
\end{abstract}

"I think the thing that discouraged me about the vice president was uttering those famous words, 'No controlling legal authority'. I felt like there needed to be a better sense of responsibility of what was going on in the White House. I believe that, I believe they've moved that sign, 'The buck stops here' from the Oval Office desk to 'The buck stops here' on the Lincoln bedroom. It's not good for the country and it's not right."

"I think people need to be held responsible for the actions they take in life. I think that, well, I think that's part of the need for a cultural change. We need to say we each need to be responsible for what we do." 
In response, Gore moves immediately away from broader concepts of character or values to a related policy proposal:

"I think the American people should take into account who we are as individuals, what our experience is, what our positions are on the issues and proposals are. I'm asking you to see me for who I really am. I'm offering you my own vision, my own experience, my own proposals. And incidentally, one of them is this. This current campaign financing system has not reflected credit on anybody in either party. And that's one of the reasons I've said before, and I'll pledge here tonight, if I'm president, the very first bill that Joe Lieberman and I will send to the United States Congress is the McCain-Feingold campaign finance reform bill..."

Bush's focus on boundary setting is clear from his closing statement quoted above. In it he cites at least three boundaries:

"the promise made will be a promise kept"

"I don't want to be the world's policeman"

"I want to make sure the education system fulfills its hope and promise... by insisting that there be a strong accountability systems"

This continues throughout the debates, for example in regard to health reform: 'I'm absolutely opposed to a national health care plan." In regard to taxes: "Everybody that pays taxes is going to get tax relief." On the inheritance tax: "I just don't think its fair to tax people's assets twice regardless of your status. It's a fairness issue. It's an issue of principle, not politics."

Affirmative action: “[I favor a] policy that rejects quotas. I don't like quotas. Quotas tend to pit one group of people against another. Quotas are bad for America. It's not the way America is all about... I think we can do that in a way that represents what America is all about, which is equal opportunity and opportunity for people to realize their potential." Gore speaks a different sort of language in regard to affirmative action: "I believe in this goal with all of my heart... How do you do it? Well, you establish respect for differences. You don't ignore differences. It's all too easy for somebody in the majority in the population to say, oh we're just the same, without an understanding of the different life experiences that you've had, that others have had." Bush's response: "If affirmative action means quotas, I'm against it." 
Even when the two agree on an issue, they express it in different language. On the death penalty they seem to agree, but in another sense they do not; both are in favor, but in different ways. When asked if he were "proud of the fact that Texas is number one in executions," Bush's response was:

"I was sworn to uphold the laws of my state. Some of the hardest moments since I've been the governor of the State of Texas is to deal with those cases. But my job is to ask two questions, sir. Is the person guilty of the crime? And did the person have full access to the courts of law?... I'm proud of the fact that we hold people accountable."

In Bush's rhetoric, the question is simply the requirements of the job, enforcing the bounds set by the people of his state. The standards of doing so are relatively simple. Gore, however, takes a different view:

"I support the death penalty. I think it has to be administered not only fairly with attention to things like DNA evidence, which I think should be used in all capital cases, but also with very careful attention. If, for example, somebody confesses to the crime and somebody is waiting on death row, there has to be alertness to say wait a minute, have we got the wrong guy? If the wrong guy is put to death, then that's a double tragedy."

He is in favor of capital punishment, but immediately points to its problems and limitations; he emphasizes its flaws, not its virtues. The standard is neither simple nor fully endorsed. It is instead a consequentialist endorsement, limited by its effects, not a full endorsement grounded in the values it promotes and public boundaries it sets.

\subsubsection{Sacred Domains: Abortion \& Guns}

Two of the prominent political issues addressed in the debates demonstrate the partisan differences in rhetoric especially clearly: abortion and guns. Though it may not count as significant evidence, the term 'sacred' is employed three times in the 2000 debates; each time it was by Bush. And each was in regard to the moral issues that inspire some of the most clear employment of sacred rhetoric.

On same-sex marriage: "I'm not for gay marriage. I think marriage is a sacred institution between a man and a woman. And I appreciated the way the administration signed the Defense of 
Marriage Act. I presume the Vice President supported it when the President signed that bill and supports it now. But I think marriage is a sacred institution."

On abortion: "I believe that the judges ought not to take the place of the legislative branch of government. That they're appointed for life and that they ought to look at the Constitution as sacred."

Bush's boundary setting and citation of the Constitution as an authority is matched by his clear invocation of values: "I think what the next president ought to do is to promote a culture of life in America. Life of the elderly and life of those women all across the country. Life of the unborn... Surely this nation can come together to promote the value of life." But in regard to this issue there is boundary setting on both sides.

Gore: "I support a woman's right to choose. My opponent does not... Here is the difference. He trusts government to order a woman to do what it thinks she ought to do. I trust women to make the decisions that affect their lives, their destinies and their bodies. And I think a woman's right to choose ought to be protected and defended."

In the single exchange devoted solely to abortion, both sides made arguments that are more sacred than negotiable. Gore's rhetoric employs one of the elements of sacredness (citation of a boundary), but Bush's rhetoric is simply more sacred, employing four different facets (protected status, non-consequentialism, boundary citation, and citation of authority).

That both sides employ sacred rhetoric in regard to abortion fits with our understanding of this issue as a double-sided sacred domain. Guns, on the other hand, are generally a singlesided sacred domain, and in the two exchanges devoted to this issue Republican rhetoric is decidedly more sacred, while Democratic rhetoric is clearly more negotiable. Gore emphasizes the consequences of gun ownership:

"The problem I see is that there are too many guns getting into the hands of children, and criminals, and people who, for whatever reason, some kind of history of stalking or domestic abuse really should not be able to get guns."

"all of my proposals are focused on that problem, gun safety... Let's have a three-day waiting period, cooling off, so we can have a background check to make sure that criminals and people who really shouldn't have guns don't get them." 
Hence Gore spends much of his debate time advocating registration, a direct policy to influence what he defines as the largest problem: illegal gun ownership.

"I am for licensing by states of new handgun purchases."

"A photo license I.D. like a driver's license for new handguns... I think states should do that for new handguns, because too many criminals are getting guns... Look, this is the year, this is in the aftermath of Columbine, and Paducah, and all the places in our country where the nation has been shocked by these weapons in the hands of the wrong people. The woman who bought the guns for the two boys who did that killing at Columbine said that if she had had to give her name and fill out a form there, she would not have bought those guns. That conceivably could have prevented that tragedy."

Bush takes a quite different approach. However, he does not offer the more strident sacrednesses of the gun rights position. He does not cite the Second Amendment or dismiss the costs of gun violence. He employs the more subtle approach of shifting the argument to national values and the boundaries of clear punishment for infractions.

"I believe law-abiding citizens ought to be allowed to protect themselves and their families."

"Well, it starts with enforcing law. When you say loud and clear to somebody if you're going to carry a gun illegally, we're going to arrest you. If you're going to sell a gun illegally, you need to be arrested. If you commit a crime with a gun, there needs to be absolute certainty in the law."

"I'm not for photo licensing. Let me say something about Columbine... Columbine spoke to a larger issue. It's really a matter of culture. It's a culture that somewhere along the line we've begun to disrespect life. Where a child can walk in and have their heart turned dark as a result of being on the Internet and walk in and decide to take somebody else's life? So gun laws are important, no question about it, but so is loving children, and character education classes, and faith-based programs being a part of after-school programs. Some desperate child needs to have somebody put their arm around them and say, we love you. So there's a, this is a society that, of ours that's got to do a better job of teaching children right from wrong. And we can enforce law... But there's a larger law. Love your neighbor like you would like to be loved yourself. And that's where our society must head if we're going to be a peaceful and prosperous society." 


\subsection{PARTISAN REVERSALS: THE ENVIRONMENT AND NATION-BUILDING}

While it is clear that Bush is more prone to sacred rhetoric, it is also the case that Democrats seem to have their own sacred domains. The first of these is the environment. In the two exchanges devoted to this issue, it is clearly Gore who is the more sacred speaker and Bush the more consequentialist. While Gore does cite the consequences of further pollution and global warming, he also speaks of fundamental values, boundaries, and authorities:

"Now, another big difference is Governor Bush is proposing to open up some of our most precious environmental treasures, like the Arctic National Wildlife Refuge for the big oil companies to go in and start producing oil there. I think that is the wrong choice. It would only give us a few months' worth of oil and the oil wouldn't start flowing for many years into the future. I don't think it's a fair price to pay to destroy precious parts of America's environment."

"domestic exploration yes, but not in the environmental treasures of our country. We don't have to do that. That's the wrong choice. I know the oil companies have been itching to do that, but it is not the right thing to do."

One of Gore's only invocations of religion, and the only biblical quote of the debates, is in regard to the environment:

"In my faith tradition, it is, it's written in the book of Matthew, "Where your heart is, there is your treasure also'. And I believe that, that we ought to recognize the value to our children and grandchildren of taking steps that preserve the environment in a way that's good for them."

But in regard to this issue Bush is essentially consequentialist, arguing that we simply need the oil reserves from the Arctic Refuge and that environmental issues should be seen as simple tradeoffs. But even in an area where his arguments are much less sacred, he tries to turn his rhetoric to a value or principle, in this case the lack of centralized control, appealing to federalism: "Well, I don't believe in command and control out of Washington, D.C."

But the clearest reversal of the normal pattern of the debates is in regard to the use of American military force and the dispute over nation-building. Bush argues American selfinterest and a more instrumental approach. When questioned about whether he has formulated guiding principles for the use of force, his first lines are "I have, I have. First question is what's in the best interests of the United States? What's in the best interests of our people?" Gore's 
opening words to the same question are "I've thought a lot about that particular question, and I see our greatest national strength coming from what we stand for in the world. I see it as a question of values."

Later in the debate, Gore repeats his focus on values over instrumental security interests, directly questioning Bush about interventions in genocides:

"Now, I did want to pick up on one of the statements earlier, and maybe I have heard, maybe I have heard the previous statements wrong, Governor. In some of the discussions we've had about when it's appropriate for the U.S. to use force around the world, at times the standards that you've laid down have given me the impression that if it's something like a genocide taking place or what they called ethnic cleansing in Bosnia, that that alone would not be, that that wouldn't be the kind of situation that would cause you to think that the U.S. ought to get involved with troops. Now, have to be other factors involved for me to want to be involved. But by itself, that to me can bring into play a fundamental American strategic interest because I think it's based on our values. Now, have I got that wrong?"

Bush's response is pure instrumentalism:

"If I think it's in our nation's strategic interest I'll commit troops."

This is part of his well-known antagonism toward nation-building (though this position changed dramatically following 9/11). In regard to Somalia, Bush's criticism is that it "started off as a humanitarian mission and it changed into a nation-building mission, and that's where the mission went wrong. The mission changed. And as a result, our nation paid a price. And so I don't think our troops ought to be used for what's called nation-building. I think our troops ought to be used to fight and win war. I think our troops ought to be used to help overthrow the dictator when it's in our best interests." The contrast between Kosovo and Rwanda is clear in Bush's mind: 'there's got to be priorities, and Middle East is a priority for a lot of reasons, as is Europe and the Far East, our own hemisphere. And those are my four top priorities should I be the president." Gore disagrees about nation-building as a concept, taking the more value-laden position: 
"I don't think we agree on that. I would certainly also be judicious in evaluating any potential use of American troops overseas. I think we have to be very reticent about that. But look, Jim, the world is changing so rapidly. The way I see it, the world is getting much closer together. Like it or not, we are now, the United States is now the natural leader of the world. All these other countries are looking to us. Now, just because we cannot be involved everywhere, and shouldn't be, doesn't mean that we should shy away from going in anywhere."

Bush's response: this just isn't possible. American forces are overextended, and we must limit military commitments - a strong statement not of values but of consequentialism. The same applies to foreign aid, which is not for principle or for show, but only for specific results, without which it should be restricted:

"I believe we ought to have foreign aid, but I don't think we ought to just have foreign aid for the sake of foreign aid. I think foreign aid needs to be used to encourage markets and reform. I think a lot of times we just spend aid and say we feel better about it and it ends up being spent the wrong way, and there's some pretty egregious examples recently... So I'll look at every place where we're investing money. I just want to make sure the return is good."

Gore sees the whole question as one of values and leadership:

"We have a fundamental choice to make. Are we going to step up to the plate as a nation the way we did after World War II, the way that generation of heroes said okay, the United States is going to be the leader."

When Bush does invoke a value - freedom - it is framed not as America promoting liberty abroad, as in the post 9/11 approach, but freedom for individual nations to chart their own course:

"I think one way for us to end up being viewed as the ugly American is for us to go around the world saying, we do it this way, so should you. Now, we trust freedom. We know freedom is a powerful, powerful, powerful force, much bigger than the United States of America, as we saw recently in the Balkans. But maybe I misunderstand where you're coming from, Mr. Vice President, but I think the United States must be humble and must be proud and confident of our values, but humble in how we treat nations that are figuring out how to chart their own course."

We should bear in mind that these exchanges took place before 9/11 and the dramatic change in Bush's foreign policy approach. By the time of the 2004 debates, Bush was no longer arguing a narrow version of American self-interest, but a grander vision of spreading democracy 
and the role of America in a free world, a rhetorical approach much closer to Gore's. This suggests that one of the two partisan reversals evident in 2000 is likely not still the case for the current parties. The environment may be the sole remaining domain with a Democratic sacred advantage.

\subsection{WINFRED SKINNER VERSUS MICHAEL FEINBERG: THE RHETORICAL MEANING OF POLITICAL NARRATIVE}

The evidence from the Bush - Gore debates seems to indicate that with the exception of a few political domains, Republicans employ a greater degree of sacred rhetoric. But in addition to this general observation, there are a few more subtle clarifications to make about how sacredness operates within presidential rhetoric. Three brief topics bear mentioning: the use of stories and narrative; the perceived role of a democratic leader; and the place of fluid versus flawed language.

It has become an expected element of presidential debate (and State of the Union addresses) to introduce short narratives about specific Americans, often ones in attendance. Both candidates employed such devices, but with much different rhetorical styles and meaning. Winfred Skinner and Michael Feinberg seemed to have very different stories to tell, which is to say that Gore and Bush employed the narratives to different ends, grounded in their competing rhetorical styles. Winifred Skinner is first mentioned in the middle of debate one:

"Now, I think that it's very important to understand that cutting benefits under Social Security means that people like Winifred Skinner from Des Moines, Iowa, who is here, would really have a much harder time. Because there are millions of seniors who are living almost hand to mouth."

But her full story comes out in the closing statement of that debate:

"There is a woman named Winifred Skinner here tonight from Iowa. I mentioned her earlier. She's 79 years old. She has Social Security. I'm not going to cut her benefits or support any proposal that would. She gets a small pension, but in order to pay for her prescription drug benefits, she has to go out seven days a week several hours a day picking up cans. She came all the way from Iowa in a Winnebago with her poodle in order attend here tonight. I want to tell her, 
I'll fight for a prescription drug benefit for all seniors and fight for the people of this country for a prosperity that benefits all."

Taken as a whole this narrative is a consequentialist, instrumental appeal. It is her circumstances and the effects of a change in social security that are at issue. ${ }^{125}$ Moreover, it is meant to appeal to many Americans in a similar position of relying on government aid, who should vote based on their own self-interest in regard to social security.

Bush's narrative appeal is more a series of boundary citations, proposing acceptable limits and appropriate roles:

\begin{abstract}
"Let me give you a story about public education, if I might. It's about Kipp Academy in Houston, Texas. A charter school run by some people from Teach For America. Young folks saying I'm going to do something good for my country. I want to teach. A guy named Michael runs the school... It's one of the best schools in Houston. Here are the key ingredients. High expectations, strong accountability. What Michael says, don't put all these rules on us, just let us teach and hold us accountable for every grade. That's what we do. And as a result, these mainly Hispanic youngsters are some of the best learners in Houston, Texas. That's my vision for public education all around America... We have to consolidate the system to free the schools and encourage innovators. Let them reach out beyond the confines of the current structure to recruit teach-forthe-children type teachers. Four, we're going to say if you receive federal money, measure third, fourth, fifth, sixth, seventh and eighth grade. Show us if they are learning to read, write, add and subtract there will be bonus plans. If not, instead of continuing to subsidize failure, the money will go to, the federal money will go to the parents for public school or charter school or tutorial or Catholic school. What I care about is children. And so does Michael Feinberg."
\end{abstract}

This is clearly a different use of narrative. Gore's story illustrates the causes and consequences of a problem, implicitly making an argument about how you should see your self-interest (if the story fits your situation), or about what you should care about (if story does not fit your situation). Bush's story illustrates the appropriate values one should uphold, implicitly making an argument about how you should feel (if fits your situation), or about what you should admire

\footnotetext{
125 Compare this to another narrative employed by Gore: "There is a man here tonight named George McKinney from Milwaukee. He's 70 years old, has high blood pressure, his wife has heart trouble. They have an income of $\$ 25,000$ a year. They can't pay for their prescription drugs. They're some of the ones that go to Canada regularly in order to get their prescription drugs. Under my plan, half of their costs would be paid right away. Under Governor Bush's plan, they would get not one penny for four to five years and then they would be forced to go into an HMO or to an insurance company and ask them for coverage, but there would be no limit on the premiums or the deductibles or any of the terms and conditions."
} 
in others (if does not fit your situation). Even in their choice of narrative, the sacred versus consequential distinction is evident.

\subsection{NUMBERS, DETAIL, AND PLANS: LEADERS AS EDUCATORS VERSUS PRIORITY SETTERS}

The more we examine the partisan distinction in regard to sacredness, it appears to be connected to a different view of the role of a democratic politician. Is it to lead a discussion of different policy consequences in order to educate the public, or is it to set national value priorities? Implicit in the first view is an emphasis on numbers, details, and plans, rather than values, symbols, and bounds. Bush tends to state broad principles: "It's a difference between government making decisions for you and you getting more of your money to make decisions for yourself"; "I am pro-life"; "I don't think its fair to tax people's assets twice regardless of your status. It's a fairness issue"; “I trust people, I don't trust the federal government. It's going to be one of the themes you hear tonight"; "I wish we could spend an hour talking about trusting people. It's just the right position to take"; "I don't believe, like the vice president does, in huge government. I believe in limited government." He generally avoids discussing numbers and offers few explicit details.

Gore, on the other hand, grounds his opening answer in a series of policy proposals: "If I'm entrusted with the presidency, here are the choices that I will make. I will balance the budget every year. I will pay down the national debt. I will put Medicare and Social Security in a lockbox and protect them. And I will cut taxes for middle-class families... I will make sure that we invest in our country and our families. And I mean investing in education, health care, the environment, and middle-class tax cutes and retirement security. That is my agenda." Throughout the debates, Gore continues to cite numbers, details, and plans, but especially numbers: "I've a plan in my budget to recruit 100,000 new, highly qualified teachers"; he will add "a $\$ 10,000$ college tuition tax deduction per child per year"; "I have been in charge of this reinventing government streamlining project that's reduced the size of government by more than 300,000 people in the last several years"; "my proposal gives $\$ 10,000$ hiring bonuses for those 
teachers who are, who get certified to teach in the areas where they're most needed"; "I believe there are 1.4 million children in Texas who do not have health insurance, 600,000 of whom... were actually eligible for it but they couldn't sign up"; "If you make less than $\$ 60,000$ a year and you decide to invest $\$ 1,000$ in a savings account, you'll get a tax credit, which means in essence that the federal government will match your $\$ 1,000$ with another $\$ 1,000$. If you make less than $\$ 30,000$ a year and you put $\$ 500$ in a savings account, the federal government will match it with $\$ 1500$. If you make more than $\$ 60,000$ and up to 100 you'll still get a match, but not as generous." This propensity led directly to the famous "fuzzy math" exchange.

\subsubsection{The Meaning of Fuzzy Math}

One of the more discussed features of the Bush - Gore debates was the much noted numbers squabble, or the accusation of "fuzzy math." While this may have appeared to be a simple ploy to discredit Gore's criticisms of Bush's proposed tax changes, it takes on a different meaning in the context of our discussion of sacredness. The phrase comes up in the very first exchange between the candidates. Bush's second comment of the debates begins, "Let me just say that obviously tonight we're going to hear some phony numbers about what I think and what we ought to do." And later in the first debate: "Look, this is a man who has great numbers. He talks about numbers. I'm beginning to think not only did he invent the Internet, but he invented the calculator. It's fuzzy math." Then he immediately argues for an easily understood boundary: "I set one-third. The federal government should take no more than a third of anybody's paycheck." This is a classic Bush statement of principle over consequences: don't count up the effects with your intellect, but feel about what is right with your values. Gore clearly takes another rhetorical style. His next statement following Bush's Internet jibe is "It's clear you can go to the website and look. If you make more than $\$ 25,000$ a year you don't get a penny of help under the Bush prescription drug proposal for at lest four to five years, and then you're pushed into Medicare..." Bush goes on to mention fuzzy math three more times: "The man is practicing fuzzy math again"; "This man has been disparaging my plan with all this Washington fuzzy math"; "I can't let the man continue with fuzzy math." The meaning of the phrase emerges as not so much incorrect calculation, but unimportant, irrelevant consequences. It is a statement about what 
counts and what does not. For Bush it is values and boundaries, not consequences and instrumental calculation.

\section{7 “I’VE BEEN KNOWN TO MANGLE A SYLLABLE OR TWO”: SACRED LANGUAGE \& CLARITY}

In the second debate when Bush said "I've been known to mangle a syllable or two myself, you know, if you know what I mean," he may have been making more than an accurate empirical observation. In a sense he was addressing a common misconception about rhetoric: that flowing language is clear language. Or that more grammatical language is more easily understood. Another way of phrasing this possible misconception is that more polished arguments are more persuasive. On the contrary, I would argue that persuasion is often grounded less in impressing an audience and more in connecting with them (which is to say making the audience feel that the speaker is similar to themselves and therefore shares their values). ${ }^{126}$ We may make a grave mistake as political analysts by assuming a correlation between the language that we respect and admire ourselves, and the language respected and admired by ordinary citizens. In this sense, the homespun approach may have great traction. Moreover, it may have a natural affinity with sacred rhetoric.

Sacred language is not necessarily flowing language; sacred rhetoric may be no more grammatically correct than it is politically correct. It is true that "Here I stand, I can do no other" certainly has a ring to it. But the ring is not in its complexity, but rather in its boiled down simplicity. This same effect may be achieved by rougher language, as long as the sentiment is equally simple. This connection between sacredness and simple talk may be grounded in the more uncomplicated and symbolic nature of sacred rhetoric. Boundaries and authorities are most clearly invoked by short statements. Further elaboration is not an improvement, but a detriment

\footnotetext{
${ }^{126}$ If this sort of heuristic is significant, then overly polished language could operate much like Popkin's tamale President Ford's failure to know how to eat ethnic food offers the same message as speaking too well: clearly he is not like us (see Samuel Popkin Reasoning Voter).
} 
to communication. Details do not improve, but simply muddy the argument. If an authority is authoritative, it is because it needs no introduction; a boundary is rhetorically effective because it is clear immediately. Values are expressed most clearly by symbols and sweeping generalizations. In this sense, sacred rhetoric lacks nuance by design, not by failure. Consequentialism, on the other hand, takes longer to explain. It requires chains of logic and connections from a demonstrated condition to its reasoned effects, and then to its normative meaning. At any point in the chain of argument agreement could be lost or counterarguments raised. Moreover, to accomplish the needed combination of steps requires a more untroubled form of language. Halting verse will not take you there. If the devil is in the details, then the details must get across.

If "I've been known to mangle a syllable or two" is Bush's self-revealing statement about his rhetorical style, Gore's counterpart would be "getting a detail wrong interfered several times with the point that I was trying to make." Interestingly, the two statements were made within moments of each other, at the end of the second debate. Gore is referring to his admission that in the previous debate he mischaracterized Bush's tax proposals, "getting a detail wrong." But Gore's statement is less self-aware than Bush's. One gets the impression that Bush knows that he makes mistakes but also thinks that in the end it doesn't make him less persuasive. Gore, on the other hand, seems to take his flaw seriously, but thinks that his misstep was in getting the details wrong. He seems sincere in his statement that "I got some of the details wrong last week in some examples that I used, Jim, and I'm sorry about that. And I'm going to try to do better... I can't promise that I will never get another detail wrong. I can promise you that I will try not to, and hard." If only he had gotten the details right. A better way to understand the debates may be that he would have been better served by not emphasizing the details at all. It wasn't so much getting the details wrong, as it was discussing them in the first place that interfered with the points he was trying to make. 


\subsection{THE ABSOLUTIST ADVANTAGE}

If the Bush - Gore debates are an indicator of a larger trend, this suggests that the use of sacred rhetoric is not equal between the two national parties. It would not be appropriate to exaggerate based solely on the 2000 debates, but the evidence may indicate a meaningful difference. Following his later victory in 2004, Bush began to outline his domestic agenda, especially the introduction of Social Security private accounts. When pressed by reporters for details, he responded that he refused to "negotiate with myself in public."127 Like many of his phrases, this one may be more strategic than it appears. To 'not negotiate with oneself' is to remain absolute, uncompromising, sacred. To refuse to do so in public is to privilege sacred rhetoric. The Republican form of sacred rhetoric is only marginally grounded in explicit references to religion, but is instead a matter of a secular sacred style, emphasizing boundaries, protected values, nonconsequentialism, and sources of authority such as the Constitution. Democrats, on the other hand, seem to prefer the logic of consequences and the instrumentality of policy effects. Rather than the simplicity of values, symbols, and bounds, Democratic rhetoric offers the greater complexity of numbers, details, and plans. Democrats are more wedded to the view that things are complicated. We cannot, and should not, reduce them. The goal of political rhetoric should not be to dumb the message down; instead it should be to bring the public up. The role of a politician is to educate. If this is true, what does it mean for their electoral prospects? Is there an absolutist advantage for the Republican party?

Paired with our evidence regarding the influence of sacred rhetoric, a Republican sacred propensity suggests not only a meaningful difference between the two parties, but also a substantial electoral advantage. Sacred rhetoric appears to have a strong activation effect, leading listeners to see the political meaning of their personal values. The greater discussion, participation, and voting that this inspires is an important political advantage. While the experimental evidence does not indicate that sacred rhetoric is more effective at changing minds, it is clearly more effective at inspiring political participation. Moreover, it is a more strident and

127 Wall Street Journal 21 December 2004, A1, column 3. See also Suskind's much discussed piece on Bush's belief system, "Faith, certainty, and the presidency of George W. Bush" New York Times Magazine 17 October 2004. 
intransigent form of citizen engagement. In the current electoral climate of a divided electorate and potentially close margins in presidential campaigns, the additional turnout that is associated with sacred over negotiable appeals is a significant electoral advantage. It may be the marginal edge required in a marginal political environment.

Whether Democrats would desire to employ a more sacred approach if they recognized its effects, or be able to do so given their other commitments is an open set of questions. That Democrats do employ sacred rhetoric in regard to some issues suggests that it is not entirely outside of their realm. Republicans, on the other hand, seem much more comfortable with sacred appeals. And as long as this difference remains, Republicans are likely to enjoy the absolutist advantage. 


\subsection{CONCLUSION: “A CURE FOR THOUGHT AND THE DISEASES IT BREEDS"}

"Why do I spend my time with fools when I could easily invent a cure for thought and the diseases it breeds?"

(Christopher Kennedy, Trouble with the Machine, 2003)

Whether sacred rhetoric is a disease depends on both your view of who is gaining its political advantages and your view of what constitutes democratic health, which is to say which of the competing theories of democracy you find persuasive. One can easily come to a negative view, as sacred appeals increase discord and decrease deliberation. But this may be a limited conclusion. If democratic politics should turn on the concerns of democratic citizens, then the first threshold in American politics is that citizens care at all. Usually this threshold is not met. About most issues most of the time Americans know little and care marginally, trusting in political elites to manage things for them. Sacred rhetoric increases citizen engagement, emboldening our absentee democracy. There are ways to appeal to citizens so that they recognize that they care, bringing them into the democratic system. Sacred rhetoric increases the democratic good of participation even as it lowers the positive benefits of deliberation. For sacredness there is no cure, only an appreciation of its contradictions and possibilities.

The psychological dynamics of sacred rhetoric are distinctive, powerful, and in a sense contradictory, with equally complex influences of the state of our democracy. The persuasive effects are distinctive because they represent a form of persuasion centered on process rather than outcome, as aspect of persuasion that has not been fully recognized by political psychologists. The initial empirical evidence indicates that the effects are strong, suggesting that sacred rhetoric is a powerful tool of the political groups that employ it. But the democratic influence is a contradiction, advantaging one normative view of democracy while disadvantaging another. Moreover, because the use of sacred rhetoric is not equally distributed among parties and interests, understanding its effects is a partisan concern as well as a normative quandary. This conclusion offers a final thought about each of these aspects of the study - the psychological dynamics of sacred rhetoric, its democratic consequences, and its influence on political power. 


\subsection{THE PSYCHOLOGICAL DYNAMICS OF SACRED RHETORIC}

"The formation of political preferences ought to be one of the major subjects of political
science... Preferences in regard to political objects are not external to political life; on
the contrary, they constitute the very internal essence, the quintessence of politics: the
construction and reconstruction of our lives together." Aaron Wildavsky (1987) "A Cultural Theory of Preference Formation"

Political persuasion is one of the earliest and most enduring interests of students of democratic politics. Is it possible to move others to our cause and how can it best be done? The avenue examined here is not a panacea for persuasion, but rather a particular mechanism for changes in reasoning and motivation. These two effects are grounded in the psychology of the sacred, or the urge to protect what we have set aside for special reverence. The sacred shift engendered by absolutist appeals results in these particular forms of persuasion, though it gives no advantage in other aspects. Of the several facets of persuasion, the most obvious is attitude change, or a simple shift of opinion. In this sense sacred rhetoric is no more persuasive than its negotiable or consequentialist counterparts. Non-sacred appeals can be quite persuasive, and sacredness does not seem to immediately change minds more than reasoned consequences. But in other ways sacredness provides a powerful distinction.

About the sacred we think differently and care more. The first of these aspects of sacredness leads to the reasoning effect, or a shift toward more absolutist thinking and justification. Our experiments demonstrate that exposure to sacred rhetoric leads directly to an increase in absolutist justifications, concentrating on non-negotiable and non-consequentialist arguments, the citation of appropriate boundaries and respected authorities, and expressions of moral outrage. The value in question becomes protected, inviolable, not to be tarnished by the cheap trading or power bargaining of mundane politics. This effect is demonstrable in how citizens justify themselves, but it is not an effect on the outcome of their opinion, manifesting instead in the process of their thinking. 
This sort of process effect has been underappreciated in studies of political psychology, perhaps because it is less visible. The most common concern of public opinion scholars is the final expressed opinion, and hence it is the most frequently measured variable. But the sacred distinction does not seem to have immediate effects on opinion, which may explain why it has come under less scrutiny. If we look again at Table 4.1, describing the principal forms of persuasion studied by scholars, purely process effects have not been emphasized. Studies of framing and priming do highlight the process of judgment (in the considerations at play within citizens' minds and the weights given to the different concerns), but the emphasis is still on how this alters the outcome of final opinions. The shift in considerations alone is not the focus, but instead what it does to individual judgments, or how priming and framing are employed to manipulate public opinion. The process is an instrumental concern rather than an object in and of itself.

A focus on process rather than outcome effects is a symptom of a greater psychological rather than behavioral approach to politics. Rather than an emphasis on what people do or say, it aids our understanding to focus on why these outcomes occur, or the underlying psychological mechanics. As Wildavsky suggested, the origins of political beliefs are a crucial but little understood facet of politics. And this applies with especial force to the origins of the extreme and unyielding beliefs that drive much of political conflict.

But the importance of process and justification alone also has to do with a shift in the concerns of political theory, or the increasing importance of the concept of deliberative democracy. Earlier studies of public opinion were framed by a background of an elite or minimalist democracy, where the essential question is how elites respond to the opinions of the mass public. In the 1970s the concern shifted to participatory democracy, or how the public's formed opinions could motivate policy through the increased engagement of ordinary citizens. But only more recently has the process of the development of those opinions and their public justifications become a focus of study in the perspective of a deliberative democracy. In this vein the discourse effects engendered by sacred rhetoric are a prime concern, and the process alone of how politics is conceptualized and discussed has important implications. 
But sacred rhetoric also has a powerful outcome effect in the form of activation. Sacred appeals are more effective than non-sacred rhetoric in encouraging citizens to engage in politics. The sacred shift increases citizens' level of political intensity as well as their intention to participate. In our experiments, citizens displayed greater extremity of opinions, had higher perceptions of the importance of the issue, and lower perceptions of the legitimacy of opposing arguments. Moreover, they expressed greater intentions to attempt to convince others of their political perspective and to contribute to campaigns that promote their views. Activation is a major concern for both students and practitioners of contemporary politics, not because of its implications for democracy, but because of its influence on elections. Parties and movements that can increase the engagement of their supporters have a distinct advantage in winning office or influencing society. This is particularly important in a polarized environment where few minds are changing and the decisive question is which side has the more active constituency. For this reason, the psychological dynamics of sacred rhetoric have important partisan consequences as well as meaning for American democracy.

\title{
8.2 DEMOCRATIC CONSEQUENCES: THE CONFLICTING DEMANDS OF PARTICIPATION AND DELIBERATION
}

\begin{abstract}
"Of the challenges that American democracy faces today, none is more formidable than the problem of moral disagreement. Neither the theory nor the practice of democratic politics has so far found an adequate way to cope with conflict about fundamental values."
\end{abstract}

Amy Gutmann and Dennis Thompson (1996) Democracy and Disagreement

It has become a common belief that citizen engagement in America has declined, leaving us with a lamentably underdeveloped civil society. The ideal of civil society depends on both cohesion and compromise - on citizens holding beliefs that inspire them to engage with other members of society, and on these same citizens nonetheless maintaining their ability to tolerate others' beliefs that conflict with their own. Strong belief systems are often what inspire citizens to participate in politics. However, strong beliefs that do not allow for compromise may also degrade civil society and lessen the prospects for democratic deliberation. In this sense a healthy democracy requires a balance between too little political intensity and too much. The 
conundrum that sacred rhetoric provides is that it increases intensity and engagement at the same time that it degrades deliberation. So which do we value more, a participatory democracy or a deliberative one? As Isaiah Berlin points out in his incisive commentary on value conflict, "some among the Great Goods cannot live together" (1992, p. 13). Different versions of democratic theory may well have this same character. Because of their contradictions, we cannot have all of the positive aspects of democracy, but must choose among them. Democratic deliberation can discourage participation because of its messy and discordant nature (see Hibbing and Theiss-Morse 1995). Likewise, participation can discourage deliberation when it is strident or unyielding. The influence of sacred rhetoric presents us with the second case, when we cannot have our participation and our deliberation too.

One way to discuss the meaning of this contradiction is to focus on the competing goals of deliberative and participatory democrats. Deliberative democrats emphasize the importance of collective discussion based on the discourse principle - that decisions should be made only if all affected by the decision would agree. ${ }^{128}$ The ideal requires that no concerned citizens be excluded, and no power relations distort the discussion. Deliberative theorists emphasize the importance of reciprocity, or the norm of employing political reasoning that is mutually justifiable. ${ }^{129}$ Reciprocity assumes that all citizens are equally motivated to come to an accord that is acceptable to all parties. A central requirement for this sort of atmosphere is a mutually agreed upon standard on which to base arguments, such as their consequences for public welfare. Under these circumstances the governing factor is in Habermas' phrase "the forceless force of the better argument" (Habermas 1984). In this sense, deliberative democracy offers a particular standard for a healthy democracy — what is legitimate is only what is deliberated to consensus by the people collectively.

\footnotetext{
128 "[T] $]$ he only regulations and ways of acting that can claim legitimacy are those to which all who are possibly affected could assent as participants in rational discourse. In light of this 'discourse priniciple' citizens test which rights they should mutually accord one another” (Habermas 1996, 458).

129 See especially Guttmann and Thompson 1996, Chapter Two, on the role of reciprocity, and Habermas 1984 and 1996.
} 
The main object of deliberation in public, and of deliberative democracy itself, is legitimacy. The theme that haunts discussions of deliberative democracy is the nagging doubt about government legitimacy which followed World War Two. In her volume on deliberative practice, Seyla Benhabib identifies three public goods that "complex modern democratic societies since the Second World War face the task of securing" (Behhabib 1996, 67). The second and third of these are economic welfare and collective identity, but the first among them is legitimacy, and the method of gaining this political good is deliberation: "I will argue that legitimacy in complex democratic societies must be thought to result from the free and unconstrained public deliberations of all about matters of common concern" (ibid., 68). Habermas himself defines deliberative democracy as the "democratic procedure that lends legitimating force to lawmaking under conditions of social and ideological pluralism" (Habermas 1996, 458). ${ }^{130}$ Deliberative democrats argue that only through deliberation is democracy freed from the weight of past custom and from the tyranny of current elites. ${ }^{131}$ Even Tocqueville, whose focus was on equality, notes that legitimacy is a major democratic concern, but deliberative democrats make it their central concern. ${ }^{132}$

But legitimacy is far from the only democratic virtue. The central point of participatory approaches, which distinguishes them from deliberative perspectives, is that democracy inherently means full democracy, of all able citizens in all aspects of representative governance. Less than full participation is less than full democracy. But participation is not less valued if citizens come to the process with fully formed opinions. It is not the development of consensus, but the expression of opinion that is paramount. Participation is not merely a means to representation; participation is seen as an end in itself, rather than simply a means to other political ends. Political participation is to be valued as a means of expression that is part of what

\footnotetext{
130 "Law can be preserved as legitimate only if enfranchised citizens switch from the role of private legal subjects and take the perspective of participants who are engaged in the process of reaching an understanding about the rules for their life in common" (Habermas 1996, 461).

131 "Communicative rationalization frees the lifeworld from the dead hand of custom, myth, and illusion on the one hand and the domination of specialists and manipulators on the other" (Dryzek 1990, 20).

132 "It is not the use of power or the habit of obedience that depraves men, but the use of power that they consider illegitimate, and obedience to a power they regard as usurped and oppressive" (Tocqueville 1835, 8).
} 
it means to be human (a political animal); hence a sense of community is a good in its own right. A central aspect of "politics in the participatory mode," is that it is meant to "reorient liberal democracy toward civic engagement and political community" (Barber 1984, pp. 114 and 308).

The important point to which this leads is that the maximands of these democratic approaches differ. Participatory approaches see political engagement (as both a means toward representation and as end in itself) as the thing to be valued most highly, while deliberative democrats wish to maximize legitimacy, which they argue is best achieved through discourse. When trade-offs are to be made, each approach argues for a different virtue to be privileged.

But the legitimacy claims of deliberative democrats are not without criticism. Why is deliberation the only or primary source of legitimacy? Consensus sacredness and traditional authority also provide legitimacy. It is an odd pretense that deliberation is its only source. Habermas argues that this is the case because we "no longer legitimate maxims, practices, and rules of action simply by calling attention to the contexts in which they were handed down" (1996, p. 97). But an important point about the origins of deliberative theory is that the concern about the legitimacy of basic institutions is a syndrome more European than American. Legitimacy is often grounded in historical weight - the older, more hallowed, and more traditional, the more legitimate an institution becomes. But in the European context, entire governments were delegitimized in the eyes of their people in the aftermath of World War Two (as were the communist governments of the Soviet Bloc in the succeeding generations). History and past practice (one of the usual sources of legitimacy) hence had little force for many citizens, and the nagging doubt over what was legitimate and how it could be identified has been a central focus of European thought. Americans, on the other hand, do not have this problem. American politics is grounded in a reverence for the Founding and our political past; hence we have trouble admitting to historical wrongdoing and have an easy and immediate answer to any question of what an emerging nation's government ought to look like - ours. Contrary to Habermas' assertion that institutions are no longer legitimized by calling attention to the context of their origins, this is precisely what Americans do (and what American law 
does). ${ }^{133}$ Legitimacy in the sense of public certainty about the form and justification of institutions is not an American problem; that Habermas was a member of the post-war German generation which has that problem is not a coincidence.

But participatory democracy has its own failures in what it values most. The Achilles heel of a participatory system is the refusal to admit that not all political engagement is positive. One of the usual assumptions of the civil society literature is that all participation is good participation; greater citizen engagement is by definition normatively superior to less. But this should not be an unexamined assumption. In a liberal democracy, too much engagement by the extremely committed, unyielding, or illiberal may be a detriment, just as too much apathy is. Instead of being seen as an unmitigated good, some commentators such as Jaques Barzun define participation differently: "participatory democracy is in fact direct minority rule, a kind of reverse democracy for coercing authority by protests, demonstrations, sit-ins, and job actions in order to obtain the rapid satisfaction of new demands" (Barzun 1986, 19). Rather than the vices of apathy, we may wish to be concerned about those of extremism. What degrades democracy more: apathy and lack of involvement or the strong, even violent, passions that curtail meaningful deliberation, make reasoned agreement difficult, and discourage participation by moderates?

When we judge between the conflicting demands of participation and deliberation there is no simple choice. We can compare their goals and advantages, but the normative quandary only deepens rather than lifts. Like many facets of democratic politics, it is a trade-off. Perhaps one of the ironies of the study of sacredness is that the same absolutist claims that reject value tradeoffs create one that is irresolvable.

${ }^{133}$ A salient example is the recent pathbreaking U.S Supreme Court decision that includes homosexuality under the generalized right to privacy; fully one third of the controlling opinion is a discussion of the history and traditions (or lack thereof) of specific types of government control, as an explicit basis of their legitimacy or illegitimacy (Lawrence et al v. Texas 2003). 


\subsection{SACRED RHETORIC AND POLITICAL POWER}

The effects of sacred rhetoric are important for both the psychology of politics and the functioning of democracy, but they also have implications for partisan politics. If sacred appeals were employed equally by different parties and movements, there would be no advantage to be had. But a benefit accrues to one group over another if their use is unequal. In contemporary American politics it is clearly Republicans who have seized the absolutist advantage. Our analysis of the competing party rhetoric suggests that while Democrats have sacralized a few specific domains, Republicans by far employ the greater degree of sacred appeals. This allows them to gain the advantage in activation and engagement that sacredness creates. In the last forty years of American national politics, Republicans have gained the presidency in seven out of ten electoral contests, even though during this entire period Democrats had the greater number of registered voters. The last time a mainstream Democrat won the White House could be considered to be 1964 with the election of Lyndon Johnson. In the intervening 40 years only Jimmy Carter, who ran as a Washington outsider with strong religious beliefs, and Bill Clinton, whose program was grounded in a move to the center, have run successful Democratic campaigns. During the same period four different Republicans were elected. The Republican dominance is a thing to be explained, and the more strategic use of language may be one of the factors that contribute to it. There are political domains where Democrats could employ sacred rhetoric as well — the environment and civil liberties stand out — but whether they will do so remains to be seen. Are political leaders on the left wedded to the perspective that things are complex, that there are no absolutes, and that the outcomes of policy trump expressions of protected values, or will they act more strategically and develop an absolutist advantage of their own?

But aside from Republicans, who else is advantaged by the use of sacred rhetoric? Which social movements and interest groups also gain the absolutist advantage is a further question to be answered. What is clear in American politics is that not all groups are represented equally. One of the flaws in Madison's vision of many competing factions within society is that some potential interests are never mobilized. But those who do organize are often driven by powerful beliefs that transcend mere economic interest, focusing on absolute or sacred claims. 
Whether the balance of sacredness among current parties and movements will alter remains to be seen, but the influence of sacred rhetoric will likely continue to play a strong role in American politics. What all of this suggests is that contemporary citizens have not lost touch with the sacred, and perhaps more importantly, the sacred has not lost its influence over them. Sacred rhetoric has important ramifications for the electoral prospects of the competing parties, for the health of American democracy, and for our understanding of political belief and communication. 


\section{BIBLIOGRAPHY}

Allen, Douglas (1972) "Mircea Eliade’s phenomenological analysis of religious experience” Journal of Religion 52,2:170-186.

Alvarez, Michael and John Brehm (2003) Hard choices, easy answers. Cambridge: Harvard University Press.

Arkoun, Mohammed (1986) "Emergences et problems dans le monde musulman contemporain (1960-1985)" Islamochristiana, 12:151-173.

Amis, Martin (2002) “The voice of the lonely crowd” Harpers August, Vol. 305, No. 1827:1518.

Barber, Benjamin (1984) Strong democracy: Participatory politics for a new age. Berkeley: University of California Press.

Barker, David (2002) Rushed to judgment: Talk radio, persuasion, and American political behavior. New York: Columbia University Press. (2000) "The spirit of capitalism? Religious doctrine, values, and economic attitude constructs" Political Behavior 22,1:1-19. (2005) "Values, Frames, and Persuasion in Presidential Nomination Campaigns" Political Behavior 27,4:375-394.

Baron, Jonathan and Mark Spranca (1997) "Protected values" Organizational Behavior and Decision Processes 70,1:1-16.

Baron, Jonathan and Sarah Lesher (2000) "How serious are expressions of protected values?" Journal of Experimental Psychology: Applied 6:183-194. 
Behhabib, Seyla (1996) “Toward a deliberative model of democratic legitimacy” in Benhabib, ed., Democracy and difference: Contesting the boundaries of the political. Princeton: Princeton University Press. (2002) The claims of culture: Equality and diversity in the global era. Princeton: Princeton University Press.

Berger, Peter (1967) The sacred canopy: Elements of a sociological theory of religion. New York: Anchor Books. (1999) The desecularization of the world: Resurgent religion and world politics. Washington: Ethics and Public Policy Center.

Berger, Peter and Thomas Luckmann (1967) The social construction of reality. New York: Anchor Books.

Berlin, Isaiah (1970) Four essays on liberty. New York: Oxford University Press. (1992) The crooked timber of humanity: Chapters in the history of ideas. New York: Vintage Books.

(1993) The magus of the north: J. G. Hamann and the origins of modern irrationalism. New York: Farrar, Straus and Giroux.

Brewer, Paul (2001) "Value words and lizard brains: Do citizens deliberate about appeals to their core values?" Political Psychology, 22 (1): 45-64.

Brewer, Mark and Jeffrey Stonecash (2006) Split: Class and cultural divides in American politics. Washington: CQ Press.

Cacioppo, John, Wendy Gardner, and Gary Berntson (1997) "Beyond bipolar conceptualizations and measures: The case of attitudes and evaluative space" Personality and Social Psychology Review 1:3-25. 
Calhoun, Craig (1995) “'New social movements' of the nineteenth century" in Traugott, ed. Repertoires and cycles of collective action. Durham: Duke University Press.

Chamber, Simone and Jeffrey Kopstein (2001) "Bad civil society" Political Theory 29(6):83765.

Chong, Dennis (1996) "Creating common frames of reference on political issues." In Mutz, D.C. Sniderman, P.M. and R.A. Brody (Eds.) Political Persuasion and Attitude Change (pp. 195-224). Ann Arbor, MI: University of Michigan Press.

Coleman, James (1988) "Social capital and the creation of human capital" American Journal of Sociology 94:S95-S120.

Converse, Philip (1964) "The nature of belief systems in mass publics" in David Apter (ed.) Ideology and Discontent. New York: Free Press.

Dahl, Robert (1956) A preface to democratic theory. Chicago: University of Chicago Press. Davis, Robert (2005) Politics online: Blogs, chatrooms, and discussion groups in American democracy. New York: Routledge.

Davis, Robert and Diana Owen (1998) New media and American politics.

DeCanio, Samuel (2000) "Bringing the state back in... again” Critical Review 14,2:139-146.

Delli Carpini, Michael X. and Scott Keeter (1993) "Measuring political knowledge: Putting first things first" American Journal of Political Science 37,4:1179-1206. (1996) What Americans know about politics and why it matters. New Haven: Yale University Press.

Downs, Anthony (1957) An economic theory of democracy. New York: Harper and Row. Druckman, James (2001a) “On the limits of framing effects: Who can frame?" Journal of Politics, 63: 1041-1067. 
(2001b) "The implications of framing effects for citizen competence" Political Behavior 23:225-56.

(2004) "Political preference formation: Competition, deliberation, and the (ir)relevance of framing effects" American Political Science Review 98,4:671-686.

Dryzek, John (1990) Discursive democracy: Politics, policy, and political science. Cambridge: Cambridge University Press.

Durkheim, Emile (1912[1995]) The elementary forms of religious life. New York: Free Press. Eagly, Alice and Shelly Chaiken (1993) The psychology of attitudes. New York: Harcourt, Brace, Jovanovich.

Eliade, Mircea (1957) The sacred and the profane. New York: Harcourt.

Elster, Jon (1983) Sour grapes: Studies in the subversion of rationality. New York: Cambridge University Press. (1984) Ulysses and the sirens. Cambridge: Cambridge University Press.

Feldman, Stanley (1988) "Structure and consistency in public opinion: The role of core beliefs and values" American Journal of Political Science 32,2:416-440.

Feldman, Stanley and John Zaller (1992) “The political culture of ambivalence: Ideological responses to the welfare state" American Journal of Political Science 36:268-307.

Feldman, Stanley and Marco Steenbergen (2001) “The humanitarian foundation of public support for social welfare" American Journal of Political Science 45(3):658-677.

Finkel, Steven E. (1993) “Reexamining the 'minimal effects' model in recent presidential campaigns" The Journal of Politics 55,1:1-21.

Fiorina, Morris (1999) "Extreme voices: A dark side of civic engagement" in Skocpol and Firorina, eds., Civic engagement in American democracy. Washington, D.C.: Brookings. 
(2005) Culture war? The myth of a polarized America. New York: Pearson, Longman.

Fishkin, James (1991) Democracy and deliberation: New directions for democratic reform. New Haven: Yale University Press.

Fiske, Alan (1991) Structure and social life: The four elementary forms of human relations. New York: Free Press.

Fiske, Alan and Philip Tetlock (1997) "Taboo trade-offs: Reactions to transactions that transgress spheres of justice" Political Psychology 18,2:255-297.

Florida, Richard (2000) The rise of the creative class. New York: Basic Books.

Frank, Thomas (2004) What's the matter with Kansas? How conservatives won the heart of America. New York: Henry Holt.

Friedman, Jeffrey (1998) “Introduction: Public ignorance and political theory" Critical Review $12,4: 397-412$.

Fukuyama, Francis (1992) The end of history. New York: Free Press.

Galston, William (2002) Liberal pluralism: Implications of value pluralism for political theory and practice. Cambridge: Cambridge University Press.

Geertz, Clifford (1983) Islam observed: Religious development in Morocco and Indonesia. New Haven: Yale University Press.

Green, Donald and Ian Shapiro (1994) Pathologies of rational choice theory. New Haven: Yale University Press.

Green, John, James Guth, Lyman Kellstedt, and Corwin Schmidt (1996) Religion and the culture wars. Lanham, Maryland: Rowman and Littlefield.

Greene, Graham (1951) The end of the affair. New York: Viking. 
Gutmann, Amy and Dennis Thompson (1996) Democracy and disagreement. Cambridge: Harvard University Press.

Habermas, Jurgen (1984) The theory of communicative action. Boston. (1996) Between facts and norms: Contributions to a discourse theory of law and democracy. Cambridge: MIT Press.

Hempel, Carl (1966) Philosophy of natural science. Englewood Cliffs: Prentice-Hall.

Hibbing, John and Elizabeth Theiss-Morse (1995) Congress as public enemy: Public attitudes toward political institutions. New York: Cambridge University Press.

Hochschild, Jennifer (1981) What's fair? American beliefs about distributive justice. Cambridge: Harvard University Press.

Hoffer, Eric (1951) The true believer: Thoughts on the nature of mass movements. New York: Harper \& Brothers.

Hurwitz, Jon and Mark Peffley (1987) "How are foreign policy attitudes structured: A hierarchical model" American Political Science Review 81:1099-1120.

Hunter, James Davison (1991) Culture wars: The struggle to define America. New York: Basic Books. (1994) Before the shooting begins: Searching for democracy in America's culture war. New York: Free Press.

Iyengar, Shanto and Donald Kinder (1987) News that matters. Chicago: University of Chicago Press.

Jacoby, William (2000) "Issue Framing and Public Opinion on Government Spending." American Journal of Political Science 44, 4:750-67. (2001a) "Core values and political attitudes" unpublished manuscript. 
(2001b) "Ideology in the 2000 election: A study in ambivalence" unpublished manuscript. (2006) "Value choices and American public opinion" American Journal of Political Science 50,3:707-723.

Kinder, Donald (1983) "Diversity and complexity in American public opinion" in Political science: The state of the discipline, ed. Ada Finifiter. Washington: American Political Science Association, pp. 389-428. (1998) "Opinion and action in the realm of politics" Handbook of social psychology. pp. $778-867$

Kinder, Donald and Thomas Palfrey (1993) Experimental foundations of political science. Ann Arbor: University of Michigan Press.

King, Winston L. (1968) Introduction to religion: A phenomenological approach. New York: Harper \& Row.

King, Gary, Robert Keohane, and Sidney Verba (1994) Designing social inquiry: Scientific inference in qualitative research. Princeton: Princeton University Press.

Kluckhohn, Clyde (1951) "Values and value-orientations in the theory of action" in Talcott Parsons and Edward A. Shils (eds.) Toward a General Theory of Action, New York: Harper.

Krosnick, Jon and Donald Kinder (1990) "Altering the foundations of support for the President through priming" The American Political Science Review 84,2:497-512.

Kuran, Timur (1995) Private truths, public lies: The social consequences of preference falsification. Cambridge: Harvard University Press. 
Klandermans, Bert (1992) "The social construction of protest" in Frontiers in social movement theory. Aldon Morris and Carol McClurg Mueller, eds. New Haven: Yale University Press.

Ladd (1996) "The data don't show an erosion of social capital" Public Perspective 7(4):1,5-22.

Lane, Robert (1962) Political ideology: Why the common man believes what he does. New York: Free Press. (1972) Political man. New York: Free Press. (1973) “Patterns of Political Belief” in Knutson (ed.) Handbook of Political Psychology. San Francisco: Jossey-Bass.

Layman, Geoffrey (1999) "Culture wars in the American party system" American Politics Quarterly 27,1:89-121.

Lemann, Nicholas (1996) "Kicking in groups" The Atlantic Monthly April.

Lupia, Arthur (1994) "Shortcuts vs. Encyclopedias. Information and Voting Behavior in California Insurance Reform Elections. American Political Science Review. 88: 63-76.

Lutz, Donald (1988) The origins of American constitutionalism. Baton Rouge: Louisiana State University Press.

Mandeville, Bernard de (1714) The fable of the bees: Or private vices, publick benefits. London: Macmillan.

March, James G. and Johan P. Olsen (1989) Rediscovering institutions: The organizational basis of politics. New York: The Free Press.

Marietta, Morgan (manuscript) "A note on method: The epistemology of political psychology" (manuscript) "Citizen competence and democratic theory: Toward an integration of normative and empirical argument" 
Marietta, Morgan and Mark Perlman (2000) "The uses of authority in economics: Shared intellectual legacies as the foundation of persuasion" American Journal of Economics and Sociology 59,2:151-189.

Markoff, John and Daniel Regan (1987) "Religion, the state and political legitimacy in the world's constitutions" in Church-state relations: Tensions and transitions. Robbins and Robertson, eds. New Brunswick: Transaction.

Martin, David (1996) Doing psychology experiments. New York: Brooks/Cole.

McClosky, H. and J. Zaller (1984) The American ethos: Public attitudes toward capitalism and democracy. Cambridge: Harvard University Press.

McGee, Michael (1980) "Social movement: Phenomenon or meaning?" Central States Speech Journal 31:233-244.

Melucci, Alberto (1985) “The symbolic challenge of contemporary movements” Social Research 52(4):789-816.

Mosca, Gaetano (1939) The ruling class. New York: McGraw-Hill.

Nelson, Thomas E. and Donald R. Kinder. 1996. "Issue Frames and Group Centrism in American Public Opinion.” Journal of Politics 58:1055-1078.

Nelson, Thomas E., Clawson, Rosalee A. and Zoe M. Oxley (1997) "Media Framing of a Civil Liberties Conflict and Its Effect on Tolerance.” American Political Science Review. 91(3): $567-584$.

Nelson, Thomas E., Zoe M. Oxley and Rosalee A. Clawson (1997) "Toward a Psychology of Framing Effects.” Political Behavior 19,3:221-246.

Nelson, Thomas E. and Zoe M. Oxley (1999) "Framing effects on belief importance and opinion" The Journal of Politics 61,4:1040-1067. 
Offe, Claus (1985) "New social movements: Challenging the boundaries of institutional politics" Social Research 52(4):817-868.

Olson, Mancur (1965) The logic of collective action: Public goods and the theory of groups. Cambridge: Harvard University Press.

Pateman, Carol (1970) Participation and democratic theory. Cambridge: Cambridge University Press.

Peffley, Mark and Jon Hurwitz (1985) “A hierarchical model of attitude constraint” American Journal of Political Science 29:871-90.

Perlman, Mark and Charles R. McCann, Jr. (1998) The Pillars of Economic Understanding: Ideas and Traditions. Ann Arbor: University of Michigan Press.

Peters, Guy (1999) Institutional theory in political science. New York: Pinter.

Petty, R.E. and J.T. Cacioppo (1986) Communication and Persuasion: Central and Peripheral Routes to Attitude Change. New York: Springer-Verlag.

Popkin, Samuel (1991) The Reasoning Voter. Chicago: University of Chicago Press.

Portes, Alejandro and Patricia Landolt (1996) "The downside of social capital" The American Prospect May-June:18-22.

Portes, Alejandro (1998) “Social capital” Annual Review of Sociology 22:1-24.

Putnam, Robert (1993) Making democracy work: Civic traditions in modern Italy. Princeton: Princeton University Press. (1995) "Bowling alone: America's declining social capital" The Journal of Democracy $6,1: 65-78$. (2000) Bowling alone: The collapse and revival of American community. New York: Simon and Schuster. 
Rahn, Wendy M. (1993) “The Role of Partisan Stereotypes in Information Processing About Political Candidates." American Journal of Political Science, 37:472-496.

Rawls, John (1971) A theory of justice. Cambridge: Harvard University Press. (1993) Political liberalism. New York: Columbia University Press.

Ritov, Ilana and Jonathan Baron (1999) "Protected values and omission bias" Organizational Behavior and Human Decision Processes 79,2:79-94.

Robinson, James Harvey (1917) “The still small voice of the herd” Political Science Quarterly 32,2: $312-319$.

Rohan, Meg (2000) “A rose by any name? The values construct” Personality and Social Psychology Review 4,3:255-277.

Rokeach, Milton (1973) Nature of human values. New York: Free Press.

Rule, James (1988) Theories of civil violence. L.A.: University of California Press.

Sartori, Giovanni (1970) “Concept misformation in comparative politics” American Political Science Review 64,4:1033-1053.

Schumpeter, Joseph (1942) Capitalism, socialism, and democracy. New York: Harper \& Row. Schwartz, Shalom (1996) "Value priorities and behavior: Applying a theory of integrated value systems" in The psychology of values: The Ontario symposium, Volume 8, Clive Seligman, James Olson, and Mark Zanna, eds. Mahwah, NJ: Lawrence Erlbaum Associates.

Sears, David (1986) "College sophomores in the laboratory: Influences of a narrow data base on psychology’s view of human nature" Journal of Personality and Social Psychology 51:515-530. 
Shapiro, Ian (2002) "Problems, methods, and theories in the study of politics, or what's wrong with political science and what to do about it" Political Theory 30,4:588-611.

Simon, Herbert (1985) "Human Nature in Politics: The Dialogue of Psychology with Political Science" American Political Science Review, 79:293-304.

Simon, Herb (1991) Models of my life. New York: Basic Books.

Skocpol, Theda and Morris Firorina (1999) Civic engagement in American democracy. Washington, D.C.: Brookings.

Smith, Adam (1909)[1776] An inquiry into the nature and causes of the wealth of nations. New York: Collier \& Sons.

Sniderman, Paul, Richard Brody, and Philip Tetlock (1991) Reasoning and choice: Explorations in political psychology. Cambridge: University of Cambridge Press.

Snow, David and Robert Benford (1992) "Master frames and cycles of protest" in Aldon Morris and Carol McClurg Mueller, eds., Frontiers in social movement theory. New Haven: Yale University Press.

Somers, Margaret (1996) “Where is Sociology after the Historic Turn?” in Terrence McDonald, ed. The Historic Turn in the Human Sciences. Michigan.

Tarrow, Sydney (1998) Power in movement: Social movements and contentious politics. New York: Cambridge University Press.

Tetlock, Philip (1986) “A value pluralism model of ideological reasoning” Journal of Personality and Social Psychology 50:819-827. (2003) "Thinking the unthinkable: Sacred values and taboo cognitions" Trends in Cognitive Sciences 7,7:320-324. 
Tetlock, Philip, R. Peterson, and Jennifer Lerner (1996) "Revising the value pluralism model: Incorporating social content and context postulates" in Seligman et al, The psychology of values: The Ontario symposium. Hillsdale: Lawrence Erlbaum.

Tetlock, Philip, Orie Kristel, Beth Elson, Melanie Green, and Jennifer Lerner (2000) “The psychology of the unthinkable: Taboo trade-offs, forbidden base rates, and heretical counterfactuals" Journal of Personality and Social Psychology 78,5:853-870.

Tocqueville, Alexis de (2000 [1835]) Democracy in America. Translated and edited by Harvey C. Mansfield and Delba Winthrop. Chicago: University of Chicago Press.

Trotter, William (1916) Instincts of the Herd in Peace and War. New York: Macmillan.

Tversky, Amos and Daniel Kahneman (1974) “Judgment under uncertainty: Heuristics and iases" Science, 185:1124-1131.

Turow, Scott (2003) Ultimate punishment: A lawyer's reflections on dealing with the death penalty. New York: Farrar, Straus and Giroux.

Walker, Samuel (1990) In defense of American liberties: A history of the ACLU. Carbondale: Southern Illinois University Press.

Walter, Otis M. and Robert L. Scott (1962) Thinking and speaking: A guide to intelligent oral communication. New York: Macmillan.

Weber, Max (1946 [1919]) "Science as a vocation" in Gerth and Mills From Max Weber. New York: Oxford University Press, pp. 129-56. (1978) Economy and society: An outline of interpretive sociology. Berkeley: University of California Press.

Weissberg, Robert (2001) "Democratic political competence: Clearing the underbrush and a controversial proposal" Political Behavior 23,3: 257-284. 
White, John Kenneth (2003) The values divide: American politics and culture in transition. New York: Chatham House.

Wildavsky, Aaron (1987) “A cultural theory of preference formation" American Political Science Review 81(1):3-22.

Williams, Rhys (1997) Culture wars in American politics. New York: Aldine de Gruyter.

Zald, Mayer (1996) "Culture, ideology, and strategic framing" in McAdam, McCarthy, and Zald, eds. Comparative perspectives on social movements. Cambridge: Cambridge University Press.

Zald, Mayer and John McCarthy (1987) Social movements in an organizational society. New Brunswick: Transaction.

Zaller, John (1992) The nature and origins of public opinion. Cambridge: Cambridge University Press.

Zaller, John and Stanley Feldman (1992) "A simple theory of the survey response: answering questions or revealing preferences" American Journal of Political Science 36:579-616. 